\title{
Scraping By and Making Do: Navigating New Zealand's Welfare System
}

A thesis submitted to Victoria University of Wellington in fulfilment of the requirements for the degree of Master of Arts in Cultural Anthropology

By Evelyn Walford-Bourke 


\section{Acknowledgements}

Thank you to Eli and Lorena, for all your help and encouragement.

Thank you to Vicky, for your never-ending support and reminders to "just get started!"

Thank you to Nana W, for all your support over this journey.

Thank you to Hayley, Ruth, Alex, and Morgan, for your patience while I disappeared off on this project.

Thank you to all those who participated in this project and helped to make it happen. 


\section{Abstract}

In August 2017, debate over Green Party co-leader Metiria Turei's declaration of two-decadeold benefit fraud sparked an ongoing discussion around poverty in New Zealand that revealed the fraying edges of the country's welfare safety net. The perception that New Zealand has a low level of poverty and a fair, coherent welfare system that ensures those "deserving" of support receive what they need is untrue. Instead, there is an extraordinary disconnect between those responsible for running New Zealand's welfare system and the daily experience of beneficiaries and NGO workers who must navigate the complex welfare landscape to address hardship. Patching together the threads of a fraying safety net, for New Zealand's most vulnerable, is little-appreciated work, but crucial to their survival nonetheless. In this thesis, I explore how beneficiaries and NGO workers use tactics to manage the gaps between policy, practice and need created by state strategy in order to address hardship. I examine the resilience and experiential expertise of beneficiaries and NGO workers as they work around the limitations of state bureaucracy to address high levels of poverty in New Zealand. 


\section{Table of Contents}

Chapter One: Navigating Welfare Services in Aotearoa New Zealand 6

\begin{tabular}{l|l} 
Navigating Welfare Service Networks & 9
\end{tabular}

$\begin{array}{ll}\text { Studying Poverty Anthropologically } & 14\end{array}$

\begin{tabular}{l|l|} 
Poverty and Neoliberalism & 19
\end{tabular}

The Governance of Poverty $\quad 22$

\begin{tabular}{l|l} 
Measuring Poverty in New Zealand & 24
\end{tabular}

Studying Poverty in New Zealand 26

\begin{tabular}{l|l} 
Thesis Outline & 28
\end{tabular}

$\begin{array}{ll}\text { Chapter Two: Weaving Together Sites and Sources } & 31\end{array}$

$\begin{array}{ll}\text { Kinky Multi-Sited Ethnography } & 33\end{array}$

$\begin{array}{ll}\text { Research Methods } & 39\end{array}$

\begin{tabular}{l|l} 
Analysis of Field Results & 42
\end{tabular}

$\begin{array}{ll}\text { Summary } & 44\end{array}$

Chapter Three: How Did We Get Here? The History of Welfare in New Zealand 46

Sober and Reputable: The Foundations of Welfare in Nineteenth Century Colonial New 48

Zealand

For the Working Man: Crisis and Innovation in Welfare During the Great Depression, 50 1929-1939

The Nuclear Family and the Keynesian Welfare State, 1940s-1970s 55

The Rise of the Active Consumer and the Rolling Back of the Welfare State, 1980s-1990s 59

Children in Poverty: Remodelling Welfare, 2000s-2010s 66

Developing Welfare Support in New Zealand $\quad 70$

$\begin{array}{ll}\text { Chapter Four: Day-to-Day Survival Under Neoliberalism } & 72\end{array}$

$\begin{array}{ll}\text { Seeking Support Through WINZ } & 73\end{array}$

$\begin{array}{ll}\text { Supervision and Sanction } & 80\end{array}$

\begin{tabular}{l|l} 
Living with Hardship & 88
\end{tabular} 
$\begin{array}{ll}\text { Falling Through The Gaps } & 91\end{array}$

Chapter Five: Weaving A Safety Net: Networking and Net-Weaving 93

Networking and Net-Making 94

$\begin{array}{ll}\text { Above and Beyond: NGOs and Care } & 98\end{array}$

$\begin{array}{ll}\text { Hitting a Wall: Limits to NGO Provision } & 100\end{array}$

$\begin{array}{ll}\text { Helping One Another } & 102\end{array}$

$\begin{array}{ll}\text { Gaps Between Policy, Practice and Need } & 103\end{array}$

Chapter Six: Constructing and Reforming New Zealand's Welfare Safety Net 105

$\begin{array}{ll}\text { Bibliography } & 108\end{array}$

$\begin{array}{ll}\text { Appendices } & 125\end{array}$

$\begin{array}{ll}\text { Appendix One: Material Hardship List } & 125\end{array}$

$\begin{array}{ll}\text { Appendix Two: Survey } & 126\end{array}$

$\begin{array}{ll}\text { Appendix Three: Survey Results Summary } & 134\end{array}$

$\begin{array}{ll}\text { Appendix Four: Benefit Rates } & 143\end{array}$ 


\section{Chapter One: Navigating Welfare Services in Aotearoa New Zealand}

In August 2017, Green Party co-leader Metiria Turei told her party caucus that twenty years before, she had committed benefit fraud. As a young single mother in the 1990s, receiving a Domestic Purposes Benefit, she had lied to the then-Department of Social Welfare by claiming she lived alone when she was subletting her home. For three years while she completed her studies, Turei estimated the lie gave her an extra $\$ 20$ to $\$ 50$ a week. Her confession was intended to illustrate the impossible choices beneficiaries faced as they struggled to manage hardship, and to justify the Greens' election campaign focus on addressing poverty. Instead, it sparked a debate about the illegality of Turei's actions and the perceived high cost of beneficiary fraud and dependency to the taxpayer. The scrutiny on her family forced Turei to resign, even as the Ministry of Social Development (MSD) decided a full investigation or prosecution was unnecessary as Turei had repaid the debt.

By the time a Labour-Greens-New Zealand First coalition won the 2017 election, reducing child poverty had become a key promise for the Ardern Government's first hundred days. A counterdebate also emerged on social media, with current and former beneficiaries using the \#IAmMetiria and \#WeAreBeneficiaries hashtags to catalogue their experiences with poverty and navigating New Zealand's fragmented welfare service landscape, which centres on Work and Income New Zealand (WINZ). Culminating in the \#We Are Beneficiaries activist group's report to Parliament (Orchard 2017), beneficiaries' stories of hardship and its impacts on them and their families complicated an imagined divide between "deserving" beneficiaries - those who fulfilled their obligations, were fairly and fully supported, and were able to leave the benefits system after a time - and "undeserving" beneficiaries - those who did not, unfairly costing the taxpayer and requiring punitive measures to "encourage" them from dependency.

This thesis explores how beneficiaries scrape by and make do, supported by NGO workers, within the current patchwork system of social support in New Zealand. In the process, I explore 
how deservingness has become embedded in New Zealand's welfare system, arguing that a specifically neoliberal expression of the concept has influenced the strategies - using Michel de Certeau's (1988) term - employed by the state to achieve its aims in the welfare realm. De Certeau defines strategy as "the calculation (or manipulation) of power relationships" conducted by "a subject with will and power" that has "a place that can be delimited as its own and serve as the base from which relations with an exteriority composed of targets or threats can be managed" (1988:35-36). In this case, strategies refer to the policies - and the practices that emerge from them - of the institution of Work and Income New Zealand (and to an extent its parent organisation the Ministry of Social Development) through its offices in local communities across New Zealand, targeting beneficiaries for management. Strategies, influenced by the notion of deservingness, include open-plan office layouts which decrease privacy and increase oversight (Andrews 2000:160); the use of security guards to police who can enter offices; the use of reception staff to filter who sees a case manager; and the use of "make-work" tasks and sanctions, which will be discussed in Chapter Four. Standards and practices designed to ensure beneficiaries prove their deservingness, then, are used to manipulate beneficiaries' behaviour, to ensure compliance with obligations and neoliberal values, calculating based on a social investment framework who is worth supporting and who has failed to make themselves worthy.

In particular, I outline how strategies - and the policies and practices that arise from them under neoliberalism impact on beneficiaries and the non-governmental-organisation (NGO) workers as they seek to manage complex situations of hardship. I explore how the notion of deservingness is predicated on a "default" figure that does not match the average beneficiary. I argue that this defines standards of behaviour that everyday beneficiaries must meet in order to demonstrate their status as responsible and "deserving". However, the journey towards fulltime employment these standards are determined by cannot be met by the majority of beneficiaries because they are actually facing ill-health or caring responsibilities or both. These additional burdens present an unacknowledged workload, as beneficiaries must work within their limited capacity to meet the requirements of deservingness. It is through this seeming 
misunderstanding that the contemporary welfare system in New Zealand seeks to generate control over beneficiaries.

Yet, as De Certeau might point out, all strategies also produce possibilities for tactics, so I also examine how beneficiaries and NGO workers resist state strategies through the use of tactics. Indeed, the Ministry of Social Development's own Statement of Intent (2018a) demonstrates a tension between ensuring "New Zealanders get the support they require" (2018a:17) through service provision and "New Zealanders participate positively in society and reach their potential”, which is framed primarily in terms of ensuring work-readiness and encouraging employment (2018a:17), which produces different attitudes and interpretations within the state welfare system. I consider these tactics by tying together a discursive analysis of welfare policy with an ethnographic analysis of beneficiary and NGO experiences. I argue that the tactics used by beneficiaries and NGO workers in everyday practice reflect the ways state welfare strategies, influenced by a neoliberal notion of deservingness, have produced an increasingly complex system of social support which has become more and more impossible for people in poverty to manage within.

As a result, beneficiaries turn to NGOs for help with the fractured patchwork of services and agencies. In doing so, they attempt to manage poverty and sometimes push back against the dehumanising way the neoliberal paradigm of social support emphasises deservingness and responsibility over other logics. Tactics, as defined by de Certeau, involve weaker powers "play[ing] on and with a terrain imposed on it and organisation by the law of a foreign power", operating "in isolated actions, blow by blow" and taking "advantage of opportunities and depends on them, being without any base where it could stockpile its winnings, build up its own position, and plan ..." (1988:37). Beneficiaries, who lack power, can use tactics to redirect the existing neoliberal welfare system to support their survival and to resist the moral dichotomy of deservingness embedded within the system "to attain and hold on to self-respect and moral worth" (Thirlway 2016:111). It is important to note, however, that while de Certeau's definition certainly accommodates illegal actions such as benefit fraud (1988:37) - and acknowledging that this thesis was sparked by an example of such tactics - my participants emphasised their struggle to make do within the system as it is without turning to fraud or other illegalities. 
Indeed, most were at pains to show how much work they did in order to "play by the rules". As a result, in this thesis I focus on the extraordinary lengths that beneficiaries go through to scrape by legally through tying together loose networks into a functioning safety net, struggling to work within a system designed to be punitive and limited in access. My research suggests that this required significant tactical work and improvisation because of the welfare system's complex, punitive structure and inadequate levels of support.

In this project, I use multi-sited ethnography to explore the networks beneficiaries and NGO workers create as they attempt to weave together disparate threads of welfare services into a safety net. Data collection methods included semi-structured interviews with NGO workers and with beneficiaries; participant observation through two volunteering roles and membership in three Facebook groups for beneficiaries and two for beneficiary advocates; and a digital survey of beneficiaries. Data was collected between June and December 2018, and primarily centred on Wellington, New Zealand's second-largest city and capital. Two NGO interviews were also undertaken in Auckland, New Zealand's largest city. Digital data collection covered a larger area of New Zealand, with the advocacy pages run from Auckland and Christchurch while the discussion-and-advice groups for beneficiaries were run by volunteer administrators who lived across New Zealand. Survey responses were also submitted across New Zealand. This ethnographic data enabled me to examine the experiences of beneficiaries and NGO workers within New Zealand's fractured welfare service landscape, focusing on the tactics used to scrape by and negotiate the strategies used by state-provided welfare - expressed in WINZ policy and practice - to control beneficiary behaviour and achieve "the mission of inculcating the duty of working for work's sake" in "poverty-level employment" identified by Wacquant (2009:15).

\section{Navigating Welfare Service Networks}

State welfare support in New Zealand centres around Work and Income New Zealand, the client-facing arm of the Ministry of Social Development. Approximately 299,000 people received primary benefits from WINZ in the September 2018 quarter, contributing to 
supporting 173,000 children and 62,000 non-beneficiary household members (MSD 2018b). According to the Welfare Expert Advisory Group (WEAG) set up by the Ardern Government, WINZ provides financial support to 630,000 people a year, excluding recipients of superannuation, student allowances and student loans (2019a:4). WINZ payments are the key form of state-provided financial support to unemployed and unable-to-work New Zealanders. Payments are provided through a three-tier system, with "primary" payments giving a main form of income; "secondary" payments providing additional income to cover high costs; and "tertiary" payments providing "top-ups" to meet unexpected, extraordinary costs. This research focuses on recipients of "primary" payments, which are also referred to as main benefits.

WINZ support is conditional and limited. The state has not revised payment levels substantially since the 1990s. As a result, beneficiaries often struggle to make ends meet, turning away from state welfare to address shortfalls. These tactics can include seeking help from family and friends and taking on debt from banks, payday lenders and layby companies. Beneficiaries also seek assistance from a variety of other state agencies, such as Inland Revenue Department (IRD) Best Start child payments or tax credits; income from the Accident Compensation Corporation (ACC) for injuries; housing through local councils; and medical care from District Health Boards (DHBs) and health centres. WINZ can refer beneficiaries to other government agencies, such as Housing New Zealand, and programs such as Family Start. Beneficiaries also turn to the NGO welfare sector to access support, advice, services, and household essentials. Most NGOs provide a limited number of specific services, which may be targeted towards a particular group. NGO services range from social workers and advocates to healthcare to clothing, food and household goods. However, limits to provision means beneficiaries must navigate multiple government agencies and NGOs, and the gaps between their services, to weave together a coherent support network that meets their needs. Often, this is done with the help of one or more NGO workers who connect beneficiaries to services and advocate on their behalf. Hodgetts, Chamberlain, Tankel and Groot have explored this fracture of welfare service provision in New Zealand after the introduction of the neoliberal paradigm and its new "technocratic and bureaucracy procedures for 'managing' the poor, which have become normalised and taken-for-granted as 'how things are done around here'" (2013:48). The 
broader context of these reforms in the global trend towards the penalisation and responsibilisation of poverty under neoliberalism has been widely studied, as well as the impact such reforms have on the everyday lives of those in poverty and their allies (Wacquant 2009; Ferguson 2015; Hancock 2004; Groot et al. 2017).

As a researcher, I first began to consider how ideas of deservingness affected the way beneficiaries were perceived and treated - and more broadly how poverty was addressed in New Zealand - during the furore over Metiria Turei's admission of benefit fraud, outlined at the beginning of this chapter. Everywhere in the debate, across traditional news media, social media and everyday conversation, a simple standard of deservingness was being used. This imagined test had a straightforward choice: comply with all WINZ obligations and requirements and become "deserving", or fail and be perceived to be irresponsible, "undeserving" for refusing, lying, cheating the system. The adequacy of New Zealand's welfare system in providing financial support - and the ease of meeting WINZ requirements - seemed taken for granted by most of those commenting.

Yet I had intimate knowledge that the system was not adequate. I had grown up in Housing New Zealand-owned state houses. My mother received the Domestic Purposes Benefit (DPB), working on-and-off stacking shelves in local supermarkets and running a small business to try and make ends meet. I knew we were poor long before I fully understood poverty was about money. I knew my stepsisters got music lessons and after-school sports. I knew they never had to rely on the kindness of their neighbours to talk to their dad on the telephone. The cost of a landline was just too much for us. But I thought that what we had wasn't so bad: a lot of struggle was hidden from me. I was ten when I discovered other people didn't share their homes with boarders, and their mothers didn't sleep on fold-out couches in the lounge. I was sixteen when I discovered my best-ever birthday present, three wishes when I turned eight, was intended to create just a little more time until there could be money for a gift.

Despite this personal knowledge, it was Metiria Turei's admission during the 2017 election that brought home to me how widespread experiences like mine were, and the lengths to which people on benefits went in order to make do. There on Twitter and Facebook were people like 
me, talking about watching their parents struggle to carve out a life for their families. They shared experiences of boredom in rust-walled WINZ offices. They also described experiences of listening to caseworkers talk down to their parents, just like I had the day we moved out of our last HNZ home. That day, the caseworker patronisingly said she couldn't believe my mother had achieved her goal to be gone in eight years. But we were, to the day. And after that, we lived in cold converted business premises, shared one room between the three of us, a half-finished DIY and a villa with 50-year-old wiring, but we never went back to HNZ. Anything else was better, and online, so many people seemed to agree. Their experiences echoed my own. Adults who had been children like me, their parents, and others, all talking about their experiences, their struggles, their hurt, the complex litany of things they did to get by. Their stories were nothing like the black-and-white narrative of "deserving" and "undeserving" beneficiaries being worried over in the media.

This research is motivated by these different experiences: why is there such a vast difference between the experience of poverty and the way it is represented in public policy? Why couldn't people be helped compassionately and adequately? Why did commentators and cartoonists and random people think so poorly of beneficiaries, without evidence or experience? Why was the default always an "undeserving" figure who had to prove they were good? Why did it seem like the WINZ system was set up for people to fail, to give people too little to survive on, to punish them for minor transgressions like missing a meeting? Why did so many children grow up like me, and worse? Why were there still kids growing up that way? And why was the only apparent government focus on child poverty, when it was our parents, my mother, who needed the help? Thinking of these questions, I became interested in the effects of these gaps on the structure of the welfare system and the lived experiences of beneficiaries and their allies in contemporary New Zealand. I wanted to know not only about how people in poverty were understood in policy, but about how people actually get by in such difficult circumstances.

From the above considerations, the key questions of this thesis emerged:

How has the notion of deservingness emerged in the welfare system and changed over time? How has it shaped welfare provision? 
How does the reality of who beneficiaries are differ from policy understandings, and how does that affect how beneficiaries experience the welfare system?

How does the difference between reality and expectation impact the way beneficiaries access support? What tactics do beneficiaries use to manage these impacts?

How does that gap between expectations and reality impact the strategies employed to address poverty in New Zealand?

Due to difficulties in fieldwork which emerged - and which will be discussed further in Chapter Two - my initial focus on beneficiaries broadened to include NGO workers' experiences, asking how deservingness shaped the ways beneficiaries access, and NGOs provide, welfare support services. How do beneficiaries and NGO workers manage between expectations on beneficiaries when seeking help, and the limitations of beneficiaries' lived reality?

So, this thesis also focusses on an additional question:

How do NGO workers and beneficiaries help one another access support and manage the impacts of the gap between policy, practice and need?

This research, though influenced by prior personal experience with the welfare system in New Zealand, is not a study of my experience of poverty or even the experience of poverty per se. It is a study of how the welfare system in New Zealand has been transformed by the influence of neoliberal values, in terms of the fragmentation of the welfare service landscape in the name of "choice"; the introduction of new measures of deservingness, responsibility and conditionality; and its impact on the strategies and tactics employed to negotiate poverty. The experiences of beneficiaries and NGO workers illustrate the gaps created in New Zealand's welfare system arising from the use of strategies to control beneficiaries' behaviour and achieve the aim of more people in precarious low-wage employment rather than on benefits (Wacquant 2009:15). This is influenced by a notion of deservingness incorporated into policy and practice that does not reflect the actual lived capacities and needs of beneficiaries and the everyday reality of poverty. Through its ethnographic methodology, this project is a tentative step towards highlighting the disconnect between the current model for providing welfare in New Zealand and the experiences of those who live and work within its confines. The project also contributes an example of the impact of welfare reforms to the pre-existing literature on the penalisation and responsibilisation of poverty under neoliberalism. 


\section{Studying Poverty Anthropologically}

Within social sciences, poverty is often broadly defined as a lack of income or resources which prevents an individual or household from meeting their needs or maintaining a decent standard of living. For example, in Moving out of Poverty, Narayan and Petesch note "other experts, especially from the fields of sociology and anthropology, find all the attention to dollars, poverty lines, and individual head counts to be a fundamentally misdirected way to understand poverty and the challenge of what to do about it. Lack of money is just one of many disadvantages of being poor" (2007:1-2). Generally, resources include food, housing, clothing and medical care alongside income. Spencer-Wood notes the World Bank also includes "a lack of a job and school, powerlessness, a lack of representation and freedom, fear for the future and living one day at a time" in its definition of poverty (2011:1). In anthropology, poverty is often viewed even more broadly, including inequality and social suffering alongside the above factors (Frerer and Vu 2007:77) and can be somewhat dependent on cultural context (Sanders 2006:1). Ferguson argues the critical problem of poverty is not "fundamentally a problem of production" or individual behaviour (2015:36), but rather a lack of "distributive entitlement" (2015:38) that would ensure resources are shared fairly across the global community. SpencerWood agrees, arguing "the social construction of poverty has extended beyond the dictionary definition of economic insufficiency" to become "a social position, created by politicaleconomic relations" that places large numbers of individuals at a disadvantage in order to advantage a select few (2011:1). Poverty, then, becomes "a struggle for resources and reputation" and "a fight against the multifaceted processes of impoverishment" (Spencer-Wood 2011:1). Ferguson also points out two critical issues with defining poverty as an individual lack of income. First, that becoming productive through getting a job is not a durable solution to poverty because the world of work is changing (Ferguson 2015:37), and second framing poverty as an individual responsibility is flawed because poverty itself is unfairly distributed globally and within communities. External, systematic factors affect individual situations so that poverty is not individuals' fault; a lack of knowledge or skill or drive (Ferguson 2015:35-38). Poverty is complex, "implicated and informed by the power dynamics of gender, race, ethnicity, class, status and region" (Spencer-Wood 2011:6), and arising from global systems of inequality (Frerer 
and Vu 2007:84). Anthropology, then, can demonstrate the localised impacts of an international system including gendered, classed and racialised aspects, while developing alternative explanations and solutions to poverty beyond treating it as an individual responsibility or simple lack of income (Frerer and Vu 2007:84).

Despite this holistic emphasis in many social sciences, poverty is also commonly defined through statistical measures, using two principal methods. First, an absolute measure describes a level of income where, if individuals or households are living on less, they cannot meet their needs and are therefore in poverty. Relative measures, by contrast, compare income to a national average, often median, to determine a standard of living below which an individual or household is said to be in poverty. Both absolute and relative measures have been critiqued for being somewhat arbitrary, and often not accurately accounting for taxation and household composition. O'Boyle attempted to address this arbitrariness, arguing for a definition of poverty that includes both physical and social dimensions in terms of "unmet physical need" (1999:302), utilising an absolute minimal living standard measure for the physical aspect and a relative income distribution measure for the social aspect. Households would only be counted as in poverty if they are "deprived" under both the absolute and relative measures (O'Boyle 1999:302). However, O'Boyle's idea was critiqued by Rector, Johnson and Youssef who argued the social aspect of poverty is already covered by the term inequality (1999:302-305). The three authors argue keeping poverty and inequality conceptually separate is essential to prevent "semantic smuggling" where one definition is subsumed by the other, and both issues become less effectively addressed (Rector, Johnson and Youssef 1999:304). Overall, the use of statistics to define poverty becomes mired in issues around the methods used to collect data and the measures used to assess it. In addition, as Sanders notes, statistical measures do not provide a full picture of the actual living situations of communities, households or individuals (2006:1). Statistical definitions or thresholds, then, are more important in tracking long-term, widespread trends in poverty, rather than in addressing the immediate issues surrounding how poverty is created, lived, and can be reduced.

In anthropology, poverty is often studied under the political stream of the discipline, particularly concerning the impact of capitalism and the production of inequality (for example 
Wolf 1990). Recently, this has created a focus within the discipline on neoliberalism and the transformation of systems of welfare and development. "Welfare" is used broadly to refer to the practices of states, state agents, NGOs and communities to support wellbeing and meet need (Langer and Højlund 2011:1). Studying welfare involves describing the experience of accessing and forming welfare support systems, as well as the cultures and social organisation that influence them (Edgar and Russell 1998:6, 11). Edgar and Russell summarise the anthropological study of welfare as research "concerned with the human face of welfare provision, the realities behind the rhetoric, the people behind the policies [that] seeks to normalise such accounts in the practice of welfare world" (1998:12), to reintroduce the human to services defined by top-down policy. Welfare has been transformed by the introduction of neoliberalism, understood as "a political project to re-engineer the state" (Bockman 2012:310).

Two key areas studied which examine the impact of neoliberalism on welfare are the expansion of "workfare" and individual responsibilisation among poorer populations. Responsibilisation, Rose argues, is a change in the strategies used by the state to manage citizens, encouraging the self-regulation of conduct "by binding individuals into shared moral norms and values" (2000:324). By enforcing individuals' responsibility, states govern "through the self-steering forces of honour and shame ... in the name of good citizenship, public order, and the control or elimination of criminality, delinquency and anti-social conduct" (Rose 2000:324). Specifically, responsibility can be defined as "individual or collective accountability through judgements of one's rational capacities, assessments of legal liabilities, and notions of moral blame" that emphasises "owning one's actions" through individual agency and willingness to change (Trnka and Trundle 2017:4). Responsibilisation, then, is a process which calls on individuals to be responsible as a key way of governing the population under neoliberalism, with Trnka and Trundle noting "[c]alls to be responsible pervade contemporary life ... in the most dramatic of circumstances as well as the most mundane" (2017:1-2). However, Trnka and Trundle also complicate this concept, emphasising how citizens have used responsibility to push back against reforms perceived as irresponsible, broadening Rose's definition to make space for other ways of utilising the idea. "Workfare", by contrast, describes a change in approach to providing welfare services where services' focus shifts from addressing need to helping individuals into 
work through behavioural and belief modification. "Workfare", then, can be understood as a specific set of strategies aiming to make individuals responsible through enforcing "correct" behaviour as a condition of welfare receipt, assuming that the causes of a person's need for benefits are "moral or ethical problems, that is to say, problems in the ways in which such persons understand and conduct themselves and their existence" (Rose 2000:334). In Rose's work, responsibilisation and workfare demonstrate how state strategies in welfare have shifted towards conditionality, "a focus upon processual issues that affiliate or expel individuals from the universe of civility, choice and responsibility, best captured by the dichotomy of inclusion and exclusion", influenced by the idea of deservingness (2000:324). Wacquant's work goes further, arguing the introduction of "workfare" and responsibilisation indicates "a broader pattern of penalisation of poverty designed to manage the effects of neoliberal policies at the lower end of the social structure of advanced societies ... part and parcel of a wider transformation of the state ... precipitated by the overturning of the inherited balance of power between the classes and groups fighting over control of both employment and the state" (2001:401), a pattern he studies through comparing European - mainly French - and American welfare systems. Wacquant's work is an example of political anthropology which uses the study of welfare to make a broader point about the impact of neoliberalism on the structure of the state $(2001: 402,405)$.

Further studies focus on how the values underpinning welfare have changed, as demonstrated by the "penalisation of poverty" noted by Wacquant (2001:401), such as through the expansion of sanctions, used to enforce behavioural change under "workfare". For example, Woolford and Nelund examined how homeless welfare service users in Winnipeg, Canada changed the way they presented themselves to services, to frame themselves as independent and their daily activities as productive (2012:305-311). By demonstrating these characteristics to welfare services, homeless individuals framed themselves as "deserving of care" and income because they were responsible citizens, abiding by neoliberal values (Woolford and Nelund 2012:304). Particularly in research conducted in the US and UK, the move towards individualisation has been shown to break down the extended informal support networks poorer communities previously relied upon to supplement state support, increasing hardship. For instance, Philippe 
Bourgois notes in his study of marginalisation in the Puerto Rican neighbourhood of East Harlem, New York that the "street culture" of cocaine sellers and buyers is ultimately selfdestructive. Individuals are violent towards friends and family but are isolated from the wider society, "failing to see the structural dynamics oppressing them" and instead "blaming themselves for their failure to achieve the American Dream" of individual wealth and success (2004:306-307). Violence becomes a significant outcome of value change, particularly in terms of the indirect violence of exclusion and lack of care, which can make individuals more vulnerable. Woolford and Nelund argue that the service users they interviewed actively attempted to display themselves as responsible citizens to help them secure care. By altering their behaviour, service users aimed to reduce the bureaucratic dehumanisation they experienced, which discredited them as whole persons in need of help and instead addressed only the part of their situations that met specific assistance criteria (Woolford and Nelund 2012:312-313). The "tough love" aspect of responsibilisation noted by Rose (2000:335) allows harsh value judgements to be made of welfare recipients based on absolute terms: individuals either fully succeed in "the rational reconstruction of the will and self-control, of the habits of independence, life planning, self-improvement, autonomous life-conduct" that allows them to "reinserted into family, work and consumption" (Rose 2000:335) or they fail. That failure is interpreted as deliberate within a neoliberal framework; as refusing not only responsibility but also "the offer to become members of our moral community" (Rose 2000:335). On this basis, punitive measures are justified, and individuals are assigned blame (Dwyer 1998:500) - without recognising the structural factors that can limit welfare recipients' capacity to comply. Indeed, Morgen and Maskovsky argue that while welfare reform claims to empower those in poverty by ending dependency on the state and encouraging employment, many welfare recipients instead experience increased punitiveness as the values underpinning welfare shifted, altering the state-citizen relationship for welfare recipients (2003:329).

In this project, I contribute to ongoing discussions around poverty and welfare under neoliberalism by exploring the localised impact of neoliberal reform on the welfare system in New Zealand. In particular, I respond to Morgen and Maskovsky's call for additional "research on the everyday resistance or political mobilisation of the poor in the face of welfare state 
retrenchment or the increasingly punitive state" (2003:332) by illustrating the tactics used by beneficiaries and NGO workers to weave together the strands of welfare support frayed by the strategies introduced by the state as part of neoliberal reforms. Drawing on the everyday experiences of NGO workers and beneficiaries, I demonstrate the gaps created between welfare policy and practice and the everyday reality of New Zealanders struggling with hardship, influenced by the concept of deservingness. I add to anthropological research on how the adoption of neoliberal values has allowed a punitive state to flourish, despite the failure of reforms to reach their objectives (Morgen and Maskovsky 2003:317). By exploring these two aspects - the depth of hardship created by a neoliberal paradigm and the tactics employed to resist it - I contribute to political anthropological literature that "unearth[s] the links between policy and everyday life to help more fully understand their dynamic interactions" (Frerer and Vu 2007:79) and to reconceptualise welfare outside of the terms set by a neoliberal framework (Lyon-Callo and Hyatt 2003:189; Morgen and Maskovsky 2003:317). In this way, I also answer Wacquant's call to "oppose the penalisation of social precariousness ... on the level of words and discourses", attending to the way "the penal treatment of tensions linked to the deepening of social inequalities" (2001:410) has become accepted as ordinary in New Zealand. In sum, I contribute towards anthropological literature which works "to humanise welfare recipients and to deconstruct, complicate, and contest the ideologically saturated policy discussions of welfare" (Morgen and Maskovsky 2003:323).

\section{Poverty and Neoliberalism}

In this thesis, following Wacquant, I use "neoliberalism" to refer to a political-economic ideology and discourse which emerged in the 1980s and transformed the relationship between citizens, state, and market. Wacquant defines neoliberalism as "a transnational political project aiming to remake the nexus of market, state and citizenship from above" (2010:213), which includes expanding the penal system, shrinking the welfare system's support while expanding its bureaucracy, deregulating the economy, and introducing new values with an emphasis on individual responsibility. As a transformative political project, neoliberalism redefines the 
borders of government, reducing control over the economic realm but increasing its enforcement of order among poorer communities more disadvantaged by economic reform (Wacquant 2010:210). This also impacts government agencies, as their "missions and capacities" are changed (Wacquant 2010:210). This usage is in line with broader anthropological understandings of neoliberalism as a specific way of governing states, organising economies, and thinking and talking about running states and economies. Harvey provides one of the broadest definitions, arguing neoliberalism is a hegemonic mode of discourse that "has become incorporated into the common-sense way many of us interpret, live in and understand the world" (2005:3).

Ferguson, on the other hand, provides one of the stricter definitions of neoliberalism in use in anthropology. He narrows the concept to a macroeconomic doctrine that believes the free market is better at organising economies than the state, and as such emphasises private enterprise through the removal of state regulation on trade, financial markets, and businesses. For Ferguson, the use of neoliberalism in the political arena references only "a regime of policies and practices ... claiming fealty to" macroeconomic doctrine, rather than a distinct aspect of the doctrine itself (2009:170). However, Ferguson's portrayal of ideology-driven political practices as an adjunct to economic practices is unusual. Rose and Miller's stance that politics is "simultaneously distinguished from other spheres of rule, and inextricably bound into them" is more typical, where politics is the primary site for the enactment of ideology through strategies and agents, which then affects other spheres like the economy (2010:276). In general, the most common definition of neoliberalism in use in anthropology recognises that "neoliberalism is, above all, a variegated phenomenon, playing itself out in different ways in different contexts, as local historical, political, social, cultural and geographical characteristics come together to constitute local varieties of capitalism" (Block 2018:51). This usage recognises, as Wacquant does, that the ideology of neoliberalism, its discourses and projects, do not represent a single unified form of governance (Morgen and Maskovsky 2003:322). Instead, neoliberalism is a specific "set of ideals and practices" (Trnka and Trundle 2017:4) that seeks "to conform the world to its logic" (Morgen and Maskovsky 2003:322) based on shrinking 
the state, increasing personal and business freedoms, and a faith in free markets as the best way to organise life (Trnka and Trundle 2017:4).

However, it is important to recognise this commonly used definition of neoliberalism is also somewhat contested within anthropology, largely because all-encompassing concepts can be less analytically useful. Wacquant, for example, calls for a more specific description of neoliberalism "that identified the institutional machinery and symbolic frames through which neoliberal tenets are being actualised" (2010:213). However, Wacquant also rejects using concepts such as Farmer's structural violence to achieve this kind of description. Farmer defines neoliberalism as "the ideology promoted by the victors of the struggles" around the development of modern systems of trade, governance and development which "helps to replicate inequalities of power" by allowing economic exploitation at a distance, though it is ostensibly based on "the dominance of a competition-driven market" (2004:313). Though Wacquant and Farmer both begin from similar places of drawing out ordinary "patterns of practice" in the social and economic realms, explaining their historical development in order to show how factors that "shape life so dramatically on the edge of life and death" come into being (Farmer 2004:312), Wacquant argues structural violence is a flawed concept. Specifically, he critiques the way it collapses together different forms of violence wielded by different types of actors within a system. Wacquant argues that by combining all forms of violence together, there is little analytical value to be gained, because "distinguishing various species of violence and different structures of domination" is key to drawing out "the changing links between violence and difference" (2004:322). Wacquant is critical of Farmer's definition of structural violence as invisible and "ostensibly nobody's fault" (2004:322), given that the historical examples Farmer gives of slavery, Haitian reparations to France, and US military occupation of Haiti were not invisible and the responsibility of many, undermining Farmer's arguments. Wacquant also notes that Farmer makes moral judgements about slavery in particular that are out of place for the historical context, "invit[ing] anachronism" (2004:322) into his argument. Overall, Wacquant argues "structural violence may be strategically useful as a rhetorical tool, but it appears conceptually limited and limiting, even crippling" (2004:322). Instead, Wacquant prefers to characterise neoliberalism through four interrelated logics: first, deregulating the 
market and promoting market mechanisms as the best way to organise societal activities; second, to withdraw from welfare and devolve service provision to the market in order to recompose recipients as contractually-obligated clientele; third, to expand the penal apparatus to "contain the disorders and disarray generated by diffusing social insecurity and deepening inequality" and reinforce the authority of the state more broadly; and fourth, to introduce individual responsibility as a key trope for the understanding of self for the population (2010:213-214). In this thesis, I utilise Wacquant's conceptual framework because it is more useful in illustrating both the cause and effect of the changing basis of the welfare system in New Zealand than Farmer's structural violence.

\section{The Governance of Poverty}

Wacquant's concept of the carceral state helps to tie together the systematic change and value change in welfare policy associated with neoliberalism in New Zealand. While Wacquant's work primarily focuses on the rise of the prison in the USA and Europe, his works also outline the transformation of work and welfare under neoliberalism. The broader transformation of the state under neoliberalism is tripartite, involving a withdrawal by government from the social and economic spheres and an increase in involvement in the carceral sphere, based on a value change from Keynesian universal support to an individualistic "philosophy of moral behaviourism" (Wacquant 2010:198). The changes induced by neoliberalism result in greater freedom to pursue wealth by private enterprise and wealthier individuals, but increase the "management of marginality" among poorer populations, drawing symbolic boundaries between those who are, and are not, "good" community members (Wacquant 2010:198). Small government for the "haves" is the other side of the coin to an expanding penal state for the "have-nots" (Wacquant 2010:214). Wacquant argues that the introduction of "the double regulation of poverty by the joint action of punitive welfare-turned-workfare and an aggressive penal bureaucracy" (2010:202) creates a scapegoat in prisoners and welfare recipients, in order to "check the social reverberations" caused by the collapse of industrial labour in advanced nations, the increase of precarious work and low wages, the withdrawal of economic regulation 
and social support by government, and the increasingly apparent inequalities between rich and poor $(2010: 211,204)$. This agrees with Harvey, who earlier argued state withdrawal from the provision of services considered key under Keynesianism such as welfare "leaves larger and larger segments of the population exposed to impoverishment"(2005:76). Personal responsibility is emphasised so that individual struggle "is generally attributed to personal failings", even as the precarity of the labour market results in individuals having fewer resources to provide themselves with a safety net (Harvey 2005:76).

In New Zealand, the economic transformation identified by Wacquant began in the 1980s and continued through to the new millennium. Significant reforms to welfare occurred in the 1990s under the "Mother of All Budgets", introducing punitive sanctions, complex bureaucratic regulations, and high obligations. Beneficiaries had to prove their deservingness in new ways, ultimately aiming to "encourage" responsibility through employment (Hodgetts et al. 2013:47). I discuss this process more fully in Chapter Three, illustrating how neoliberal reforms "strip[ped] away the protective coverings that embedded liberalism allowed and occasionally nurtured" (Harvey 2005:168). It is important to note here that - as Hodgetts, Chamberlain, Tankel and Groot outline - neoliberal reforms have drastically changed New Zealand's welfare support system through tightening eligibility criteria; increasing the micro-management of beneficiaries through "work readiness", parenting and other categories of obligations; increasing punitive sanctions, which primarily operate as income reductions; and generally shifted welfare away from a right to support towards a program that aims "to reduce dependency on government assistance and to produce well-adjusted and economically productive citizens" (2013:47). It is through these kinds of reforms, Wacquant argues, that the blame for social insecurity is shifted away from states and the global system onto welfare recipients and prisoners (2009:3). By blaming individuals, carceral states can argue they have a public mandate to introduce punitive measures to control those who fail to be "deserving" community members. Yet, under neoliberalism, individuals are considered "undeserving" by default.

Through reform, the welfare system becomes a key site to "encourage" behavioural change through individual responsibility which centres around becoming "productive" through employment (Wacquant 2009:xvii). Work is portrayed as the ultimate cure for insecurity, 
though often the work prisoners and beneficiaries find themselves performing is precarious, low-paid, low-skilled, and increasingly not full-time (Wacquant 2016:1082). Yet, this type of employment and living situation is normalised (Wacquant 2010:204). Wacquant is clear, however, that it is not the individuals within a post-reform neoliberal system that are the focus of his research, but rather "the multilevel structural processes whereby persons are selected, thrust and maintained in marginal locations, as well as the social webs and cultural forms they subsequently develop therein" (2016:1078). In the following section, I discuss how the population of New Zealanders in poverty is (not) measured as an example of the structural processes that push individuals into the marginalised positions Wacquant studies, as statisticsbased public policy cannot be effective at preventing or reducing poverty if the data it is based upon is flawed.

\section{Measuring Poverty in New Zealand}

There is one key issue when studying poverty in New Zealand: there is no agreed definition of poverty used by the state. In fact, poverty in and of itself is not tracked. Instead, low-income households and material deprivation are the two principal categories used to infer the level of child poverty in New Zealand (Statistics New Zealand 2019). The data for both categories of measures comes from the annual Household Economic Survey (HES), involving approximately 3500 households. The baseline measure for low-income households is those receiving 60 percent or less of the median equivalised disposable annual household income, before and after housing costs. Disposable income, according to Statistics New Zealand, means after any tax owed is paid and any tax credits owing are received. In addition, material deprivation is measured based on a list of 17 items included in the HES: households face material hardship when they go without 7 of the listed items, and severe material hardship when they go without 9 or more items. ${ }^{1}$ According to the Child Poverty Monitor, in 2017, 12 percent of the child population of New Zealand lived in households experiencing material hardship while 6 percent

\footnotetext{
${ }^{1}$ See Appendix 1.
} 
experienced severe material hardship: 135,000 children going without things they and their families need (Office of the Children's Commissioner 2017).

The 60 percent measure itself was originally proposed as an absolute poverty line households should not fall below, rather than a measure of when households are low-income. The measure was based on focus-group research in the 1990s borne from concern the poverty measure in use at the time - the married couple benefit rate - was flawed after two decades of policy and economic change meant it was out-of-step with wages (Stephens, Waldegrave and Frater 1995:3, 10-11). Yet the distinction between low-income and in poverty is considered crucial elsewhere. For example, the US measures 48 different poverty lines to account for different household compositions and income sources (United States Census Bureau 2018). Being able to access this type of data is an essential aspect of governance, as noted by Rose and Miller, requiring "a huge labour of enquiry to transform events and phenomena into information" for the purpose of making reality "stable, mobile, comparable, combinable ... a form which can be debated and diagnosed" (2010:283). Yet when there is no fundamental definition to base data collection on, and the data collected is itself flawed, reality is not accurately represented - and as a result, the policy decisions it informs becomes flawed too. Rose and Miller argue that "[g]overnment depends upon calculation in one place about how to affect things in another" (2010:283), but this action cannot be effective when based on inadequate information.

Even after Statistics New Zealand completes its three-year remodel of statistical indicators in 2020, it will not measure general poverty, though new child poverty indicators - including poverty persistence - will be tracked to meet the requirements of the Child Poverty Reduction Act 2018 introduced by the Ardern Government. Gaps in the data collected will continue to exist. For example, the Act does not require Statistics New Zealand to analyse populations the agency itself already acknowledges are proportionally overrepresented in hardship statistics namely Māori children, Pasifika children, disabled children, and children with a disabled parent or caregiver. Statistics New Zealand also acknowledges that households facing the greatest disadvantage in terms of low incomes and material deprivation are the least likely to complete the HES, meaning they become underrepresented in the statistics. The Ministry of Social Development, too, recognises that HES data can be flawed if non-respondents to the survey 
vary in significant ways from respondents (2018b). Even with population weighting, MSD acknowledges bias towards better-off households can occur (2018b). This means there will be little improvement in statistical models current policy understandings of poverty are based upon, so policy for addressing poverty in New Zealand is likely to continue to prioritise "common-sense" understandings of hardship over genuine critical engagement with the lived experience of poverty (Harvey 2005:39). In turn, this affects the ability of welfare institutions, like Work and Income New Zealand, to appropriately service communities, continuing to break apart the threads of New Zealand's welfare safety net while beneficiaries struggle to meet neoliberal expectations. Beneficiaries and NGO workers, then, are left to attempt to weave back a safety net to address need and provide individuals with stability.

\section{Studying Poverty in New Zealand}

Previous studies in New Zealand examining welfare and the introduction and expansion of neoliberalism through the 1980s, 1990s and into the 2000s have two streams. The first focuses on the physical, experiential elements of poverty, such as a lack of food ${ }^{2}$ or adequate housing. One example is Rebekah Graham's 2017 doctoral thesis on food insecurity in Hamilton, where the lived experience of lack of food was the "in" to examining hardship and poverty. Material deprivation is used to illustrate the reality of poverty and its impact on daily life, particularly on health and for children. Graham builds on this research in her later work with Hodgetts, Stolte and Chamberlain (2018) which explores the experience of food rationing and the impact of shame derived from neoliberal narratives around poverty and healthy eating. Another example of this is Sarah Gerritsen's 2005 thesis on food insecurity among primary school students in Wellington, which found a small but significant number of students in poorer areas - as defined by school decile - regularly went hungry, and critiqued schools' stigmatisation of lack of food and responses to hunger. Smith, Parnell, Brown and Gray's work on food purchasing practices among low-income, food-insecure families in Dunedin reinforce these findings, illustrating the

\footnotetext{
${ }^{2}$ Both in terms of overall quantity of food, and in terms of sufficient filling, nutritious "healthy" food that meets dietary guidelines.
} 
financial pressure of food spending and where families compromise in order to make ends meet (2013).

The second stream of research into neoliberalism in New Zealand has a more theoretical basis, focusing on value change. One example is Susanna Trnka and Catherine Trundle's 2017 work on the individualisation of responsibility under neoliberalism, particularly around the impact value change has on the provision of care and the social contract, in the introduction to their edited collection Competing Responsibilities. Another example is Māmari Stephens' work on social security law reforms, where she argues that the original basis of the law in Christian ethics has been replaced by "a vision, and not a coherent one, of what it means to be good in New Zealand" that ensures "beneficiaries' freedom to choose to live life in a way consonant with the common good is frustrated, if not substantially abrogated, striking the wrong balance between the law's protection of individual autonomy and its implementation of social imperatives in pursuit of the common good" (2013:383).

More recently, a third stream of scholarship has emerged which attempts to explore the pairing of the physical experience of poverty and welfare and the value changes prompted by neoliberalism to viscerally explore the everyday lived reality of poverty in New Zealand. For example, in Tarapuhi Bryers-Brown's Master's thesis, she describes not only the practical aspects of interacting with "the chaotic meshwork of CYF, WINZ and HNZ processes and bureaucracy" (2015:51) but also her participants' psychological and emotional reactions to the strategies of the state. Bryers-Brown aims to demonstrate the ongoing reinforcement of historical trauma by state agents to Māori communities by describing how participants are made to feel "unworthy and not good enough" (2015:34). However, it also illustrates how poverty impacts people more deeply than just in physical terms - and that this impact is purposefully engineered and accepted as normal. For example, WINZ template letters make it clear benefit recipients are being watched for potential undeservingness. The link between changing strategies for welfare provision prompted by neoliberalism and the everyday experience of poverty is also examined in the 2017 edited collection Precarity: Uncertain, Insecure and Unequal Lives in Aotearoa New Zealand by Groot, Van Ommen, Masters-Awatere and Tassell-Matamua, which draws together changes in policy and practice with the 
experiences of beneficiaries struggling to make ends meet. By demonstrating how precarity emerges among those living with poverty - and among those in low-paid work as once-secure unskilled jobs become part of the "gig economy" - the authors illustrate why the state's current approach to poverty is deeply flawed. A third example is Hodgetts, Chamberlain, Tankel, and Groot's work on approaches researchers working with communities in poverty should take to draw on the "intimate understandings of their situations" possessed by people experiencing hardship "as a basis for conceptualising and theorising issues and developing responses" in ways that could have meaningful impacts for communities (2013:48-50).

\section{Thesis Outline}

In Chapter Two, I describe the methodology used in this project. I begin with a discussion of the challenges encountered in fieldwork and their influence on the methods used. Then, I outline multi-sited ethnography as the principal methodology, paired with Danilyn Rutherford's "kinky" empirical approach. Next I discuss the qualitative data collection methods used to explore beneficiaries' and NGO workers' experiences navigating the fragmented welfare service landscape and the support networks they weave together, which included semi-structured interviews, participant observation and a survey. I then outline the process of data analysis, including the use of field notes, transcription, and iterative coding. The chapter concludes with a summary of the research approach and the limitations of the methods used.

Chapter Three discusses how deservingness became embedded in New Zealand's welfare system as it developed, encompassing different groups along racialised, gendered and classed lines in different eras. I outline the evolution of welfare in New Zealand from its nineteenth century origins influenced by a colonial desire to be a "better Britain", through to its expansion into one of the world's most comprehensive systems in the twentieth century under the universal and protectionist ideology of Keynesianism. I then discuss how the welfare system transformed as neoliberalism replaced Keynesianism as the dominant political-economic paradigm in response to ongoing financial crises at the turn of the new millennium. I describe how, in the 1990s, an individualised expression of deservingness was introduced as part of 
neoliberal reforms, with beneficiaries re-coded as a burden on the taxpayer. I then discuss how these changes were consolidated throughout the early twenty-first century, particularly by the Key-English National Government from 2011 which increased conditionality through behavioural obligations and punitive sanctions. I argue that the strategies introduced under neoliberalism, influenced by the entrenched notion of deservingness, act to control beneficiaries' behaviour as they seek limited support and "encourage" movement into low-paid unskilled labour.

In Chapter Four, I elaborate on how beneficiaries experience neoliberal deservingness in their daily lives, embedded into practice, policy and perception. First, I outline the bureaucratic, punitive and thin safety net provided by WINZ, describing the complexities of the application process and payments. I then discuss how welfare obligations are enforced, emphasising the gap between policy understandings of "obligation" and the reality of supervision and sanction experienced by beneficiaries. Next, I link this to a wider gap between WINZ expectations of beneficiaries and beneficiaries' realities, discussing how WINZ advocates employment as a cureall for poverty while the majority of beneficiaries experience disability or possess caring responsibilities that limit their employment opportunities. Finally, I discuss how beneficiaries' situations of hardship are often complex, and how this can further impact on beneficiaries' capacity to perform deservingness according to neoliberal standards. Overall, this chapter outlines how the current state-provided welfare system makes it difficult for beneficiaries to adequately meet their needs, creating gaps in support beneficiaries turn to NGOs to address.

Chapter Five discusses how beneficiaries and NGOs work together to manage situations of poverty. I begin by outlining the current welfare service landscape negotiated by beneficiaries in New Zealand, including the types of services I explored in fieldwork. I focus on the way NGO workers and beneficiaries negotiate through that landscape to weave together threads of support. I then discuss the care and support NGOs can provide to clients, over and above services, which set them apart from state-provided welfare. Next, I look at the limitations NGOs face as they attempt to address poverty, particularly around funding and service capacity. I then discuss the use of digital networks by beneficiaries to share skills in managing poverty, knowledge about accessing entitlements and support for one another. I argue that this usage of 
social media demonstrates the tactics used by beneficiaries to resist the strategies put in place by the state. While Wacquant argues welfare is solely a site for the enactment of neoliberal ideals through the use of punitive measures and the dichotomy of deservingness, this research shows beneficiaries and NGOs also push back, adapting ideals such as entrepreneurship without accepting others such as strict individualism. Together, NGO workers and beneficiaries weave together safety nets and manage the impacts of the gaps between the real ability to address need and the expectations of the current welfare system.

In Chapter Six, I conclude by summarising the impact of neoliberal strategies, influenced by the concept of deservingness, have on beneficiaries and influence the tactics beneficiaries and their allies use as they struggle to make ends meet. I reiterate the answers to my research questions provided throughout the thesis, illustrating the complexities of beneficiaries' needs and experiences and linking to the overall impact neoliberalism has on the way poverty is addressed in New Zealand. Finally, I discuss the limitations of this research and the potential for further research into the experience of poverty in New Zealand with the hope of better addressing the needs of those experiencing hardship. 


\section{Chapter Two: Weaving Together Sites and Sources}

"My name's not going to be included in your thesis, is it? I'm not sure my organisation would like it." (Fieldnote, 2 July 2018)

"And you're definitely not including my name, right? There's no way it could be traced back to me?" (Interview, 18 September 2018)

In this chapter, I explore the complexities of doing research on poverty in contemporary New Zealand, within a system that fosters a climate of suspicion where those in poverty fear being targeted. I describe the methods used in this study and how, borrowing from Danilyn Rutherford, I took up a kinky multi-sited approach to weave together sites and sources in the absence of close relationships with informants. Initially, I planned to use a more traditional single-sited ethnographic research methodology for this thesis, centred on conducting participant-observation with a small sample of four to six beneficiaries to explore how situations of hardship were managed day-to-day within Wellington's network of welfare support organisations. I aimed to contextualise the impact welfare reform had on the experience of, and narrative around, hardship in New Zealand, linking into anthropological discussions around the rise of the neoliberal state. However, when I attempted to advertise the project through NGOs and advocacy networks, the general response from beneficiaries was that while they supported the project, the potential risk of being identified - and the implicit risk that participation would threaten their benefit entitlements - was too great to volunteer themselves. Even some NGO workers I interviewed were hesitant to volunteer their perspective on the issues we were discussing without reassurance I would not individually identify them or their organisation, in case it affected their employment. While I had anticipated some difficulty in finding participants, this unexpectedly strong reluctance to participate in ethnographic research and fear of identification could not be overcome in the short time I had to conduct fieldwork under a Master's degree framework. 
Yet, the change in approach forced by this situation ultimately gave me more insight into the experiences of beneficiaries and NGO workers as it required me to piece together the fragmented networks of support beneficiaries often navigate for myself in order to find participants. I ended up navigating state and non-state welfare service networks to make sense of the system, teasing out threads from eleven semi-formal interviews with NGO workers and beneficiaries; a survey run among beneficiaries who used Facebook advocacy and support groups; and four months' volunteer work with two NGOs. By taking up a methodology of multisited ethnography, I was able to expand my fieldwork in three directions. While still centred on welfare services in Wellington, I was also able to conduct fieldwork in Auckland and online on Facebook and Twitter. By incorporating semi-formal interviews, an anonymous survey, and participant observation, a multi-sited methodology allowed me to explore the welfare service networks beneficiaries and NGO workers negotiated as they sought to alleviate experiences of poverty. I was able to gather ethnographic source material while addressing the unexpectedly intense fear among potential participants of taking part in this research project. This ethnographic source material is complemented by secondary sources, including NGOs' annual reports and statistics publicly available from the Ministry of Social Development to corroborate my findings. I also conducted historical analysis of welfare policy in New Zealand in order to both contextualise the current system in New Zealand and to trace out the way its discursive foundations continue to shape social welfare policy. By casting our understanding of the contemporary system within its historical context, I aim to show how the system has transformed over time and to suggest, however implicitly, how other possibilities might still exist. As Danilyn Rutherford argues, this produces "construct validity: a higher level of confidence that we are doing justice to a messy reality" (2012:468).

Overall, the methodology I have used for this thesis is "slightly off-kilter" (Rutherford 2012:466), in response to needing to negotiate my access to the field by navigating welfare support networks, rather than being introduced through beneficiary-participants acting as interlocutors for me. Using multi-sited ethnography to overcome the challenges imposed by this access difficulty and the time limitations of Masters research became an advantage, generating evidence of the repeated, shared experience of hardship and difficulty experienced 
across New Zealand's welfare safety net. It also made me consider more deeply "the slipperiness of [my] grounds and the difficulty of adequately responding to the ethical demands spawned by [my] methods" (Rutherford 2012:466). This research could "never get to the bottom of things" completely but was driven by the expectation that engaging nevertheless could make a difference (Rutherford 2012:465). As Rutherford argues, "[b]eing off-kilter is a strength ... it is what comes with getting real" (2012:466), and ultimately that is what this project has aimed to do: show the reality of navigating poverty in New Zealand today. I stitch together the threads of New Zealand's fraying social safety net, rather than exploring a concentrated study group's experiences the way more traditionally-conceived ethnography would. I then use this stitching-together as the grounds from which to understand the experiences of beneficiaries and NGO workers navigating a fractured system.

In the remainder of this chapter, I contextualise my response theoretically by exploring the relationship between Danilyn Rutherford's (2012) concept of kinky empiricism and multi-sited ethnographies. I then describe my approach to data collection and analysis. In doing so, I demonstrate how these hybrid methods allowed me to reconstruct something which mirrors beneficiaries' everyday experiences navigating welfare, despite the difficulties I had enrolling people in this study.

\section{Kinky Multi-Sited Ethnography}

Ethnography as a method centres around personal experience, both of the research participants and the researchers themselves (Sharman 2007:118). It produces knowledge "from an intense, inter-subjective engagement" (Clifford 1983:199). As Sharman notes, ethnography "at its most basic, is the telling of stories with all of the epistemological and political complexities that implies" (2007:118). By contextualising personal experience within its social, political, economic and historical contexts, ethnography attempts not just to convey the realities experienced by people in their daily lives, but to "produce an experience that allows them to share that space" through "an honest and intimate narrative" (Sharman 2007:128) that 
brings people "close enough to imagine how it might feel to walk in another's shoes" (Rutherford 2012:476).

Multi-sited ethnography is a sub-type of ethnography which is constructed around a particular group or individual, thing, conflict, story, metaphor or concept, following this subject from site to site to map out connections across a larger system. This contrasts to single-sited ethnography where a researcher focuses on detailing one group at one location. Marcus describes multi-sited ethnography as moving "out from the single sites and local situations of conventional ethnographic research designs to examine the circulation of cultural meanings, objects and identities in diffuse time-space" (1995:96) to examine something "that cannot be accounted for ethnographically by remaining focused on a single site of intensive investigation". Multi-sited ethnography, unlike single-sited ethnography, acknowledges that the borders between "levels" within a system - between local and national, state and global, for example are not fixed (Marcus 1995:96). Instead, ideas, actions and people flow between sites, so that for instance a modern welfare system in New Zealand is influenced by mid-twentieth-century economic theory as much as early-twenty-first-century economic reality. By linking between sites, Marcus argues, a multi-sited approach enables a researcher to "ethnographically construct aspects of the system itself" and not just its effects among daily life "on-the-ground" (1995:96). Lyon-Callo and Hyatt agree, arguing it does not make sense to "conduct ethnographic studies focused on specific spaces or places when the issues confronting them are part of a larger web of global interconnections." (2003:188).

However, Lyon-Callo and Hyatt also critique Marcus and multi-sited ethnography - alongside Arturo Escobar's (2001) focus on global activist networks - for failing to specify the methodological and analytic issues anthropologists studying "up" need to address to perform useful activist work (2003:188). In particular, they call for a focus on the "insidious" discursive aspect of modern neoliberalism that makes its effects "totalising and natural" (Lyon-Callo and Hyatt 2003:188). The pair argue that researchers should not accept the framework neoliberalism sets up for "conceptualising and imagining the world" (Lyon-Callo and Hyatt 2003:189). Instead, researchers should recognise the possibility for, and try to generate, other responses to the impacts of neoliberalism - and to help the communities they work within to 
do the same, though they acknowledge there is no one simple way to achieve this work (LyonCallo and Hyatt 2003:197). Here, then, Rutherford's concept of kinky empiricism can be used by researchers in combination with a multi-sited approach to recognise methodological and analytical issues attached to "studying up" (Nader 1972), and to become actively "attuned to the real world effects of their own practices and the texts that they put into the world" (Rutherford 2012:476). By following Rutherford and allowing research to be "slightly off kilter" (2012:466), researchers can create space to engage with participants, experiences and research in ways that can generate alternative ways of imagining the world within - and beyond - the current neoliberal paradigm as Lyon-Callo and Hyatt call for. This can have significant potential when paired with a multi-sited approach that allows a researcher to follow threads discovered in research to new people, places, concepts, and things, including to already-in-use ways of challenging the discursive and experiential elements of neoliberalism being driven from community grassroots. Rutherford argues researchers must be "aware of the analytic and ethical twists and turns born of a research method that forces them to get close enough to imagine how it might feel to walk in another's shoes" (2012:476), accepting that "[u]ncertainty and justice go hand in hand in those moments that force us to choose among contending ways of doing the right thing" (2012:473). Taking up kinky empiricism in this way helps researchers using a multi-sited approach to navigate between sites and between the difficulties involved in fieldwork.

Following Rutherford, I take up these threads by tracing out the locally-situated and looselybound networks of welfare support services. In doing so, I recreated the kinds of webs beneficiaries and NGO workers navigate and stitch together. I move beyond a discursive analysis of welfare in New Zealand to better align with the actors trying to navigate the webs of information, institutions and bureaucracy associated with the New Zealand welfare system. I aim to demonstrate the fundamental difficulties these actors face in coping amongst widespread hardship, and to contribute to research pointing towards places where poverty could be better addressed.

Multi-sited ethnography was my primary methodology for this project. While, as mentioned above, I had planned to conduct a single-sited ethnography with four to six beneficiary 
participants in Wellington, New Zealand over four months, my research process instead became much more of an "an ongoing negotiation" as Clifford terms it (1983:135). In my research proposal and ethics approval application ${ }^{3}$, I had identified participant recruitment as a potential issue. However, the issues I saw arising had more to do with navigating potential participants' expectations of the project and the comparatively intensive nature of participant observation. I noted that I would need to be clear in introductory meetings about the scope, time frame and potential impact of the project, as project advertisements such as posters would have limited space for explanation. I wished to both set explicit bounds on the project, and to prove my trustworthiness to participants by ensuring I was honest about the aims and outcomes of an achievable project (National Ethics Advisory Committee 2012:32; Levinson 2010:201). I did not foresee the difficulties that would arise in finding four to six beneficiaries to conduct participant-observation with, in a region of 22,000 beneficiaries (MSD 2019a). Though I recognised that the outcomes of my project would not immediately benefit my participants, I did not recognise the level of perceived risk participants imagined was involved in my research. Yet over the fieldwork period, I encountered a high level of fear of "going against" WINZ, which appeared to be driven mostly by an intense fear of losing financial support or being punished if participation was discovered. This insight shaped a great deal of my thesis.

I began field research in June 2018 by approaching several welfare support organisations I was already aware of based in Wellington via email, asking to set up an interview. I wanted to begin to explore the welfare safety net in-depth with the same well-known organisations that might be a beneficiary's first place to seek help, and to ask if these organisations would help advertise my project to potential beneficiary-participants. I successfully set up two interviews this way, one with a health organisation and one with a budgeting organisation. The first was supportive of my project and agreed to put up a flier advertising the project, while the second was less so. The organisation's representatives instead had some important criticisms and questions about my methods, the support I could give participants, and whether I could guarantee participants' privacy, which prompted the first in a series of research-and-rethink sessions. As Sharman

\footnotetext{
${ }^{3}$ HEC approval no. 0000025998.
} 
argues, "[i]n the field, we must be willing, at all times, to stretch ourselves, to be uncomfortable" (2007:119). So, I changed tack slightly and approached five public libraries and community centres in three suburbs and the Wellington CBD to advertise the project through their community noticeboards, to reduce what I was asking of NGOs that I did not have a relationship with. I also conducted a third interview with an NGO representative, who was the first to ask me directly if they would be identified in my work - as quoted at the beginning of this chapter - building on the privacy concerns raised in the second interview. Again, they stated they could not risk advertising the project. Finally, I attempted to run two information sessions at a community centre near one of Wellington's WINZ offices, which was advertised on the centre's Facebook page and in the local library, which I had already approached about displaying my project poster. Once again, there was a lack of interest with no attendees. I had hoped beginning with already-existing service and support networks would help me to build relationships and open up conversations around poverty. Instead, I found questions I could not adequately answer and dead ends, even as I tried to widen my approach to finding participants.

During this time, I also attempted to join two Facebook groups for beneficiaries and one for beneficiary advocates, to begin to explore what key issues beneficiaries were facing and the ways they supported one another through digital networks. Perhaps online I could open up the kinds of conversations I was failing to find in person and take away the pressure of in-person meetings, easing the risk my project was perceived to pose. However, I was initially denied membership by the administrators of the Facebook groups I had tried to join. Partly this was because their groups were national and I was asking for local participants. The administrators also raised concerns, however, about the privacy and safety of participants, mirroring the NGOs' concerns. One of these groups' primary aims - alongside information-sharing - was providing a safe place for beneficiaries to share their experiences with WINZ. Administrators were cautious about recommending a project that could allow participants to be recognised by WINZ workers through their Facebook usernames, or a researcher who could prove not to be sensitive about individuals' experiences and situations. Again, my attempts to utilise alreadyexisting social media support and advocacy networks failed to help me open up conversations with the potential participants I was trying to reach. At this point, I began to rethink my 
approach more fully. I still had not considered deeply enough the risk that participating could pose, or be seen as posing, to participants. The fact that that risk, reluctance and fear existed was undeniable. Over and over, I found people who ran support networks wished to protect their members, providing respite from the everyday demands of poverty and - especially in the case of social media - a space to express themselves freely. Punishment and unfair treatment so pervaded beneficiaries' and NGO workers' experiences of the state-based welfare system that choosing not to participate or advertise the project was a "no-brainer" decision: people were reluctant to expose themselves or others to potential risk. In making the same choice, over and over, beneficiaries and NGO workers illustrated both the internalisation of responsibilising neoliberal logic among those working within the welfare system, and how that system has embedded expectations of punitiveness and casual cruelty through everyday interactions between the state and those seeking help. Through these experiences, the difficulties people face when accessing welfare to not only make ends meet financially but to survive with a degree of physical, mental, emotional, social and spiritual wellbeing intact was brought home to me.

Knowing that the timeframe I had to conduct fieldwork was limited by the framework of a Masters' degree, my supervisors and I agreed I should expand my focus. I moved from a methodology of single-sited ethnography towards a multi-sited one, drawing out the threads of the New Zealand welfare safety net rather than just what was experienced by beneficiaries based in Wellington. I reached out to further NGOs, first to those in the Wellington and Hutt regions, then in Auckland, conducting seven further semi-formal interviews. This included one direct interview with a beneficiary participant. Their interview began with the quote I opened this chapter with: "And you're definitely not including my name, right? There's no way it could be traced back to me?" (Interview, 18 September 2018), continuing to demonstrate reluctance to participate due to perceived risk. I then searched out volunteer roles so that I could still conduct participant-observation, working one day a week at an NGO that aimed to provide a "one-stop-shop" for people in need and picking up evening shifts at an NGO that provided donated prepared food free to anyone. Finally, I also received permission from the administrators of the Facebook groups I had persuaded to allow me to join to run a survey, so 
long as it did not gather identifiable, personal data, and advertise the project more generally alongside. This survey was also advertised in five further Facebook groups, including a Wellington-based notices group, two parenting forums, a further WINZ-focused group, and a group focused on IRD and WINZ issues. The survey resulted 44 survey responses, as well as around a dozen comments on the Facebook posts. Ultimately, my ethnography encompassed three sites - Auckland, Wellington, and online - allowing me to explore the welfare service networks beneficiaries and NGO workers negotiated as they sought to alleviate experiences of poverty while respecting the fear and need for privacy and dignity of potential participants. I was able to build up a picture of the welfare system in New Zealand today and how it has been influenced by the deployment of neoliberal strategies over time: to see, as Marcus puts it, how "the world system....becomes, in a piecemeal way, integral to and embedded in" the experiences of my participants (1995:97).

\section{Research Methods}

I used three methods to gather data during field research: semi-formal interviewing, participant observation, and an anonymous survey. I also completed fieldnotes throughout the research process to record and reflect on the work I was undertaking.

Participant observation emphasises forming relationships with participants and accompanying them through their day-to-day lives, "to experience, at a bodily as well as intellectual level, the vicissitudes of translation" (Clifford 1995:119) between the specifics of daily life and how these fit into a broader system (Clifford 1995:127). I had planned to use participant observation to explore how beneficiary-participants navigated the complexities of the welfare system and discuss their individual experiences. I had hoped to be able to spend a few hours a fortnight with each participant about their circumstances, experiences and challenges, and perhaps even have further opportunities to explore welfare support networks by, for example, visiting a WINZ office with a beneficiary-participant and observing staff-client interactions from the waiting area. Instead, due to the access issues discussed above, I moved to conduct participant observation by taking up two volunteering roles and joining four beneficiary and beneficiary 
advocate Facebook groups. In the first role, I worked for one day a week with an organisation that provided social work services, a food bank, and supplied goods through their op-shop. Mainly, I worked organising baby supplies and making up packs of essential baby needs, viewing what was donated; how it was sorted, organised, and supplied to those in need; and what expectant mothers and their families needed to do in order to receive assistance. My second volunteering role involved a variety of evening shifts across two different roles, for an organisation which collects and distributes prepared food to anyone who arrives to request it. I recorded an outline of what happened at each shift, a reflection on events, and ideas related to my project generated from each session in fieldnotes. I also attended a Welfare Expert Advisory Group community meeting to conduct participant-observation, for which I also completed a fieldnote. In these fieldnotes, I primarily recorded details about the content of the experience, but also its setting, ideas thrown up by the interaction and recommendations from interviewees for further research opportunities (Aull Davies 2008:233; Madden 2013:121-122). Secondly, I conducted semi-formal interviews with representatives from ten NGOs and one beneficiary. Unlike in my original plan to conduct audio-recorded semi-formal interviews with participants in their homes to explore my participants' life histories - specifically around how they came to access welfare, how they use social media to seek additional support and community, and how they reflect on their experiences - all the interviews with NGOs were conducted in NGO offices in Wellington and Auckland, while the interview with a beneficiary was conducted in my office at Victoria University of Wellington. Most of the NGO interviews were not audio-recorded at the request of the NGO workers, who - again - were concerned about the privacy of their comments. All, however, allowed me to take detailed notes during our conversations, which I then summarised and sent for approval to those who requested it. I completed interviews with two advocacy groups, two health organisations, one advice network, one budgeting organisation, and four "one-stop-shop" social work organisations. "Semi-formal" refers to a type of interview which is formal in the sense that it is pre-planned and "carried out away from the action" to a degree (Ely et al. 1993:57), yet also not formal because a pre-made list of questions is not used. Rather, I had a shortlist of seven topics I wished to discuss, but which were open-ended so that I could have a more natural conversation with interviewees 
about their interpretations of each area and what they felt was most relevant. This helps to achieve the aim of an ethnographic interview "to seek the words of the people we are studying, the richer the better, so that we can understand their situations with increasing clarity ... to learn to see the world from the eyes of the person being interviewed" (Ely et al. 1993:58), not just how they act but why. However, it is important to acknowledge that interviews do not produce "ultimate truth", as what people claim and what people do can be different. As Briggs argues, it is crucial to recognise that interviews are constructed in a way that is "construed as a natural, normal and effective means of producing knowledge and shaping social relations" (2007:552). However, this construction is not necessarily accurate, which is why it is important to use other methods and to corroborate data using, for example, NGOs own annual reports.

Finally, I also constructed a survey using the Qualtrics software package, which I then distributed as a shareable link through the Facebook beneficiary support and advocacy groups I had joined. The survey originated in the reluctance of these groups' administrators to advertise the project. I was allowed to join the groups because these people supported my research and wanted to help, but they were deeply concerned about members' privacy and that people might be interested in participating but not willing or able to meet with me. By using Qualtrics, I was able to create a survey that could be completed on both web and mobile browsers, increasing the accessibility of the project as the administrators wanted. However, it also placed limitations on the data collected, as I felt I was unable to ask about age, gender and ethnicity to ensure no identifiable information was collected. This survey included fourteen questions: four multi-choice and ten where respondents could type in their answers, providing a mix of closed and semi-structured questions (De Munck 1995:100). ${ }^{4}$ I generated the questions from a combination of areas I wanted to explore more deeply after my early interviews and difficulties, and the discussion topics I had for interviews going forward, following De Munck's recommendation that questionnaires should be related to data already raised in fieldwork (1995:100-101). All questions were optional to help ensure privacy and maximise responses, as people could skip questions they did not want to answer and move on to other questions

\footnotetext{
${ }^{4} \mathrm{~A}$ copy of the survey is available in Appendix 2.
} 
instead. I received 44 responses, of which 27 were fully complete, over the three months the survey was open. Running a survey, De Munck argues, is "the most efficient and inexpensive way to gather data from a sample that can then be generalised to the larger target population" (1995:98), helping to reinforce the threads I was seeing in participant observation, being told about in interviews, and finding myself in, for example, Facebook posts in the advocacy groups or statistics collected by the Ministry of Social Development.

\section{Analysis of Fieldwork Results}

At the end of fieldwork, I collated the survey responses, fieldnotes, the responses to four Facebook posts, and interview transcripts. I took a thematic approach to analysing this data, which allowed me to align information from different sources within one interpretive framework. This was an iterative process, involving first categorising data through open descriptive coding, then axial coding to ensure categories were consistent, before grouping these codes to generate themes. In the first stage, I printed copies of each data source and began by annotating each one, looking for specific examples of acts, events, tactics, meanings, and relationships (Gibbs 2012:47). Beginning with such literal aspects of the interview speech, social media comments and fieldwork experiences I had recorded enabled "the construction of a conceptual scheme that suits the data" as recommended by Ely et al. (1993:87). This is encouraged under open coding, which is conducted without a pre-conceived scheme of codes or categories, to help organise data as a first step towards analysis (Gibbs 2012:50). Following Aull Davies, who argues that categories are "low level theoretical concepts" to label, classify, and think about data I created a two-level scheme for coding transcripts, survey responses, Facebook posts, and fieldnotes (2008:234). The first level focused on concrete items identified by participants, including food, money, housing, clothing, transport, paperwork, budgeting, and NGOs. The second focused on more theoretical items, including responsibility, frustration, stress, access, struggle, poverty, deserve, afford, stigma, and penalty. By beginning thematic analysis of my data in this way, I could begin to clarify the threads between experiential aspects 
of poverty and the impact these had on beneficiaries and NGO workers, and start to draw out the broader framework these experiences and impacts were understood within.

Axial coding, by contrast, involves examining the categories generated in the first stage, regrouping them, and re-coding texts to ensure codes are consistently applied (Gibbs 2012:50). This stage helps to generate a clear coding frame, where each category is listed and defined for further analysis (Gibbs 2012:39). During this stage, I refined the list of categories I had generated as I had completed open coding. In this way, I was able to draw on the data to explore the relationships between concepts I had identified in the first stage of my analysis, refining what I knew and drawing together different types of data and different types of fieldwork experiences (Koven 2014:510). The axial coding process resulted in the consolidation of categories such as money and budgeting or frustration and stress, so that I was moving closer to "the generalisation of [the] social reality" (Aull Davies 2008:237) beneficiaries lived within by drawing together the visible and less visible parts of poverty experienced by my participants. I was also able to pull out more threads from the broader framework I had identified in the first stage, noting that there was a gap between the real experience of poverty and the way poverty was explained or perceived in policy by those not experiencing it. Once this second stage was complete, I was able to review the frame in its entirety, further following Ely, Anzul, Friedman, Garner, and McCormack Steinmetz's recommendation "to ask questions, to compare across data, to change or drop categories, and to make a hierarchical order of them" (1993:87). At this point, I then focused more on the "gap" idea I had explored in the second stage, looking through the data to discover how the different arguments about poverty were framed; to find what might be behind the difference. I worked to develop themes from the category hierarchy I had developed, following Ely, Anzul, Friedman, Garner, and McCormack Steinmetz's definition of a theme as "a statement of meaning that (1) runs through all or most of the pertinent data or (2) one in the minority that carries heavy emotional or factual impact ... that highlights explicit or implied attitudes toward life, behaviour, or understanding of a person, persons or culture" (1993:150). Generating themes from categories I developed from the data, and then returning to the data in an iterative process of analysis, helped me to tease out the 
links between categories and themes, and assess my findings overall, influencing what I focused on as I wrote this thesis.

From here, I developed the critical themes of tactics and deservingness that I weave throughout this thesis. Tactics focused on the everyday practices and experiences of beneficiaries negotiating welfare and how participants articulated their acts of pulling together support to survive. Deservingness, in terms of a value judgement, appeared to animate a significant amount of my data, with "good" beneficiaries deserving help because they have proved themselves responsible and "bad" beneficiaries undeserving of help and in need of punishment to preserve the integrity of state welfare against fraud or exploitation. Yet deservingness also wove its way through counter-arguments presented by participants: that people deserved a "good" life, or that ill and disabled beneficiaries deserved more of a "good" life than other types of beneficiaries because they could not help their unemployment, for example. In this way, I was able to develop my argument about the broad welfare safety net in New Zealand across multiple sites, taking up Rutherford's kinky empiricism to ensure I was working towards accurately representing the experiences of my participants while still "exploring the analytical ... twists and turns" thrown up by my data (Rutherford 2012:476).

\section{Pulling Together Fraying Edges}

By using a methodology of multi-sited ethnography in this research, I have been able to draw out the complexities of New Zealand's welfare support net as it is experienced by those on-theground. Though the process of research did not go according to plan as I encountered greater fear of identification among participants than I expected, by taking a different, "kinky" approach I was able build an understanding of the welfare system as it is often experienced by those who must fill its gaps in contemporary New Zealand. As noted by Ely et al., for most research projects, "the broad and general plans we laid at the start in order to establish credibility will almost certainly be redefined and augmented as the real thing comes along" (1993:157). While this project was limited in time and scope by the framework of a Masters degree, it has produced useful knowledge of the everyday experiences of beneficiaries and 
NGO workers as they go about attempting to alleviate the poverty they experience in New Zealand today (De Munck 2009:36; Marcus 1995:99). Through the use of semi-formal interviewing, participant-observation, and an anonymous survey in Wellington, Auckland, and the digital sphere, I was able to build up a description of everyday poverty, exploring how strategies and tactics around welfare have changed over time and the hopes people within the system hold for its future. 


\section{Chapter Three: How Did We Get Here? The History of Welfare in New Zealand}

"A never-ending cycle of nothingness," that's how one NGO worker described the welfare system in New Zealand today, sitting in her office two floors up overlooking centre-of-town traffic in the country's capital (Fieldnote, 27 June 2018). Constant small trip-ups keep the cycle going, keeping people in "nothingness". She pushed the papers covering her keyboard aside, logging in to show me this branch's visit data from the last month: 20 people have been through for help with Work and Income New Zealand benefits. That's equal to one a day, every day they are open. Her organisation helps people figure out their next steps: finding paperwork, getting an advocate, referring on to service providers, knowing who to approach for each issue they face. Providing advice and linking up with other organisations is all her NGO does - but it's enough. Being able to make small steps forward can make a huge difference, she says. Then, she tells me about the importance of keeping a box of tissues in every working space. Her office, the meeting room, the reception desk. It's a point of pride for her. "WINZ don't have tissues", she says (Fieldnote, 27 June 2018). A lot of people cry, though, from stress, from relief, from finally having someone listen to them.

Financial hardship is compounded by the anxiety of mounting debt and collection agencies demands, the closure of support services, increasing rents, and social isolation. She tells me matter-of-factly that people live in tents in the Green Belt, the chain of parks and reserves that lie between Wellington city and the outer suburbs. They come in, sometimes, when their things get stolen. The city council knows they're there and doesn't like it, but there's not much to be done to put a stop to it. The way she says it, it's just ordinary. Just another example of hardship growing harder. As I'm leaving, she mentions another example. Earlier in the week, a couple with an appointment about their benefits at 11AM arrived at 8AM, when the building opened. "They were happy to wait," she said, "because it's warm in here" (Fieldnote, 27 June 2018). Across my fieldwork, similar stories arose of people struggling with WINZ's complex 
bureaucracy, struggling to find help through multiple services, struggling to survive. How has the welfare system in New Zealand, designed to support, reached a point where all this confusion about access and entitlements to benefits, stress, people living with so little - has become just ordinary?

This chapter discusses how desperate hardship became commonplace within New Zealand by tracing the historical development of its welfare system. Specifically, I argue that welfare support has, historically, been based on constructing an ideal of "deserving" beneficiaries, with beneficiaries classed as undeserving excluded, as part of a state strategy determining who can and cannot access support. I show how deservingness has gendered, classed and racialised aspects, despite an ongoing discourse of New Zealand as egalitarian. Through this notion of deservingness, New Zealanders come to understand who is in poverty - and why - in particular ways over time, so that the hardship of specific groups becomes accepted. I demonstrate that that acceptance of hardship is far more wide-ranging today than it has ever been, as the specifically neoliberal understanding of deservingness embedded in the welfare system today has become tied to individualised expectations. I show that in comparison, in the past, deservingness was attached to unevenly defined racialised and gendered categories, which were expanded over time as the welfare system moved towards a universal system of entitlement based on citizenship. Since the 1990s, however, individuals have been expected to take responsibility for their hardship - largely ignoring the structural causes of poverty - with a focus on changing behaviour through a complex, punitive bureaucracy. Ultimately, I explore how the experience of poverty today is still influenced by the racial, gendered and classed dimensions of earlier eras, though its key harshness arises through the implementation of neoliberal strategies which "supervise [beneficiaries] ordinary conducts and even their intimate life with neither scruples nor respite" (Wacquant 2009:28) in order to control beneficiaries' behaviour and ensure they are "deserving" of support.

In this chapter, I will discuss the development of the welfare system through the nineteenth to twenty-first centuries. When the first welfare supports were legislated in the late nineteenth century, they were framed by the extreme poverty and inequality seen in industrialising Britain (Labrum 2009:395). As such, the introduction of pensions for settlers who fell into hardship as 
they aged and became unable to work were seen as a way to make the colony of New Zealand a "better Britain". But these pensions were only available to European settlers who were "sober and reputable", proving their poverty was not their fault (Brooking 2004:89-90, Nolan 2009:374). During the twentieth century, the notion of deservingness was expanded under a Keynesian cradle-to-grave welfare system. However, European men were still prioritised under relief measures during the Great Depression, with a separate and lower-funded scheme provided for Māori (King 1997:80, McKinnon 2016:293). In the following decades, nuclear families became the focus of the welfare safety net, while sole mothers fought for support (Brooking 2004:122, Dalley and McGibbon 2005:301, Moon 2011:453, McClure 1998:185-187). At the end of the twentieth century, Keynesianism was replaced by neoliberalism as the key political-economic paradigm in New Zealand after a sustained economic crisis (Labrum 2009:419, Franklin 1991:156, 160). Under neoliberalism, state-provided welfare was rapidly contracted, with a new focus on individual rather than categorical deservingness (Larner 1997:7-8, Labrum 2009:417, Rose and Miller 2010:295, 272).

In addition, this new model of state support emphasised the figure of the "undeserving" beneficiary over the "deserving" figure. As a result, deservingness has become much more conditional on individuals, who are assumed to be able but unwilling to work. This change in discourse has supported not only a rise in hardship as welfare increasingly turns to punitive "workfare", but also a tacit acceptance that this change is necessary. In New Zealand today, 9.7 percent of the working-age population - almost 300,000 people - receive benefits (MSD 2019a:2). These beneficiaries support around 170,000 children (Duncanson et al. 2018:4). Almost half a million New Zealanders cannot "deserve" hardship, to struggle to live.

\section{Sober and Reputable: The Foundations of Welfare in Nineteenth Century}

\section{Colonial New Zealand}

The welfare system in New Zealand is often traced back to the 1898 Old Age Pensions Act, the first piece of legislation to provide state-funded benefits. The Act was informed by settler- 
colonial ideas such as common law brought by British settlers who, having lived with the British Poor Laws, arrived with particular ideas about a state's obligation to care for its citizens. This idea of obligation was paired with the portrayal of New Zealand as an egalitarian "better Britain", where stark wealth inequalities did not exist, which had been used to advertise settlement to farmworkers, artisans and labourers displaced by industrialisation. On arrival, these settlers set up the small-scale poverty protection measures common in Britain. Friendly societies, craft unions, and church-based charity proliferated (Moon 2011:44; Labrum 2009:395-396). At the same time, the colonial government made moves to introduce a system of "outdoor" and "indoor" relief similar to Britain under the 1885 Hospitals and Charitable Institutions Act (Labrum 2009:395). Outdoor relief provided in-kind help to those assessed as sober and moral citizens in their own homes, while indoor relief was provided in workhouselike institutions (Brooking 2004:89). However, both were unpopular among settlers.

Influenced by settlers' desire for a better system, the Liberal government under Premier Seddon introduced the 1898 Old Age Pensions Act. Seddon wanted to address in particular the hardship he saw in his electorate among former miners, as they became unable to work with age. The character test introduced to the legislation is an early example of the state constructing deservingness. Only formerly employed and tax-paying residents (and their wives) of at least 25 years, with no criminal histories, were eligible if they faced financial hardship in their old age. This eligibility also depended on their hardship being due to age, not irresponsible loss of money through gambling or alcohol use, for example. The pension, which provided around one-fifth of the average yearly wage at the time, was therefore unavailable to most of Seddon's miners. There were also steep abatements for property ownership or savings, which further disqualified many elderly settlers who were experiencing financial hardship but not abject poverty (Brooking 2004:89-90). The legislation also specified that Māori, Chinese and Indian persons were ineligible for support through the pension scheme (Nolan 2009:374). These caveats demonstrate how the early foundations of New Zealand's welfare system were partial at best, and how Parliament decided the requirements of deservingness to enshrine in law. Moreover, it also shows how deservingness in New Zealand's welfare system was structured by racial exclusion, with settlers creating support organisations among themselves, alongside the 
government choosing who was eligible for assistance. These exclusions on the basis of race continue to exist within the kinds of inequality experienced by some beneficiaries within the welfare system in New Zealand today.

In the case of old-age pensions, living a "sober and reputable" life, contributing to building the colony through work and tax-paying, not bringing hardship on themselves and belonging to the desired category of European settler were key (King 2012:269; Moon 2011:44). The Liberal government considered those who did not fulfil these requirements as undeserving of aid, from the miners prone to drunkenness in Seddon's electorate to Māori and non-white migrants despite their contribution (Brooking 2004:90). For its time the pension legislation was considered innovative, particularly as the principal aim for many British migrants was to become independent from employment through farm ownership (Labrum 2009:395; Nolan 2009:358-359). As Brooking argues, this made the government's land reform program the main form of state-provided welfare support to "deserving" settlers during the nineteenth century, far outweighing the novel provision of pensions (2004:90).

\section{For the Working Man: Crisis and Innovation in Welfare During the Great}

$$
\text { Depression, 1929-1939 }
$$

The next significant developments to the welfare system in New Zealand occurred in the aftermath of the Great Depression, as the government grappled with how to restore economic prosperity and a sense of security to the country after the global economic crisis. George Forbes' government had employed orthodox British measures for an economic recession in reacting to the crisis sparked by the collapse of the UK and US stock markets in 1929, cutting government spending and increasing taxes to balance the budget (McLauchlan 2014:142). Wages, set through Arbitration Court industry-wide awards, were slashed by 10 percent (Atkinson 2005:269). The pensions established in 1898 and the family allowances introduced in 1926 were also both cut back (Atkinson 2005:269). Financial instability - or the threat of financial instability - had been felt across the country as unemployment steadily rose, peaking 
at 75,000 men unemployed in 1933 (Van der Krogt 2017:301). Three decades on from the enactment of the Old Age Pensions Act, the notion of deservingness continued to prevail over relief measures. I argue that during this period, the "deserving" recipient of welfare support expanded to encompass the working man. However, deservingness remained based in morality and race, with Māori understood as "undeserving" and non-white migrants excluded from the narrative altogether (due in large part to the introduction of the $£ 100$ poll tax which caused a significant drop in non-white migrant numbers).

Though deservingness widened beyond old-age pensioners in this period to the "working man", the shame attached to accepting charity was deeply felt. As Tennant demonstrates, this shame was tied into deservingness through the values prized among New Zealanders: self-reliance had become valued as settlers lost familial and community networks when they migrated, and which took time to establish in the new colony (Tennant 2013 48-49; Tennant 2007:46). Even as these networks were rebuilt and the state began to legislate for welfare support, self-reliance remained a significant value. Admitting that one was struggling to provide for one's family, even as a working man "deserving" of support, was difficult. For example, Paul Moon describes a case recorded in 1930 in Lower Hutt where a family preferred to face the loss of all their possessions - and the father jail time - rather than the stigma of asking for help:

“... a man who was suffering from tuberculosis, and was too sick to get work: but he had a wife and kids and couldn't see them starve, so he went and stole something or other, something quite trivial ... He got caught and the Magistrate sentenced him to three months. So he was locked up, but that didn't help much, because his family was still starving. His wife was a very proud woman. She wouldn't ask for charity, and she sold every stick of furniture they had to feed those kids. By the time the neighbours found out about it, they had nothing, absolutely nothing. They were just sitting in an empty house eating out of a communal pot with their fingers." (2011:202)

Despite the prevalence of this shame, charitable assistance was available. Primarily, charity was organised through churches, who felt it was their religious duty to address hardship in their communities. As such, it provided an additional form of welfare support for those struggling. Indeed, church-based charity could be more accessible than state-based welfare because churches tended to view poverty as having structural causes as well as personal ones (Van der 
Krogt 2011:299), loosening demands of deservingness in favour of the doctrine of "love thy neighbour". For instance, Van der Krogt explores the rise in the number of food parcels distributed by the Auckland City Mission between 1930-1 and 1931-2 from 9,000 to 17,000 (2011:301). The Auckland Anglican congregation ran the Mission, and its founder, the Reverend Jasper Calder, described the organisation as starting with "... no money, no rules, but with an excellent committee, a lot of enthusiasm and a mighty big faith" (Auckland City Mission 2017). Within a decade, the Mission was "one of the most significant providers of charitable aid in Auckland" - which it still is today - supported by church congregations and secular organisations (Auckland City Mission 2017). As Van der Krogt's statistic shows, when need among the Auckland community increased as the Great Depression rolled over New Zealand, the Mission increased its efforts despite being dependent on donations (Auckland City Mission 2017). Van der Krogt also shows that beyond meeting increased need, the Auckland City Mission's stance fundamentally changed over time from promoting personal virtue - which made one "deserving" of aid - to arguing for greater structural change to end "the depth of suffering in the Depression - and its spread beyond the working class" (2017:301).

The change emphasising broader causes of hardship occurred throughout Christian church communities across New Zealand, as they took up an active role in calling for greater help for the unemployed during the Depression. This support ranged from Catholic priest John Higgins beginning sociology classes in Wellington in 1932 to teach that "[c]apitalism in its present-day form is not simply a good system being abused: it is an abuse raised to the condition of a system until evil has become systematic" (Van der Krogt 2017:302) to one meeting of clerics in Auckland moving to register its "indignant protest in the name of Christianity against the chronic poverty and distress that have grown into a national scandal in this country" (McKinnon 2016:321) with the government, and demanding recognition of "the natural rights of all citizens to an adequate standard of living" twice in September 1935 (McKinnon 2016:321-2). Together, churches across New Zealand ensured that the elevated level of need in the community during the Great Depression did not go unnoticed or unmet. This shows the practice of giving charity, as Trundle argues, goes beyond a "strange type of gift" (2014:16). During the Depression, "the limited, fragile relationality that charity engenders between givers and recipients" (Trundle 
2014:6) spurred much greater action for change, as Christians across denominations were intimately confronted by the consequences of widespread and ongoing unemployment. Deservingness became more and more irrelevant in the face of need and the weight of the fundamental principle of "love thy neighbour" behind Christian charitable practice, which drove unprecedented inter-denominational cooperation on both the provision and political fronts (Van der Krogt 2017:301).

However, the United and Reform coalition government did not rise to meet community need to the same degree as churches. Instead, following Britain's lead, relief work was introduced. The suggestion of an unemployment benefit was rejected because it would be demoralising (Moon 2011:202). This insistence on work for welfare payments shows that work had become more central as criteria for deservingness in the early twentieth century than in the nineteenth. Rather than entitlement based on a "sober and reputable life" proved through previous work, entitlement became based on actively working. However, the work offered by Unemployment Board relief schemes was often menial labour, such as digging ditches and weeding footpaths. Men could also be required to live far from their families in work camps for a meagre daily wage (McLauchlan 2014:142). The schemes were criticised as "make-work", but the small stipend provided by the scheme was desperately needed by many. This was particularly true in urban areas, where the "back-up" work provided by seasonal farm labour requirements was unavailable. For rural men, the short-term work shearing or fruit-picking, for example, often provided accommodation, food, and an influx of cash.

Again, the racialised element of deservingness also defined the boundaries of state support schemes, as Māori were excluded from the relief schemes. Many in government (and in New Zealand's Pākehā population at large) believed the effects of the Depression passed by largely rural Māori communities, with individual Māori who found themselves in difficult times able to "go home to the pā" for food and shelter (King 1997:80). The belief was that since this "option" was unavailable to Pākehā, Māori had an advantage, so could be justifiably excluded from the relief work scheme. The reality for Māori was starkly different. When unemployment reached its peak - 75,000 men jobless in 1933-40 percent of the unemployed were Māori (King 
1997:80). ${ }^{5}$ While an entirely separate relief work scheme was set up for Māori through the Native Affairs Department, rather than the Unemployment Board, workers were paid much lower than Pākehā workers (McKinnon 2016:293). The scheme also failed to target the areas with the largest unemployed Māori populations. Ultimately, it was this failure that saw the Māori relief scheme officially ended. However, more significantly, there was also a mistaken belief that the return on Māori land developed into farms under the Māori relief scheme would provide for Māori communities. Instead, it had become clear that even if fully "developed" into European-style farms, the available Māori land would never be enough to fully support the growing Māori population by itself (McKinnon 2016:294).

In the 1935 election, the ineffectual Reform and United coalition were overwhelmingly voted out. On the day the new Labour Government was sworn in, relief workers were given a week's holiday and a Christmas bonus, and pay rates were equalised between Pākehā and Māori (Dalley and McGibbon 2005:281). The new government quickly set to work, using the previous government's $£ 38$ million in overseas reserves to pay the pre-Depression award rate to some categories of workers and begin a new wave of state home building (Brooking 2004:210). Influenced by John Maynard Keynes' ideas around boosting aggregate demand to meet productive capacity, the government introduced the 1936 Employment Promotion Act and the Industrial Efficiency Act to boost employment and investment in secondary industry (Moon 2011:239, 243). Benefits were restored to pre-Depression levels and, in 1936, a guaranteed price scheme was introduced for key agriculture exports (Brooking 2004:210). Significantly, a breadwinner wage was also instituted by the Arbitration Court. The breadwinner wage was designed to ensure one man earned enough to support a family of five (Dalley and McGibbon 2005:281), so the "deserving" figure of the working man would not need demoralising handouts. Slowly, globally improving economic circumstances were being felt in New Zealand. On re-election in 1938, Labour introduced their most ambitious piece of social legislation: the Social Security Act. This piece of legislation expanded New Zealand's welfare support system

\footnotetext{
${ }^{5}$ While unemployment statistics were collected by the Unemployment Board and the Native Affairs Department, the total number of people employed in New Zealand at the time is uncertain as the Census collected data on wage rates and number of hours worked rather than number employed (Statistics New Zealand 1933).
} 
into one of universal entitlement based on citizenship, providing for all from the cradle to the grave - ostensibly without stigma or prejudice (Dalley and McGibbon 2005:282). Prime Minister Savage argued that this was the only way to ensure that all New Zealanders could "enjoy a higher standard of life with access to everything that goes to elevate the mind - the soul, if you will" (Moon 2011:242). The Act provided for universal pensions from age 60; unemployment, widow's, orphan's, sickness and disability benefits; free education; and subsidised health care (Littlewood 2017:50). Benefit eligibility and full rates were also extended to Māori (Moon 2011:243). The move provoked "admiration and alarm" internationally (McLauchlan 2014:147), and was condemned as "applied lunacy" by the Parliamentary Opposition - a riff on Savage's claim the Act was "applied Christianity", and a critique of the need to double income tax to 15 percent to pay for the new services (Brooking 2004:121).

The legislation, then, presented an apparent revolution in the "deserving" figure entitled to receive welfare support, "removing" the racialised and morality-based aspect of deservingness. But the legislation was, in fact, a reactionary move. The economy was not recovering as quickly as hoped, which meant ongoing unemployment and poverty (Moon 2011:240). A new expectation had developed that the state would take responsibility for ensuring each citizen had the necessities of life, rather than just mitigating the worst excesses of extreme poverty. Faith in the ideal of egalitarianism had to be restored, after the welfare measures in place before the Great Depression failed to accommodate the increasing numbers of people in need seen during the crisis. This prompted a profound change not only in welfare provision but in the approach to welfare (Labrum 2009:393). Yet as Nolan argues, all the measures produced in the "social laboratory" did not prevent the growth of poverty (2009:374), despite an increasing expectation that the state needed to protect workers through legislation (Moon 2011:43). As a result, the Social Security Act can be seen as both framing a new understanding between New Zealand citizens and the state - where the state owed a duty of care to citizens expressed in rights to assistance, as much as citizens were obliged to perform duties to the state - but also carrying through older ideas of New Zealand as egalitarian. Rather than erasing deservingness as the key to welfare support, the "deserving" figure was widened to "New Zealand citizens" rather than the "working (Pākehā) man" under the Social Security Act. 
The Nuclear Family and the Keynesian Welfare State, 1940s-1970s

From the 1940 s to the 1970 s, the New Zealand population enjoyed unprecedented access to universal welfare support funded by general taxation, as the state continued to follow the Keynesian economic model to promote prosperity through supported growth. Labrum defines welfare for this period as "all public activities which improved a citizen's material and psychological circumstances" (2009:392). These activities included free services such as healthcare and education; state-provided goods like housing; and state protections such as guaranteed employment and the minimum family income, alongside benefits and pensions. Indeed, Bell argues that this period of universal provision still resonates today as the benchmark for the Kiwi "good life" (2017:12-13). The quintessential hallmarks of this "good life" - including owning a home, having a well-paid permanent job with four weeks' holiday, and being able to support a nuclear family - became set in the country's cultural imagination because the state guaranteed that most New Zealanders could achieve them. This level of prosperity was set as the "birthright of all" (Dalley and McGibbon 2005:301).

To provide this "birthright", the state introduced new welfare measures over time. For example, in 1946 the Labour government introduced a family allowance paid directly to married mothers - both Māori and Pākehā - on a per-child basis from birth to age 16 to explicitly encourage family building (Brooking 2004:122; Dalley and McGibbon 2005:301; Baker and Du Plessis 2011). The government argued that building families built the population, and therefore, the prosperity of the nation. Again, this follows a Keynesian focus on supporting consumer spending power to drive economic growth. There was also a state house building program, which guaranteed security of tenure and the possibility of ownership to middle New Zealand. The full male employment policy then ensured income to rent or purchase housing (Nolan 2009:375). In fact, historian David Thomason has argued the extent of the welfare measures provided during this period advantaged the "baby boom" generation of the 1940s1950s above every generation of New Zealanders since (Brooking 2004:122), even though some benefits - such as homeownership - were passed down over time, particularly in middle-class Pākehā families (James 2017:218). By 1950, New Zealand ranked fifth in the OECD in terms of 
economic prosperity, despite its comparatively small population, and would retain that ranking until 1966. This affluence drove optimism and a desire to continue to secure growth and wealth into the future (McLauchlan 2014:146).

However, while deservingness during this period remained centred officially on "New Zealand citizens", I argue the welfare system remained exclusionary in many ways. Continuing popular belief in New Zealand as an egalitarian society meant social policy focused on providing equal opportunities, rather than securing equal outcomes (Nolan 2009:375). The belief in equality obscured the moralised and racialised aspects of deservingness still affecting the provision of "universal" support. As a result, individual families became responsible for their failure: those willing to work to succeed, could, supported by the state. One fundamental way this was expressed in social policy was the use of Pākehā nuclear families as the average, defining success in terms of whiteness (Wanhalla 2009:461). This supported the use of assimilationist policies by the state, such as the pepper-potting policy in state housing provision. Under this policy, new housing developments were required to place one Māori family per street - and no more - to encourage conformity to "mainstream" Pākehā styles of living (Nolan 2009:376). The standardised three- and four-bedroom layout of state housing, too, prioritised nuclear families over intergenerational ones. Ultimately, the practice was abandoned as Pākehā families refused to live near Māori families, and Māori families had a clear preference for living near other Māori families (King 1997:95). This demonstrates the continuing influence racial exclusion has had on the structure of New Zealand's welfare system.

The moralised aspect of welfare provision, meanwhile, came to the fore when the rise of single parenting - particularly lone mothers - was recognised in the 1970s. When the Domestic Purposes Benefit (DPB) was introduced in 1973, it was aimed at providing for women who had been abandoned by their husbands - or ex-husbands as divorce rates increased. Its introduction was seen as a momentous change to the welfare system, especially as the DPB was quickly expanded to include single mothers and unsupported single women as well (Magee 1991:147). For the first time, unmarried mothers could choose to raise their children knowing they would have a secure income, and mothers in unhappy marriages knew they would have a level of financial support if they left (Lynch 2002:140). Unlike previous benefits for sole parents, 
where eligibility was restricted to those in work (Moon 2011:451), the DPB was intended to be universal. It both acknowledged the changing structure of the family in New Zealand society and reinforced the traditional stay-at-home role for mothers (Moon 2011:451).

Even though the payment provided less than half of a working woman's average weekly wage, the number of women receiving the DPB increased rapidly between 1973 and 1976. The rise prompted significant backlash amongst media and the government. For example, on 6 July 1976 MP for Otago Central Warren Cooper criticised the DPB in Parliament because:

"I am concerned about the average guy whose wife stays at home and looks after the two or three children. His housing and his other needs must be met first. He has a moral right to the Government's care and concern. I do not support with any enthusiasm the increase in extra-nuptial births ... The availability of the domestic purposes benefit appears to give them an unreal community status. Naturally the whole blame cannot be vested in the mother, nor should it be. It takes two to tango ... In many cases, of course, unmarried mothers, with the assistance of family and friends, are not leaning on the State. I have high regard for them because they are prepared to accept responsibility." (New Zealand Parliament House of Representatives 1976)

Cooper's words demonstrate the prioritisation of the nuclear family ideal based on morality and, despite his caveats, how it often placed an uneven share of the blame for poverty on women. It also demonstrates the way notions of responsibility and deservingness pulled together the figure of Cooper's "average guy" (New Zealand Parliament House of Representatives 1976). Cooper contrasts the moral right of men with families to state support, to the lack of deservingness of unmarried mothers because they violate moral norms. As a result of the backlash typified by Cooper, the Minister for Social Welfare, Bert Walker, called for all solo mothers in de-facto relationships - or even those found to be having sex at all - to be stripped of their entitlements (Moon 2011:453). Critics of the DPB supported Walker's move, arguing that benefits should not be provided to those who were "irresponsible" in their relationships and sex lives, especially as the cost of the DPB was becoming a strain on the taxpayer due to its expanding provision (Moon 2011:451). However, some of this criticism was inaccurate. For example, before being granted the DPB, a separated woman had to get a maintenance order from the courts which the Department of Social Welfare would then collect 
to offset the cost of providing the benefit (McClure 1998:179). The Department was also on dubious legal grounds if it attempted to enforce de-facto partners to provide, as legislation already in place did not require step-parents or foster-parents to do so (McClure 1998:181). Nevertheless, within six months of Walker's announcement, 500 women had lost their benefits (Moon 2011:453). Here was the beginning of a movement towards a more punitive welfare system in New Zealand, spurred by fears of change in society and benefit dependency (McClure 1998:185-187).

Again, despite welfare during the 1940s to 1970s being officially centred on universal provision for New Zealand citizens, the real figure fully "deserving" of support was more restricted. Racialised and moralised aspects of deservingness still impacted service provision to Māori families and sole parent families, who found themselves being measured up against (Pākehā) nuclear families and found wanting. This perceived lack, then, justified assimilationist policies towards Māori. It also produced a gendered mutation in the moralising element of deservingness underpinning provision. Despite MP Warren Cooper insisting "it takes two to tango" (New Zealand Parliament House of Representatives 1976), it was mostly sole mothers left to raise children who were targeted by policies such as the removal of the DPB for pursuing relationships. Overall, then, during the mid-twentieth century, the welfare system was still shaped by a critical dividing line been the deserving and undeserving poor.

The Rise of the Active Consumer and the Rolling Back of the Welfare State, 1980s-1990s

During the 1980 s and 1990s, the state rolled back welfare from universal provision to limited provision. The official figure provided support changed from the "New Zealand citizen" back to the "deserving poor" (Larner 1997:23). However, there were two critical points of difference to the early nineteenth century concept of deservingness. First, deservingness remained broad, with continued welfare provision for the unemployed, the ill and disabled, and single parents (Labrum 2009:418, McLean and Dalley 2005:377). Second, "deserving" became a category that 
had to be actively performed: the "deserving poor" became those who took responsibility, worked towards independence and exercised choice as consumers in the welfare support services they accessed (Baker and Du Plessis 2011). These changes to the welfare were a crucial part of broad economic restructuring undertaken to avert financial crisis, and followed the new ideas of neoliberalism adopted by the government and Treasury. As part of these reforms, the relationship between the state and citizens was also reformed (Larner 1997:7-8, Labrum 2009:417). Welfare recipients were not the only community members recast as consumers. Instead, the entire community was to ascribe to new neoliberal values - such as responsibility and independence - as individual taxpayers and consumers (Rose and Miller 2010:295, 272). However, welfare recipients were expected to prove their embrace of these values in ways other citizens were not, even as their incomes and entitlements were cut (Brooking 2004:164). The wide-ranging and rapid reforms did not rescue the economy from stagnation but instead led to repeated recessions. As a result, unemployment jumped. Higher numbers of New Zealanders found themselves navigating financial hardship in a fracturing welfare system that was being pushed to prioritise profit and consumer "choice" over coherent provision (Labrum 2009:419).

In the early 1980s, New Zealand's economy was doing poorly, falling to eleventh place in the OECD rankings. Events including Britain fully joining the European Economic Community, drastically reducing British consumption of New Zealand exports in favour of European goods and removing New Zealand's primary export market - international wool prices collapsing (McLean and Dalley 2005:377), and the oil shocks triggered by OPEC hit the economy hard (James 2017:97). After decades of guaranteed full male employment, by 1978, unemployment had risen to 45,000, and did not drop into the 1980s. The cost of providing welfare, meanwhile, had risen to 23 percent of GDP from 13 percent twenty years earlier (Labrum 2009:417). Yet the Muldoon government's attempts to improve the economy amounted to fine-tuning the existing Keynesian model, increasing borrowing and public spending to shore up the economy through the Think Big projects (Phillips 2005:360). In 1984, Muldoon called a snap election to combat his unpopularity in Parliament. It backfired: the electorate replaced Muldoon with David Lange. 
The Lange Government inherited a financial crisis. The new Finance Minister, Roger Douglas, took the need for reform as an opportunity to put the monetarist and New Right theories he supported into practice. Many in Treasury, too, supported these theories and Lange's moves to enact them (King 2012:490; Phillips 2005:363). The financial market was deregulated; the New Zealand dollar was floated (Franklin 1991:158); Keynesian economic controls were abandoned along with controls on foreign exchange; GST was introduced; subsidies for farmers and manufacturers were cancelled, and superannuation was taxed (Brooking 2004:153). Douglas and Treasury were determined to make New Zealand a competitive player on the global stage, hoping this would reduce inflation and the need for government borrowing to cover the budget deficit (Franklin 1991:156, 160). The reforms, nicknamed Rogernomics, were implemented "faster and more wide-ranging than anywhere else in the world", calling back New Zealand's reputation as a "social laboratory" for innovative legislation (Labrum 2009:419). A key part of these reforms was introducing neoliberal values to the country: not only was New Zealand going to become independent economically, but citizens were encouraged to embrace individualism themselves.

However, the drastic changes brought few immediate economic gains. By the end of the Lange government's first term, unemployment had continued to rise, with over 100,000 people out of work; national debt increased; inflation did not fall; and the country dropped to twentieth place in the OECD gross domestic product (GDP) ranking (Brooking 2004:155; McLean and Dalley 2005:337). Yet Lange's government was re-elected for a second term in 1987, and Roger Douglas was returned to his position as Finance Minister. McLauchlan argues Labour's election win was due to public relief at visible action on the economic situation (2014:206). By contrast, Franklin argues that the influence of falling tax rates and a boom in investment markets on voters was key, as they embraced their role as individual entrepreneurs (1991:159). However, when the stock market crashed shortly after the election and unemployment began to climb even higher, public support fell. When Douglas proposed another round of economic and social reforms in response, including privatising State Owned Enterprises (SOEs) and a flat rate of income tax that would benefit wealthier New Zealanders, Lange sacked Douglas and called for a pause on reform (McLauchlan 2014:207; Brooking 2004:158). 
The reforms of the 1980s, while not achieving their short-term aims in terms of boosting economic growth, were successful in transforming New Zealand's economy. More significantly, the reforms were also successful in transforming the expected relationship between state and citizens. The social impact of Douglas' reform program was vast. King, for example, argues the reforms ripped the core out of small regional communities, who were dependent on single state-run industries like forestry for employment and on state services like post offices for connection (2012:480). One key aspect of this change in the relationship between state and citizens was that the state backed away from guaranteeing full male employment, despite - or, arguably - because of rising unemployment, particularly in the agricultural and manufacturing sectors most affected by the reform programme (Labrum 2009:418). Instead, self-reliance and individual responsibility were promoted. Labrum argues this effectively encouraged greater tolerance of unemployment and poverty as people struggled with their situations (2009:418). McLean and Dalley agree, arguing the reform program "smashed the icons of the 1950s consensus" (2005:377). During this period, then, was the beginning of the reintroduction of the "deserving poor" over provision for all as values changed and individuals became more focused on their own needs during a decade of rapid change.

The basis of the relationship between the state and citizens changed from the state maximising the welfare of the breadwinner and his nuclear family, to the promotion of the individual taxpaying consumer who did not rely upon the state (Larner 1997:7-8; Labrum 2009:417). Neoliberalism, Rose and Miller argue, breaks with Keynesian "welfarism at the level of moralities, explanations and vocabularies" so that the reframing of the citizen and their relationship to the state in this way is key to reform $(2010: 295,272)$. In the realm of social policy, the emphasis on individualising provision drove a new focus on profitability through competition, innovation and public-private partnerships (Larner 1997:8). Further, the state was to pull back from "direct controls over, and responsibility for, the actions and calculations of businesses, welfare organisations" and even, to some extent, individuals who were to become active citizens and entrepreneurs (Rose and Miller 2010:296). In the welfare policy, in particular, this new framing of individuals as "rational economic actors" drove a splintering in provision (Larner 1997:23). While support among Labour's caucus - and voter base - for 
welfare did prevent the introduction of significant changes to the welfare system, there was still a shift towards privatising provision to minimise cost and ensure consumer choice. Charitable provision began to increase, returning to the significance it had held earlier in the twentieth century. However, in a new development, private service provision was also explored by the state through contracting businesses to provide specific welfare services. It was believed this increase in competition in the welfare sector would improve consumer choice, and therefore, individual outcomes as welfare recipients could tailor services to their situations (Larner 1997:27). However, this also demonstrates how welfare has moved away from "a coherent mechanism that would enable the unfolding of a central plan" to networks "assembled from diverse and often antagonistic components" (Rose and Miller 2010:290). For the first time, New Zealanders were expected to organise their safety net among the services on offer as active, autonomous citizens under a neoliberal push towards individual responsibility for solving individual situations of poverty, as much as towards consumer choice. The state's exploration of private service provision and withdrawal from public provision, coupled with a change in the relationship between the state and citizens that emphasised individualism, brought to an end the expectation of universal welfare provision through the promotion of customised provision organised by the consumer to best suit their needs.

Of course, it is also important to note that these moves were not isolated to New Zealand, but rather part of a global change in the way welfare was operated under neoliberalism, particularly around the introduction of individualising and responsibilising elements. In the US, for example, Hancock explores how the "welfare queen" stereotype developed as reforms to the Aid to Families with Dependent Children (AFDC) program were debated, spreading until everyone accessing welfare was classified as "undeserving" based on racialised, classed and gendered stereotypes that conflated "a person's public action - receiving government benefits - with his or her private identity" and blamed individuals for their situations $(2004: 9,12)$. This change in discourse increased the marginalisation of welfare recipients, with AFDC reframed as Temporary Assistance for Needy Families, emphasising the short-term, independence-fostering nature of the support (Hancock 2004:16, 20). In the UK, too, similar changes moving towards individualised provision for responsible, and therefore "deserving", citizens can be identified. 
Although Lister argues reform in the UK has been more piecemeal than in the US, a "pragmatic individual problem-solving approach" has been introduced which emphasises "paid work, which all too often is equated with social inclusion" (2001:67-68). Further, Deacon notes the influence of US ideas on UK New Labour reforms, particularly around the inclusion of morality-based changes such the emphasis on personal responsibility $(2000: 6,15-16)$. However, Deacon is also clear that the debate in Britain is also shaped by uniquely British influences, such as the Christian Socialist tradition of the Labour Party which views individuals as "responsible moral agents" (2000:11, 7). As a result, reforms aiming to create a new welfare contract between state and citizens were influenced both by the locally specific context and by neoliberal ideology.

During the 1990s, deservingness became explicit in welfare provision once again, based on a specifically neoliberal understanding of the "deserving poor". The Bolger Government was elected in 1991, with new Finance Minister Ruth Richardson directly targeting the welfare system for comprehensive reform. Richardson also believed in monetarist New Right ideas like Douglas. With New Zealand continuing to struggle economically, Richardson argued continued neoliberal reform was the solution. The "Mother of All Budgets" announced by Richardson shortly after the election win saw the abolition of the remaining universal benefits like the family benefit; the introduction of means-testing; the value of payments halved (Labrum 2009:419); the age of eligibility for unemployment benefits raised to 19; and a two-week standdown period introduced for all main benefits before payment was received by applicants (Moon 2011:563). Limited provision was embraced here, under the "Mother of All Budgets", over the tinkering of the previous government. Overall, welfare spending was cut by more than a billion dollars, despite unemployment standing at 11 percent (Brooking 2004:164). The cut was justified by turning back to the narrative of deservingness: benefits were still available across a broad range of need, but recipients needed to be encouraged to be independent, to take responsibility and find employment, rather than being dependent on the community to support them. Yet benefit rolls continued to grow despite the reduced payments. The cuts just caused financial hardship to jump, as evidenced by a rapid rise in the use of secondary payments (Labrum 2009:419). 
The Bolger Government also continued to support an attitude shift among New Zealanders towards individual responsibility, even going as far as to propose a code of social and family responsibility around employment, money management, childcare and health aimed at households (Baker and Du Plessis 2011). While the code received little support from the public, it demonstrated the Bolger Government's commitment to enforcing neoliberal values, outlining precisely how beneficiaries were expected to perform in terms of running their households to be seen as "deserving". Efforts to discover "undeserving" beneficiaries, by contrast, were much more popular among the public. For example, a campaign introduced encouraging people to report neighbours for welfare fraud generated a total of 11,000 phone calls about potentially fraudulent behaviour (Levy 2011; Baker and Du Plessis 2011). Across the decade, then, the emphasis on welfare support belonging exclusively to the "deserving poor" was reintroduced to New Zealand society, driving a new emphasis on discovering who was "undeserving" because they were not responsibly independent.

In addition, unlike in earlier decades, poverty had also begun to be portrayed as an individual problem. However, this move was supported internationally as more of the world embraced neoliberalism. For example, American economist Michael Porter from Harvard University blamed New Zealand's continuing economic struggle on "commitment to egalitarian principles of social justice... which has underpinned much of the basic thrust of government policy with its emphasis on income distribution" in the Porter Report commissioned to help improve New Zealand's economy (Franklin 1991:161). The media, too, began to portray beneficiaries as an "underclass" (Nolan 2009:377) of the community, who relied on others to pay for their "dependency". Again, this "underclass" was characterised by a lack of individual responsibility, choosing not to act responsibly to minimise their cost through securing work (Labrum 2009:420); they did not perform deservingness according to neoliberal-value standards, even as the community around them embraced individualism and came to prize their independence through work and wealth.

Though many in the electorate had voted for National hoping for an end to reforms, a new phase began instead (Moon 2011:564). Not only was the relationship between the state and citizens being rewritten through the changes in welfare - with "a hand up" replacing "a hand 
out" (McLean and Dalley 2005:376) - but so was the relationship between citizens. The egalitarian basis of state service provision fell away, replaced by individuals prioritising their own needs and exercising their responsibility and choice in addressing those needs. Publicity around welfare dependency and political worry around the expense of social services continued to focus on the "dependent" - and therefore undeserving - unemployed. This was despite the fact that half of all welfare spending went towards superannuation for 15 percent of the population (Labrum 2009:417). These discursive shifts towards emphasizing the problem of dependency contributed to how citizens understood poverty and social assistance. Reforms to welfare did not affect superannuants: their incomes remained steady, while the incomes of beneficiaries fell on average by a fifth (McLean and Dalley 2005:376). The difference between how poor beneficiaries and superannuants were perceived reflects the way specific ideas of dependency and deservingness became implicit in welfare reform. The reforms set in motion by the Lange Government in the 1980s gathered pace, moving New Zealand further from universal provision. Instead, following - or rather, setting - global trends, New Zealand moved towards a minimal state-provided welfare safety net even as unemployment remained high, with little improvement in New Zealand's economic circumstances until the turn of the new millennium.

\section{Children in Poverty: Remodelling Welfare, 2000s-2010s}

Economic circumstances improved as New Zealand entered the 2000s, though the country was still in a recession. This meant as it became clear the 1990s welfare reforms were not succeeding in reducing beneficiary numbers or the overall cost of welfare provision, there was economic "wiggle room" to make adjustments. For example, in 2001 the Ministry of Social Development (MSD) was established by re-joining some of the units of the old Department of Social Welfare split in a 1992 reform - namely, WINZ and the Ministry of Social Policy. Spending was also less tightly controlled, with MSD distributing over $\$ 20$ billion annually by 2005 to around one million New Zealanders through benefits, superannuation, and StudyLink allowances for tertiary students. Yet financial hardship continued, as evidenced by the rise in child poverty. Monitored by the Child Poverty Action Group (CPAG), child poverty became an 
increasingly common media topic in the early 2000s. In response, the Clark Government introduced the Working for Families tax credits system (James 2017:220). This package included a tax credit guaranteeing families with children a minimum annual income, an in-work tax credit, a new baby tax credit, and a per-child tax credit. This move to address child poverty demonstrates a key change in the notion of deservingness which underpins the welfare system in New Zealand. While working-age adults are expected to prove they are "deserving", children are perceived as automatically "deserving" because they cannot have contributed to their poverty. Vulnerability, then, emerged as a new moral dialogue around public benefit support in specific, age-related ways.

Here, the moral aspect of nineteenth century welfare re-emerges, where deservingness is defined by not causing your hardship. However, as Wacquant notes, this not "a simple return to the government of poverty characteristic of the savage capitalism of the close of the nineteenth century" (2009:27). While children are classified as "deserving" because they are not responsible for their hardship - alongside the elderly provided for under superannuation who contributed in the past, and students provided for under StudyLink with the expectation they will contribute in the future - the deservingness of adults continues to be shaped around the performance of active neoliberal citizenship. The Working for Families (WFF) package carefully navigates this thread between "deserving" children and adults who need to prove their deservingness. The per-child tax credit is the only payment in the package available to families without at least one caregiver in work, with full payments available exclusively to families with at least one caregiver working full-time. For this, WFF was critiqued by the Child Poverty Action Group when it was introduced, who argued "[l]eaving the worst off further outside the normal living standards of society is a recipe for disaster" (Baker and Du Plessis 2011), significantly disadvantaging the children of beneficiaries who could not access the majority of the package.

During the first two decades of the twenty-first century, Labrum argues, the belief that New Zealand's welfare system is comprehensive, innovative, and compassionate appeared to remain widely held (2009:390). However, she argues, this belief is "self-satisfied, uniform and overly protective", obscuring reality (Labrum 2009:390). The relationship between state and citizens was rewritten as New Zealand embraced neoliberal values and adjusted to the reforms of the 
1980s and 1990s. Deservingness has remained key to the limited provision of welfare support. In particular, it restricts the support provided through WINZ to working-age beneficiaries while other payments like superannuation for the elderly, Working for Families tax credits for lowincome families and StudyLink payments for tertiary students have much broader eligibility and lower oversight.

Conditionality increased under the Key Government's 2011 reforms to the welfare system, influenced by the Welfare Working Group's recommendations. Implemented recommendations included introducing new punitive measures to encourage job-seeking by beneficiaries, including sanctions for failure to provide information, attend meetings, or rejecting a job offer deemed suitable by WINZ. It is important to note, however, that the support mechanisms recommended by the working group to support beneficiaries' employment were largely not implemented. The recommendation to take up a more data-focused approach to policy and practice, such as the forward liability system used by the Accident Compensation Corporation (ACC) was also implemented (James 2017:226). The ACC used this system to reduce long-term dependency on its payments to workplace accident victims by actuarially calculating the risk of long-term dependency posed by each client, targeting support to high-risk victims to support them back into work. The difference between expected and actual cost is then claimed as return on investment (James 2017:226-227). To enable the use of this method on a much larger scale, the Key Government instituted the Integrated Data Infrastructure (IDI) system to pull anonymised data from across government departments for analysis (James 2017:229).

Whether these reforms were moving the welfare system into the modern era, as the Key Government argued, or simply increasing hardship was fiercely debated. The reforms were also criticised for their gendered and racialised partiality, with protest over those who did not fit into specific categories being excluded from support (Labrum 2009:390). However, the Key Government forged ahead, claiming that the only solution to poverty is a job. Yet some small changes to the welfare system to ease hardship were also introduced. For example, benefit rates for families with children were lifted by $\$ 25$ a week in 2014, in the first review of benefit rates since the 1990s. The change demonstrates how the Key Government also negotiated the line between "deserving" children and adults who had to prove their deservingness, attempting 
to address child poverty even as new punitive measures were introduced to ensure adult beneficiaries were compliant and "deserving".

Today, the welfare system in New Zealand encompasses a wide range of government agencies, private businesses and non-government organisations (NGOs) interacting to provide income and material support to those struggling with poverty and precarity. ${ }^{6}$ According to the Welfare Expert Advisory Group, over 630,000 New Zealanders a year receive a welfare payment directly from Work and Income New Zealand with a further 395,000 receiving payments through the Inland Revenue Department (IRD) Working for Families tax credits (2019b). Third-party providers contribute to the patchwork of services these beneficiaries can access, with some organisations adapting to the neoliberal environment and others being founded because of the increased need neoliberal reforms caused (Tennant 2013:61; Conradson 2008:2122). These third-party providers are largely NGOs, as service contracts procured from the government under the competitive funding model tended not to cover actual service costs (Tennant 2013:65). There is little profit to be made between philanthropic and government funding, with high accountability and compliance costs (Conradson 2006:156, 163; Conradson 2008:2122). Yet NGOs are a key part of the current welfare system, as they provide services above and beyond those beneficiaries can access under state-provided welfare, and even help beneficiaries to access their state entitlements (Tennant 2008:5). As Tennant argues, "'the voluntary sector" and "the state" are not opposed; rather the relationship between them, even as one of "mutual convenience", enables a much greater degree of support and services for those who need them" $(2008: 2,9)$.

Currently, the primary approach of the welfare system - along with most government spending - is social investment. The New Zealand Treasury defines the social investment approach as a way of seeking out who needs better outcomes over the long-term, and how those better results are obtained (2015). "Better outcomes" are aimed at improving service provision to meet the needs which emerge from better data collection and analysis, such as "enjoying economic opportunity; engaging and achieving in education; maintaining good health; and

\footnotetext{
6 "NGOs" has become the preferred term for third-sector welfare providers today over the earlier 'charity', largely due to the term's neutrality (Fieldnote 26 July 2018).
} 
enjoying safety and security" (Treasury 2015). Initiatives for "better outcomes" also need to be able to prove measurable results on a like-for-like return on investment basis, so that new and improved service provision is effective and efficient (Treasury 2015). Social investment is overseen by the Social Investment Agency (SIA), launched in July 2017. The agency describes its mandate as "overseeing and coordinating the government's approach to social investment". It achieves this by working with the public and private sectors "to help them take a lifetime view of service users", encouraging innovation and advising on investment priorities as well as "trialling and testing new approaches for targeted populations" (SIA 2017). Under the Ardern Government, this investment approach has pivoted towards including measures of wellbeing to improve outcomes.

In addition, reforms have been introduced to soften welfare. For example, the Winter Energy Payment is automatically provided to beneficiaries and superannuants between May and October to ensure people can afford to heat their homes over winter. Then, in the 2019 Budget, benefit payments were tied to wage rises instead of the Consumer Price Index to ensure beneficiaries' incomes are not left behind as wages - and cost of living - rises. However, these mostly amount to tweaking the system as investment in welfare continues to decline as a percentage of GDP (Cordery 2012:474). Benefits remain conditional, and the qualities of neoliberal deservingness remain embedded within the welfare system. Beneficiaries still "fall under the same principled suspicion: they are considered morally deficient unless they periodically provide visible proof to the contrary" (Wacquant 2009:15). This emphasis on individualised deservingness "foster[s] of victim blaming while absolving the economic drivers implicit to increased social inequality", Hodgetts et al. argue, presenting a key challenge in adequately addressing poverty within New Zealand today (2013:51).

\section{Developing Welfare Support in New Zealand}

I have argued the welfare system in New Zealand had its origins in limited social support measures introduced by the state in the late nineteenth century, which were then extended into the 1920s. However, this was not enough to protect the populace from the global impact 
of the Great Depression. I have shown that as a result, more radical legislation embracing the Keynesian model was enacted in the late 1930s which introduced a universal welfare system where entitlement was explicitly based on citizenship, though still underpinned by racialised and moralised aspects. I have traced this through to the mid-1980s, where the neoliberal paradigm was introduced into New Zealand in response to economic crisis. Nicknamed Rogernomics, these neoliberal policies saw sweeping cuts to government spending, the beginnings of the privatisation of government services, and a new emphasis on the values of individualism, responsibility and independence. I then showed how after the 1990 election, moves to cut spending, privatise services and increase efficiency focused in on the welfare system, with main benefit rates slashed in half. I explored how limited provision officially replaced the universal provision, and increased expectations that beneficiaries would prove their deservingness were introduced: individuals would take responsibility for their situations, choose services to help them resolve their poverty, and become independent through work.

The New Zealand state, known for a century for being a hotbed of innovation in social legislation, took up neoliberalism under Douglas and Richardson more rapidly and across a broader range of areas than anywhere else in the world. Since then, despite rising poverty and increasing demand, spending on welfare services as a percentage of GDP has declined continuously (Cordery 2012:474). I argued that an underlying drive to provide only for the "deserving" has remained throughout the development of the welfare system. Despite the explicit framing of welfare assistance during the 1940s to 1970 s as universal, based on birthright, assistance has remained targeted towards the "deserving" and pulled away from those perceived to be "undeserving". Precisely what has constituted deservingness has evolved, however. This trend has continued as the Welfare Working Group recommendations enacted by the Key Government introduced a new level of conditionality and responsibilisation to the welfare system, increasing sanctions and a punitive focus on gaining (any) employment. Yet the Ardern Labour Government offers hope of change away from punitiveness, as the state works to include wellbeing as an element in economic decisions and as poverty and financial hardship in New Zealand becomes more visible. 


\title{
Chapter Four: Day-to-Day Survival Under Neoliberalism
}

\begin{abstract}
"In poverty, as in physics, starting conditions are everything. There are no secret economies that nourish the poor; on the contrary, there are a host of special costs."
\end{abstract} (Ehrenreich 2001:27)

"We ask people to bring WINZ rejection letters", this NGO worker tells me in his office behind an op-shop, "but often people don't have them" (Fieldnote 20 July 2018). He says "it's hard to know whether WINZ didn't give them one, or if they didn't apply. I'm not even sure WINZ print the letters anymore. It's so hard to get any information from them" (Fieldnote 20 July 2018). We've already been talking for half an hour about the services his NGO provides, but the conversation really gets going when I ask about WINZ. The rejection letter is used to make sure people are not missing out on help they're entitled to, I'm told, but people have such negative experiences in the offices they just try to avoid WINZ as much as possible (Fieldnote 20 July 2018). This pushes his NGO into a difficult position: do they insist someone apply when it's traumatic for them? Do they spend hours going through the digital application process, helping someone compile evidence, and attending appointments? Should people be made to reapply if WINZ have failed to send out a letter or record evidence supplied, or if they have been turned away by reception staff? And most importantly, if the NGO turns someone away, can they access help any other way? Often, staff just aid, then try to address issues that might stop people applying for help by providing advocacy or linking people in with literacy and digital literacy courses, for example. A lack of training and time on the part of WINZ staff, too, makes the process of accessing state support difficult not just for service users but also for the NGO staff trying to help them.

In this chapter, I explore the tactics used by beneficiaries to survive within the welfare system on a day-to-day basis. I also build on the discussion of deservingness in the previous chapter by demonstrating the ways this notion influences the strategies which affect the everyday 
experiences of beneficiaries when accessing WINZ payments and managing their daily lives. I argue making ends meet presents an unacknowledged workload for beneficiaries, as they must weave together support from a thin, punitive, and bureaucratic state safety net and a fractured web of NGO providers. Tactics, as defined by de Certeau, are "the "actions" which remain possible" for the weak in struggles between strong systems and their processes and weak individuals (1988:34). Tactics allow individuals to "use, manipulate, and divert spaces", to "use the constraining order of the place" in ways that produce "unexpected results" (De Certeau 1988:30). These tactics are "determined by the absence of power", operating "in isolated actions, blow by blow", taking up opportunities as they present themselves, yet unable to keep any advantage for long (De Certeau 1988:37-38). Tactics "vigilantly make use of the cracks that particular conjunctions open in the surveillance of the proprietary powers" (De Certeau 1988:37). Within the welfare system, tactics present themselves in weaving together support and in stretching resources to make ends meet. Tactics can also be employed to help mitigate or evade strategies imposed by the state to govern behaviour and attempt shape beneficiaries into compliant, low-wage workers (Wacquant 2009:15). However, even with the best, most creative resource management, beneficiaries are often left with gaps they cannot fill. Beneficiaries then face impossible choices that can have longer-term ramifications, such as illhealth from being unable to afford groceries. In this chapter, I will discuss the application process for benefits; the ongoing process of maintaining access to financial support; how beneficiaries manage hardship with regards to housing, budgeting, and food; and the impact of hardship on beneficiaries.

\section{Seeking Support Through WINZ}

Work and Income New Zealand provides three types of payments which make up the income of beneficiaries, as described by my participants. ${ }^{7}$ Primary payments provide a main source of income for beneficiaries. The most common primary benefits are Sole Parent Support (SPS) for

\footnotetext{
${ }^{7}$ Full descriptions of each payment, including who is eligible, are available on https://www.workandincome.govt.nz/products/a-z-benefits/index.html
} 
single parents with children under 14; Supported Living Payment (SLP) for those with a health condition that impairs their ability to work for over six months; and Jobseeker Support (JS) for those with no employment, part-time employment looking for more work, a health condition lasting fewer than six months that impairs their ability to work, or a single parent whose youngest child is over 14. Secondary, or "top-up" payments, cover additional regular costs such as high rent or medical care. This category includes Accommodation Supplement and Disability Allowance payments, as well as Temporary Additional Support. Most are weekly payments, though the Winter Energy Payment is specifically provided from May to October to help with additional costs expected in winter. Secondary payments tend to require reapplication on shorter, three- to six-month timeframes than the year allowed for main benefits. Tertiary, or "one-off" payments, cover unexpected or essential costs that an applicant could not have known about in advance and planned to cover themselves. Benefit Advance payments and Recoverable Assistance Payments are generally required to be repaid, while Special Needs Grants are generally not. ${ }^{8}$ These must be applied for each time one is needed, and more stringent eligibility requirements are put in place if a beneficiary exceeds a set quota of tertiary payments in a year.

To receive benefits from Work and Income New Zealand, potential beneficiaries must complete two processes. First, applicants need to complete the online "Check What You Might Get" eligibility quiz created by the Ministry of Social Development. ${ }^{9}$ The quiz provides a preliminary indication of what payments a person may be eligible for, based on their family, education, housing, health and employment situations. From here, potential beneficiaries complete the second process, applying online through the MyMSD platform. Both processes have been implemented relatively recently, with participants noting both make accessing benefits easier only if one is digitally literate and has access to both a device and internet. It was noted across several NGO interviews that helping people complete online applications has become a key aspect of their work.

\footnotetext{
8 'Food grants' generally refers to Special Needs Grants. Recoverable Assistance Payments are also available to low-income non-beneficiaries, as are most secondary-type payments.

${ }^{9}$ Accessible from https://check.msd.govt.nz/
} 
One common issue is that potential beneficiaries must set up a MyMSD account to access the MyMSD website portal if they have not used the platform before. This may involve setting up a login if the potential beneficiary has a client number and an email address or phone number already registered with WINZ. If not, "clients" will need to call WINZ to set up a client number, register their details, and then create a MyMSD login. Potential beneficiaries can also use their verified RealMe ID if they have one. RealMe is a program created by the New Zealand Government and New Zealand Post as a single login for a variety of government services, including WINZ, Immigration New Zealand and IRD. This is a much more involved process, requiring the verification of a home address and a photo to be supplied from a Post Shop. Applicants for primary benefits, including Jobseeker Support, Supported Living Payment, and Sole Parent Support, have no choice but to apply online. Applicants for secondary and tertiary benefits can choose between applying online, via a paper form which they can print from the website or collect from a service centre, or by phoning the call centre. However, WINZ strongly encourages beneficiaries to use the online application form: the hold message for the call centre informs callers about the MyMSD platform.

Yet the online application form was a key point of difficulty among my participants, particularly the fact the form does not allow changed answers without starting an application over or phoning the call centre and having a WINZ worker make changes. For one advocacy group I interviewed, working through these applications was the critical issue they helped beneficiaries with directly. Reinforcing this point, another participant wrote in the survey "it's very hard to use the online service to apply as if you don't fit into the categories or boxes it won't accept your answer. And you can't get an appointment until you have done online forms. So you just have to make it up." Here, then, is a clear example of the punitive bureaucracy beneficiaries must contend with. Completing these applications costs in terms of data or internet access, but also in time. The inability to change answers if a question is misunderstood or an incorrect answer accidentally given is a significant source of frustration. It is also, I argue, the first step in "emphasis[ing] and enforc[ing] the sacred border between commendable citizens and deviant categories ... those who merit being salvaged and "inserted"... into the circuit of unstable wage labour and those who must henceforth be durably blacklisted" (Wacquant 2009:xvii). In 
completing the first two processes of application, potential beneficiaries demonstrate their ability to employ tactics - such as reaching out to an advocate - to complete tasks that could provide them with welfare support. Potential beneficiaries also demonstrate their willingness to jump through hoops to prove their deservingness, working through circular bureaucratic processes to establish their eligibility for payment.

Once an application form is completed and submitted, the "run-around" my participants described experiencing continues with the third process, pre-benefit activities. These tasks must be completed before an application can be processed. Applicants have 20 days to complete pre-benefit activities. These can include attending a job-readiness seminar, reading and accepting obligations in MyMSD, supplying evidence such as medical certificates or children's birth certificates in hard copy to a service centre, completing a jobseeker profile for WINZ's jobs board or attending an appointment with all required supporting documentation. Different main benefits have different pre-benefit requirements depending on circumstances, but all have some form of activity that must be completed. If activities are not completed inside the 20 days, then the application is cancelled. Two survey participants noted this time limit could be particularly frustrating when WINZ makes mistakes, such as losing forms or failing to inform applicants of specific documentation needed before appointments so that they must resupply information and re-book appointments under a countdown. One NGO participant noted that WINZ losing documentation is a regular issue. They suggested introducing an online portal for supplying scanned documents, similar to the Connect portal used by the student loan and allowance service Studylink, which could go some way to fixing the issue. Currently, clients must repeatedly collate documents and travel to a service centre to hand them over. For some beneficiaries, she noted, this could also involve travelling to public libraries to print copies of bills or bank statements, or taking identity documents to a JP to be certified, adding to the travel, cost, and time required to complete an application. Indeed, one participant summarises this entire process of applying for benefits as "[p]hone calls, online applications, follow-ups, armour, knowledge of your entitlements otherwise it won't be offered", demonstrating the range of tasks, time, and skill needed to obtain a payment. Many respondents referred to this 
as a kind of "emotional armour" necessary to endure the difficulties associated with working within the system.

Even if all three processes have been completed, and an application approved, a one- to twoweek stand-down applies. Once accepted as eligible beneficiaries, payments do not start for two to three weeks since payments are made a week in arrears. When combined with the initial application period, beneficiaries often described waiting for one to two months to receive any payment at all. Here, then, a significant gap in welfare support is identified: during this application period, applicants can have no income, no savings, no access to secondary level payments unless already receiving them, limited access to tertiary-level grants, and rent and bills still to pay. The thinness of the state safety net is illustrated; how easy it can be to fall through. My participants make it clear that WINZ's application process is not as streamlined or straightforward to access as MSD claims it to be. Despite the relative incoherence in these processes, WINZ determines whether or not an application is approved. Thus, persistence and attention to detail through the indignities of an inconsistent and complex process demonstrates whether one is "deserving" or not, though it is worth noting that an applicant's willingness to critically engage with these procedures is excluded from that idea of deservingness.

Yet even when benefits are gained, beneficiaries continue to face hardship as benefit levels are low, particularly given high living costs in New Zealand. ${ }^{10}$ Secondary benefits are designed to accommodate higher-than-average costs, but a significant percentage of beneficiaries receive them, illustrating how low main benefits are. In the survey I ran, 39 of 45 respondents received secondary payments - and many received two or more. This is also reflected in MSD's statistics, with 300,741 Accommodation Supplement recipients; 231,952 Disability Allowance recipients; and 65,727 Temporary Additional Support recipients in the June 2019 quarter (2019a).

The insufficiency of benefit levels can be further demonstrated through an example budget, utilising the highest per-person weekly main benefit payment of $\$ 385.60$ after tax per week for

\footnotetext{
${ }^{10} \mathrm{~A}$ full list of payment rates and thresholds, including comparisons to Superannuation and Student Allowance, is available: https://www.workandincome.govt.nz/products/benefit-rates/benefit-rates-at-1-april-2019.html\#null A full list of asset and income limits is available: https://www.workandincome.govt.nz/products/payment-for-oneoff-costs/index.html
} 
a sole parent with a long-term illness or disability receiving a Supported Living Payment. An example budget for a two-child, sole-parent family based in my primary field-site of Wellington using this payment plus supplementary payments could look like:

\begin{tabular}{|l|l|}
\hline Income & Per week (net) \\
\hline Supported Living Payment for a sole parent & $\$ 385.60$ \\
\hline $\begin{array}{l}\text { Accommodation Supplement, band three (sole parent with 2+ } \\
\text { children), zone two }\end{array}$ & $\$ 220.00$ \\
\hline Disability Allowance (maximum rate) & $\$ 64.29$ \\
\hline Total & $\$ 669.89$ \\
\hline Expenses & Per week \\
\hline Rent - cheapest two-bedroom unit on Trade Me for Wellington & $\$ 400$ \\
\hline $\begin{array}{l}\text { Groceries - 2018 New Zealand Estimated Food Costs for a basic diet for } \\
\text { an adult woman, a 5-year-old child and a 4-year-old child }\end{array}$ & $\$ 139$ \\
\hline Electricity - estimating a \$150/month bill on a low user plan & $\$ 37.50$ \\
\hline $\begin{array}{l}\text { Internet and phone - basic internet and pre-paid mobile phone with } \\
\text { Skinny }\end{array}$ & $\$ 13.75$ \\
\hline $\begin{array}{l}\text { Transport - Snapper cards for parent and eldest child (under-fives } \\
\text { travel free) for bus network plus walking, assuming a home near shops, } \\
\text { childcare centre, medical centre and school }\end{array}$ & $\$ 20$ \\
\hline Remainder & $\$ 49.64$ \\
\hline
\end{tabular}

Now, this remainder would need to cover early childhood education costs for the four-year-old child, as it is a WINZ obligation that a child over three attends at least 20 hours' ECE with a registered provider per week (and while 20 hours' free ECE is available for three- to five-year-

\footnotetext{
${ }^{11}$ It is important to note the authors of the Estimated Food Costs study have recently made it clear the estimates are intended to be used as part of cost-of-living research, not to guide actual food spending, in response to WINZ's use of the study to set food grant levels (One News 2019a). The inadequacy of the study for food grants in particular was also noted in one NGO interview I undertook (Fieldnote, 26 November 2018). However, because the study has been used by WINZ to guide its understanding of 'reasonable' food budgets, I feel it is a useful baseline for this thought exercise.
} 
olds, most centres require parents to sign up for plans beyond these hours); school costs for the five-year-old child; medical costs for the parent, as SLP eligibility is restricted to those with an illness or disability that will prevent them from working for six months or longer; personal care and cleaning supplies, which the New Zealand Estimated Food Costs project gives as $\$ 25.60$ per week; clothing and shoes; bank fees; any debt or fine repayments; payment plans or lay-by payments; household contents; dental care; insurance; et cetera. Suddenly a "surplus" of \$49.64 becomes a significant shortage based on short- and medium-term costs, before I have even included long-term costs that go beyond providing for bare necessities. Note that what I describe here is one of the highest levels of income to which a beneficiary may be entitled, using a basic budget format employed by an NGO I visited during fieldwork.

While my example individual could be eligible for additional payments, such as Childcare Subsidy due to the long-term illness or disability that makes them eligible for SLP or Temporary Additional Support, these payments would require a new round of application, activities, and appointments. Benefit applicants must weigh up the cost involved in applying to decide whether "it's not worth the stress to argue for a couple of dollars more", as one of my survey respondents wrote, demonstrating the affective weariness making sense of these cases' complexities.

The shortage I identify does not just appear in this single example, either. As part of its review process, the Welfare Expert Advisory Group compiled the Example Families and Budgets: Investigating the Adequacy of Income report, where they compared income and expenses for six example family situations based on "the most common family types accessing a main benefit" and average expenses for Manurewa, Auckland (WEAG 2019c:9). The research found that no beneficiary family had sufficient income to cover core expenses, in line with similar research completed by the Living Wage and Poverty Measurement Project (WEAG 2019c:5, 3). The list of core expenses, developed with a group of Auckland budget advisors, is similar to the list I used, influenced by a Wellington-based NGO, including rent, food, power, clothes, medical costs, transport costs, and school and childcare costs but no debt repayments (WEAG 2019c:34). "Participatory" expenses, such as sports costs, low-cost activities and contingency savings, 
were well beyond beneficiary households (WEAG 2019c:14-17). While it is important to note the limitations of examples like this, I agree "[t]hey provide a tangible and relatable assessment of the difference between people's incomes and their expenses at the level of the individual family" (WEAG 2019c:3). Key limits to this exercise include assuming households receive correct and full entitlements; that they carry no debt; and that they have housing and household furnishings and appliances (WEAG 2019c:12). For many beneficiary households, this is not the case, particularly being debt-free. I will discuss this more fully later in this chapter as I flesh out the tactics used by beneficiaries to manage poverty.

In this section, I have demonstrated the stressful, time-consuming process of accessing benefit payments through the complex WINZ bureaucracy. I have also explored the meagre income this process obtains. Beneficiaries must balance the cost of working through a complex bureaucracy against the thin safety net of income provided.

\section{Supervision and Sanction}

Punitiveness, alongside thin support and complex bureaucracy, were core experiences of stateprovided welfare reported by my informants. Neoliberal policies and practices instituted over the last 30 years have introduced a focus on individualised responsibility. In this section, I will explore how benefit obligations and sanctions act as responsibilising practices, influenced by the notion of deservingness. As defined by Rose, responsibilising practices are strategies used by the state to manage citizens, encouraging the self-regulation of conduct "by binding individuals into shared moral norms and values" and allowing governance "through the selfsteering forces of honour and shame" (2000:324). Trnka and Trundle expand the concept, arguing that responsibilising practices extend to judging individual capacity to exercise agency and willingness to change, "assessments of legal liabilities, and notions of moral blame" (2017:4).

While the stated aim of such strategies is to "encourage" employment and independence, the policies fundamentally misunderstand who beneficiaries are and what they need, thereby acting instead to punish people for their complex situations of hardship and the inequalities that exist within New Zealand's capitalist society. Beneficiaries are commonly (mis)perceived as 
"lazy" and in need of encouragement to take up employment and, thereby, become responsible, productive citizens. However, I argue that the majority of beneficiaries are in fact willing to work but disabled, ill or holding caring responsibilities, which reduces their ability to take on paid employment, rather than able to work but unwilling. I further reinforce the point that accessing state support is a time-consuming, unacknowledged workload. Fulfilling obligations requires a continual "run-around", continuing the negative experience outlined above when applying for benefits throughout the time of benefit receipt.

Agreeing to obligations, as noted above, is a pre-benefit activity required before an application for benefits will be processed. These obligations can include (MSD 2018c):

- informing WINZ about changes in circumstances that might affect eligibility such as starting a relationship, beginning employment, starting a business or being admitted to hospital;

- searching or preparing for work, including updating WINZ on how this obligation is being met "as often as we reasonably require" (MSD 2018c)

- taking and passing a drug test from a training provider or potential employer;

- completing activities set by a contracted service provider;

- ensuring your partner completes youth activities;

- completing work ability assessments;

- enrolling children in a Primary Health Organisation (PHO);

- ensuring children under five are up-to-date with Well Child checks through a Well Child provider;

- enrolling and ensuring children attend an approved early childhood education (ECE) program from age 3 and school from age 6;

- attending appointments, seminars, and job interviews;

- undertaking rehabilitation, voluntary work, work experience or community activities;

- taking any offer of full-time, part-time, temporary, seasonal or subsidised employment, depending on whether a person has full- or part-time work obligations 
Managing these obligations can represent a heavy workload for beneficiaries, not just in terms of the activities themselves but also the worry and stress they can cause, particularly when there are gaps between what WINZ policy allows as "reasonable", how this policy is implemented in busy WINZ offices, and what beneficiaries can realistically achieve. For example, my beneficiary interviewee explained that the effort involved in attending WINZ appointments because of their chronic illnesses meant they "always need one or two days to recover from a WINZ appointment". They told me "just having to bus into town is traumatic enough", but then in their nearest WINZ office "anytime anyone walks across the floor it shakes like there's being an earthquake, which is fucking traumatising. It's stressful. Like I know it's not an earthquake at this point, but it's still feeling that shit and I have to take anti-anxiety pills every time I go there. And there's like no water cooler, no bathroom" (Interview, 18 September 2018). This interviewee currently receives Jobseeker Support with a medical exemption, Disability Allowance and Temporary Additional Support (TAS) payments, and have to travel into this service centre regularly to submit medical certificates for their exemption, reapplications for the TAS payment, and expenses for the Disability Allowance. They note that these administrative requirements "don't all line up nicely" (Interview, 18 September 2018), compounding time spent, and that they struggle to complete things as MyMSD frequently tells them to call, then the call centre tells them to do things online, and they are stuck going around in circles. The effort required to maintain access to essential income is unacknowledged, and the "run-around" is obscured by the idea the policy and processes are themselves coherent, even if different levels of bureaucracy disagree on how to implement them or simply do not do so consistently. They are, my interviewee notes, now being pushed to prove they are moving towards employment. One way they have been asked to do this is by attending work-readiness seminars held early in the morning, though this interviewee explains they "can't do that. I can't do mornings. It's just like my body can't do it at the moment, so it's- I don't know..." (Interview, 18 September 2018). This demonstrates how the actual effort required to complete what appear to be simple obligations can be much higher for beneficiaries than it would appear.

The cost of travel and accessing resources, in particular, can be a hardship for beneficiaries, as noted in interviews I undertook with NGO workers. Tasks perceived as "easy" by WINZ workers 
and policy-makers consume a beneficiaries' day. Another example an NGO worker gave me was a service user who was told they needed to apply for jobs and take in proof they had applied at their next appointment to show they were meeting their search for work obligation. This involved calling to make the next appointment; travel costs to go to their nearest library and back; paying to use that library's internet; searching for suitable jobs; completing applications and their CV; checking their emails for application confirmations; paying to print these emails; then later, travel costs to a WINZ service centre for their appointment - and this was for a literate and digitally literate person who already had an email account and a CV. Simply finding the money to pay for tasks like this, the NGO worker noted, can be difficult on a tight budget, reducing the money available for other essentials like food. I will discuss beneficiaries' budgeting tactics more in the next section. Yet, beyond the cost, each task includes several subordinate tasks which are invisible to WINZ policy and within the WINZ office.

Also, the lack of guidelines for what constitutes "reasonable" expectations can create friction between WINZ and beneficiaries. For example, one NGO social worker I interviewed discussed being asked to advocate for a service user when WINZ attempted to sanction them for failing to attend appointments and job interviews. The individual was on home detention and therefore unable to meet "reasonable" obligations which did not account for their circumstances (Fieldnote, 20 July 2018). The \#We Are Beneficiaries report, too, identified that a gap appears to exist between the ways WINZ enacts its obligation policy and what is "reasonable" for beneficiaries. For instance, one submission reads:

"The third year of my postgrad study involved in an internship with both study and fulltime (unpaid) work responsibilities. My job prospects after that would be extremely high. Halfway through, WINZ called me to tell me I had to attend a 'job search workshop' which I simply couldn't afford. I was a single parent on a benefit with the costs of a working person (e.g. childcare/petrol costs etc.). I was just scraping by. I tried to explain my situation but WINZ said they would have to cut my benefit as my obligation was to "seek paid work, not unpaid work"'" (Orchard 2017:17).

Here, then, is a clear gap between what WINZ believes beneficiaries ought to be able to do, and what beneficiaries can achieve. This is compounded by the fact that the majority of beneficiaries have illnesses, disabilities or caring responsibilities, as noted above. In my survey, the majority of respondents were receiving Jobseeker Support with a medical exemption or 
Sole Parent Support or Supported Living Payment benefits - a total of 32 out of 45 respondents. This finding is reflected by MSD's figures for all beneficiaries, which show in the June quarter that 213,029 people received Sole Parent Support, Supported Living Payments or Jobseeker Support with a medical exemption, far more than the 75,323 people "job ready" on Jobseeker Support payments (2019b). ${ }^{12}$ These figures clearly show that the majority of beneficiaries are not merely unemployed: their financial hardship is tied to health conditions or caring responsibilities or both. However, MSD's statistics do not extend to tracking the level of overlap in these additional responsibilities, and I did not ask survey respondents for this detail in order to offer a higher degree of anonymity to participants. Indeed, the gap between WINZ expectation and beneficiary reality is demonstrated by the framing of the "default" benefit as Jobseeker Support - and therefore by obtaining employment - when the majority of beneficiaries are unable to work full-time and may not ever be able to work full-time. As my survey respondents explained, this gap between their capability and the expectations from state welfare for them caused severe stress and anxiety when interacting with WINZ, but their need for an income left them no choice. One writes:

"It's been difficult to access support because of my fear of WINZ. I try to minimise my interactions with them, as any contact with WINZ causes me severe anxiety. This anxiety prevents me accessing additional support when I need it."

Respondents experience a lack of support, one writing "they treat you like a criminal when you go in to WINZ". Several reported feeling like they had to nag for appointments or beg for entitlements, creating more stress and work to be done. Between judgemental staff and having to repeat intimate details, most of my survey respondents had negative interactions with WINZ. Indeed, even NGO interviewees reported negative interactions. One social worker wondered exactly how poorly the people they worked with were treated when they were alone, given how dismissive and rude case managers behaved when she was there to advocate (Fieldnote 26 November 2018). The experiences of my beneficiary interviewee when fulfilling their

\footnotetext{
12 There were also 3,617 people receiving Youth Payments, Young Parent Payments, Jobseeker Support Student Hardship, Emergency Maintenance Allowance or Emergency Benefit payments, which have a variety of eligibility requirements and work obligations but are not the focus of this thesis (MSD 2019b).
} 
obligations, then, such as the difficulty and exhaustion of attending an appointment, are not unique.

Failure to meet an obligation results in a sanction. Generally, sanctions result in a reduction of the amount of benefit paid. ${ }^{13}$ For households with children, sanctions are capped at a 50 percent reduction in benefit. Sanctions can be lifted once re-compliance is proven. A beneficiary can also challenge them. Either way, supplying the evidence to lift a sanction is placed onto a beneficiary, giving an example of the individualisation of responsibility. For example, if a person fails a drug test, they can "re-comply" by taking and passing another test within five days. The cost of both tests is then docked from a person's benefit. Sanctions are most commonly imposed for missing an appointment.

Another example is the recently-ended 70A sanction, where a sole parent's benefit was docked by $\$ 28$ per week per child if they do not name their child's other parent. This name was used by WINZ to claim child support through the IRD, to offset the cost of providing the SPS benefit. Beneficiary parents were not paid the child support claimed. The \#We Are Beneficiaries report included several stories illustrating the impossibilities of this sanction, from a grandmother who did not know the father of her deceased daughter's child and therefore could not provide the information (Orchard 2017:85); a domestic abuse survivor trying to protect her newborn who was disbelieved (Orchard 2017:67); and two mothers chased by WINZ for child support, who had to fight through the legal system against WINZ despite "good and sufficient" reasons to not supply their child's father's name (Orchard 2017:67-68). Sanctions add to the unacknowledged workload faced by beneficiaries, as well as the stress and anxiety accessing WINZ support causes.

Beneficiaries must regularly prove their compliance or risk their income, even when mistakes are made by staff members or policy is implemented incorrectly. Indeed, a key issue for one advocacy NGO representative I interviewed was the inability of WINZ staff to use the powers of

\footnotetext{
${ }^{13} \mathrm{~A}$ list of current sanctions is available: https://www.workandincome.govt.nz/on-a-benefit/obligations/notmeeting-your-obligations.html

A series of evidence briefs on sanctions completed for WEAG is also available: http://www.weag.govt.nz/weagreport/evidence-briefs/
} 
discretion they were allowed under the Social Security Act without higher approval (Fieldnote 26 November 2018), as it meant case workers could recognise a greater range of "good and sufficient" reasons for breaches of obligation, like the examples above provided where the 70A sanction was imposed. At another interview, a participating NGO worker noted they often had to compare the information they were given in offices to the online Guide to Social Development Policy ${ }^{14}$ to ensure they were being given correct information, as different staff members can give conflicting, poor, or outright incorrect advice without being held accountable for it - though if beneficiaries made mistakes, left out evidence or missed tasks they did face consequences (Fieldnote 18 October 2018), which Hodgetts et al. also found in their research (2014:2045). The NGO worker emphasised that it should not take being accompanied by an advocate or a lawyer to sort out issues at WINZ, as these services are not available to everyone, but a lack of expertise on policy and law among overworked, under-pressure staff made it necessary (Fieldnote 18 October 2018).

This issue has been ongoing since the introduction of neoliberal strategies to the welfare system in the 1990s, with Andrews exploring the issue in her thesis around downward social mobility experienced by middle-class women after marital separation, including participants' experiencing "for the first time in their lives, reliant upon government institutions and social policies for their livelihood" (2000:158). In one example, Andrews describes the hierarchy of implementation for the former Training Incentive Allowance (TIA) as, first, what the law states; then, what a Ministerial directive instructs in terms of establishing a welfare programme and its policy based on the law; then, a policy document is prepared by senior officials within WINZ to provide day-to-day procedural guidelines (Andrews 2000:164-165). The beliefs of her participants around eligibility for the TIA payment based on their interactions with frontline staff in WINZ offices, she explained, were often at odds with the actual content of policy documents (Andrews 2000:165). One of Andrews' participants stated:

\footnotetext{
${ }^{14}$ Available here: https://www.workandincome.govt.nz/map/. This site was, however, contentious among NGO participants, as some felt it does not accurately reflect Ministry of Social Development policy or current social security law, but is an interpretation by another layer of bureaucracy that can be contested (Fieldnote 27 November 2018).
} 
"No, the frontline staff don't even know ... I had to argue with the woman on the desk, she went out and checked with her supervisor and came back and said "Oh, you're right". But the key is that they say "It's not our policy to pay that" so the answer is "It's not your policy to pay it but it's the law that you have to". And there should be no discrepancy, there should be no difference between those two things. They're a government department for goodness' sake." (Andrews 2000:165)

Further, these beliefs were at odds with the interpretations of WINZ officers and an advocacy agent she also spoke with as part of her research, which created an apparent "problem in the manner in which the directive is implemented, or not, as the case may be ... this results in a combination of narrow interpretation by senior WINZ staff resulting in a restrictive policy document, lack of knowledge on the part of front-line staff, and an overall institutional attitude of suspicion towards applicants and beneficiaries (Andrews 2000:1660). In a second example, Andrews also explores how WINZ was criticised for withholding information in a 1995 High Court Case, Ankers v. Attorney-General, because "employees of WINZ had unreasonably obstructed applicants from receiving Special Benefits" by failing to ask about special circumstances that would make them eligible, a failing compounded "when in 1991 a computer calculation was routinely applied. The questions which would lead to a special benefit being applied for were simply not asked" (Andrews 2000:161). However, this also creates space for tactics to be implemented. As Baker and Davis explain, these gaps between policy and practice mean advocates can, by "assiduously follow[ing] the rules ... counter the desired effects of workfare policies" and "[turn] the ambiguities of street-level deliberative provisions to the advantage of beneficiaries" (2017:544).

Despite election promises, the Ardern Government has softened but not overhauled the explicitly punitive strategies introduced under the previous government. For example, the number of sanctions imposed during Labour's tenure has fallen dramatically from 14,778 in the December 2017 quarter to 8,536 in the December 2018 quarter due to changes made to the way sanction policy is to be applied by WINZ (MSD 2018d). But this is far different from Labour and Greens' election promises of an end to sanctions. Only the 70A sanction has been entirely removed, with the change to take effect in 2020. The failure to end compulsory drug testing and its associated sanctions have been a particular point of contention after MSD deputy chief executive Viv Rickard acknowledged imposing sanctions "doesn't help people become 
employed and independent" (One News 2019b). However, Rickard also claimed it was beyond MSD to end the imposition of sanctions, as they are legal requirements under the Social Security Act.

Further, the Opposition has also not changed its position on the need for a punitive approach, with National leader Simon Bridges standing by his claims sanctions were "about making sure we had expectations on beneficiaries that would lead to better lives for them" (Satherley 2018). He argues sanctions are necessary to be both "fair to taxpayers, hard-working taxpayers who deserve actually their money to be spent well, but also the beneficiaries who in terms of getting into a job, have a better life quality actually have more esteem and more of a purpose" (Satherley 2018). However, again, this approach is mismatched with the reality of beneficiaries. As discussed above, the majority of beneficiaries are willing to work but caring or ill or disabled. This was reflected in my survey results - where 32 of 45 respondents received a Jobseeker Support with a medical exemption, Sole Parent Support, or Supported Living Payment benefit and in MSD's own statistics. This means not only is beneficiaries' ability to work is compromised but their ability to meet obligations as they face greater challenges around managing caring responsibilities and health issues.

In this section, I have demonstrated how maintaining access to benefits by working through obligations and avoiding sanctions continues the unacknowledged workload beneficiaries face. It is time-consuming, confusing, and has severe consequences for mistakes or mismanagement. The system of sanctions and obligations appears counter-productive. There is a gap between the ideology of neoliberalism, where poverty is easily solved through individuals taking responsibility and gaining employment, and the "on-the-ground" reality of beneficiaries.

\section{Living with Hardship}

In addition to the difficulties of accessing and maintaining state support, beneficiaries also have to manage complex situations of hardship. As touched on earlier in this chapter, benefit payments are low compared to living costs in New Zealand. As a result, beneficiaries must 
juggle their needs to ensure their day-to-day survival. These needs are complex not only because of the multifaceted nature of poverty - as defined in Chapter One - but by beneficiaries' everyday experience of ill health, disability or caring needs as discussed above. In this section, I will discuss the tactics used by beneficiaries to make ends meet, particularly around housing, food and budgeting. Here, I demonstrate that for beneficiaries, taking individual responsibility for their situations as per neoliberal values is challenging on two levels. First, beneficiaries lack options and the capital required for genuine choice in ways more welloff New Zealanders fail to comprehend. Second, many of the issues faced by beneficiaries in their daily lives link to greater structural issues they cannot address on their own. This illustrates the gap between neoliberal ideology and the effect its implementation has on beneficiaries as they try to weave together gaps in support to make ends meet.

As I have established, it requires a significant amount of effort on the part of beneficiaries in order to access subsistence-level support. It requires further significant efforts to make that support "work" to ensure day-to-day survival for beneficiaries and their families and to stretch resources to cope with hardship and weave together fraying threads of support as best they can. My beneficiary interviewee notes that:

"WINZ pay you enough to survive, ish. But even then that's pushing it. But they don't really pay you enough to have a life outside of eating, not great food, and you know ... like if it's not, you know, necessary to your physical health or you're not prescribed it by a doctor, then they're not going to pay for it ..." (Interview, 18 September 2018) Managing their budget means going without. Without the therapy that could improve their physical health, without transport, without community. For my survey participants, managing also means going without: without doctors' visits and prescriptions, without heating, without hot water, without clothes and shoes, without food, without suitable housing, and again, without transport. This was the primary tactic used by survey respondents to manage their poverty, with a total of 19 suggestions of some form of going without. The majority of my respondents described their financial situation as living hand-to-mouth, relying on personal networks of family, friends and NGOs to survive. Participants described themselves emotively, using descriptors like dire and horrible alongside terms like struggling, poor, very-low-income, 
and surviving. "Surviving" is a key term, one said, rather than living. There is nothing left for "living" once bills are paid.

Even managing "surviving" in the first place is difficult. Two NGO participants from different organisations used the phrase "life chaos" to describe beneficiaries' situations (Fieldnotes 28 June 2018; 26 June 2018). One NGO interviewee further explained that beneficiaries can face higher costs non-beneficiaries do not. For example, electricity is much more expensive for consumers with poor credit history, requiring an upfront bond or a pre-paid account. Generally, pre-paid accounts with companies such as Globug that require no credit history are more expensive than monthly-billed electricity - and electricity is switched off immediately once credit runs out until it is topped up again, in stark contrast with monthly accounts (Edmunds 2015; Edmunds 2018), compounding the high cost of living.

However, budgeting remains the second most common tactic used by survey respondents, identified in 13 responses. A key budgeting technique is the use of automatic payments or redirections to split costs. Redirections are where WINZ splits a benefit payment, sending off a rent or utility payment before the remaining money is sent to a beneficiary, though they are considered an exceptional measure and can only be set up by application. Other budgeting techniques mentioned by survey respondents included comparison shopping and buying things second-hand or food on special. However, budgeting can also include measures which produce greater poverty in the long run. A key example is the use of debt to make ends meet. Five survey participants included a form of debt as a critical tactic for them, including using loans, credit cards and overdrafts. Contending with many sources of difficulties, from high living costs to problems with WINZ, mean beneficiaries struggle to juggle everything. As one NGO participant stated:

"[B]eneficiaries are good people and good budgeters, but money has come to be synonymous with morality in the neoliberal era. Those without money are seen as not as good, which has a devastating impact on self-worth and the ability to seek out and organise help across multiple issues or organisations. There is an absolute lack of choice." (Fieldnote 28 June 2018).

Beneficiaries use a much wider variety of tactics in order to cope with a lack of choice associated with low income, even as meeting the demands of neoliberal deservingness through 
spending and consumption practices becomes increasingly difficult. Beyond budgeting and going without, survey respondents identified tactics, including selling their possessions, finding free food, going to bed early or going vegan. "Managing", then, can include "negative" tactics that put beneficiaries at risk as well as "positive" ones, with the overriding focus on "vigilantly mak[ing] use of the cracks that particular conjunctions open in the surveillance of the proprietary powers" (De Certeau 1988:37) in order to survive.

\section{Falling Through the Gaps}

In this chapter, I have demonstrated how it is near-impossible for beneficiaries to meet their needs through state welfare support alone. The bureaucratic, punitive WINZ system is difficult to access - and to maintain access - for many New Zealanders facing hardship. The low income individuals can then obtain is not enough for them to adequately meet their everyday needs, so that beneficiaries continue to struggle with "a never-ending cycle of nothingness" (Fieldnote, 27 June 2018), as described by both NGO interviewees and survey respondents. Here, then, are the gaps beneficiaries must attempt to weave together by employing a variety of tactics and turning to NGO service providers, working to manage their welfare support network. However, it is never enough. As Batty and Flint note, these tactics are often "perceived as a set of routinised practices: mundane, ordinary, normal, and "common-sense"" (2013:3) by those in poverty, when they are actually extraordinary, demonstrating skill in creatively managing the extreme difficulty of scraping by. Among those struggling with poverty in New Zealand, going hungry, going cold, going sick, going without has become "mundane, ordinary, normal, and "common-sense"'" (Batty and Flint 2013:3), just the tactics used to make ends meet, as my survey respondents outlined. Managing within an increasingly complex welfare system presents an unacknowledged workload for beneficiaries as they attempt to reach neoliberal standards of responsibility and deservingness, and for the NGOs attempting to help them as described by my NGO interviewees. The majority of beneficiaries experience illness, disability or caring responsibilities that stymie their efforts to reach these standards. Overall, in this chapter I have explored how beneficiaries scrape by and make do within the current patchwork system of 
social support in New Zealand, demonstrating how the punitive system impacts beneficiaries in myriad ways. 


\section{Chapter Five: Weaving A Safety Net: Networking and Net-Weaving}

“... precarity is a web where narrow and naïve solutions merely pluck at a single thread which fails to resonate with the wider circumstance and ultimately leaves those affected only more hopelessly entangled." (Groot et al. 2017:14)

Four-thirty PM, and already there's a queue, two lines ten people deep. The serving windows don't open until six and everyone knows it. They're here anyway, to get a good spot, to socialise with volunteers, to get a hot cup of tea or hot chocolate as they wait. This NGO provides free food to anyone who queues, dishing up prepared food from the city's myriad cafes, restaurants and bakeries that would otherwise go to waste. At four, the first-shift supervisor opens up the site and the first round of volunteers go out with trolleys to pick up the day's supply. At four-thirty, the next round of volunteers arrive to begin sorting food, unpacking trays of donated UHT milk drinks and bagging up bagels and rolls leftover from the day before, six to a bag. Not everyone who queues wants the same things: some are homeless and can't carry too much; some need food parcels as they can't come to queue; some are backpackers or broke students just looking for dinner; and some need loaves of bread and bags of bagels to stretch their grocery budget out for the week. As the trolleys return, it's all go, six or seven people crowded in the narrow space removing toothpicks and individually bagging items from large boxes, scooping out individual servings from buckets. Shelves are divided by quality and type of food, from filling meals - vegetarian curry and rice, eight-packs of sushi, sandwiches filled with meat and salad - to more plain savoury items, ham-and-butter sandwiches, pies and small filled buns. Then there are two more rows of shelves, crammed with savouries - cheese scones and bread, always bread - and sweets - piles of chocolate pastries, raspberry-whitechocolate muffins, individually-wrapped slices, containers of semolina halva. Volunteers come and go, as each have a specific job, their time repaid in two or three items of food. Everybody swirls around each other, and one of the older volunteers reminds others "don't say you're 
sorry" when they bump, "it will lose meaning". My shift ends at ten to six, as third-shift volunteers get ready to hand out everything that's been shelved. The queue is three lines now, stretching back out onto the footpath. At least forty people, waiting for the windows to open. Some will go straight back to the end of the queue, waiting to see if there are seconds or just more bread. Others are so hungry that they sit right down on the footpath to eat what they've been given. They're only open until seven, with the last volunteers leaving around seven-thirty after the space has been cleaned and NGO workers have come by to pick up food parcels or supplies for their services, crossed off a list on the blackboard. Everyone gets fed.

In order to manage complex situations of hardship, beneficiaries often search for support beyond what they can scrape together through WINZ. Beneficiaries can call upon "formal" welfare support systems in terms of non-governmental organisations (NGOs) and "informal" ones, such as the social media networks I explored as part of my fieldwork. In this chapter, I will explore how beneficiaries network among both types of non-state support to "net-make", utilising tactics to create possibilities for themselves out of a fractured landscape of service provision with the assistance of NGO workers and online communities. Turning to these nonstate forms of support is a key tactic employed by beneficiaries in making ends meet, as they can provide a wide range of support services. Generally, however, goods or services are provided rather than cash income. However, the support provided also goes beyond just needs for "surviving", providing community and support and reinstating a sense of "living" amongst poverty for beneficiaries. Ultimately, while NGOs themselves fight to provide goods and services, it is the care that they give that appears most powerful for beneficiaries: to be listened to, be allowed to vent their frustrations, to not be blamed or punished for their own situations. In this way, NGOs and "informal" support networks help to push back against the impacts of neoliberalism, in terms of the increasingly punitive state identified by Wacquant.

\section{Networking and Net-Making}

Non-governmental organisations play a significant role in New Zealand's frayed welfare landscape, picking up threads the state has unwound and assisting beneficiaries to make ends 
meet (Larner and Butler 2005, Larner and Craig 2005). "NGO" is a wide category, covering all non-state services in the welfare sector, including the not-for-profit organisations most commonly associated with the welfare sector, advocates, foodbanks and community food providers, religious groups, budgeting organisations, counsellors, legal support organisations, health organisations, drop-in centres and support groups. Organisations can then be broadly split into those which focus on one specific area where they provide support, such as healthcare, and those that provide multiple services, such as social work, community food and budgeting advice. As outlined in the previous chapter, beneficiaries seek to manage complex situations of hardship through a variety of tactics, due to the gap between the meagre stateprovided welfare supplied by WINZ and high levels of need. Turning to NGOs for assistance is a key tactic for beneficiaries. Between 42 respondents who completed this portion of my survey, 87 services were used, indicating that respondents sought out multiple NGOs to meet their needs. Food banks and community pantries; budgeting organisations; and counsellors were the most commonly used type of NGO service reported by informants. Respondents also reported seeking help from health organisations, churches, advocates, legal services, drop-in centres and support groups. One survey respondent writes that beneficiaries turn to non-state support "because the financial support you receive is in fact not enough for the basics, gradually the things you owned before going on a benefit break down and wear out, and you can't replace them. It's hard to afford shampoo". NGOs step up here to provide support when beneficiaries seek them out, weaving threads in to their safety net. However, this is its own time-consuming process, as beneficiaries navigate between multiple services for support.

During my research, two key reasons for seeking out NGO support emerged: first, to address immediate need and second, for help dealing with WINZ. "Dealing with WINZ" can run from clarifying letters WINZ has sent (Fieldnote 27 November 2018), providing advocacy at WINZ appointments, and even enabling people to side-step the dehumanising experience of seeking help from WINZ offices at all. However, as Hodgetts et al. explain, often these two reasons are linked in beneficiaries' experiences navigating New Zealand's chaotic “landscape of diverse, uncoordinated and disordered service provision" (2014:2042), as state-provided support leaves shortages and can be difficult to access further assistance from, as outlined in the previous 
chapter. This was also reflected in the responses of NGO participants, who explained beneficiaries know what they need but "don't want to feel like they're begging" to get it, or to be given only what someone else thinks they could manage with (Fieldnote 26 November 2018). But because this is the way WINZ policy on providing secondary or tertiary assistance is enacted in its offices - which are, as de Certeau terms it, places "with will and power ... from which relations composed with an exteriority composed of targets ... can be managed" (1988:36) - people avoid seeking help from state-based welfare until they reach a crisis situation (Fieldnote 13 August 2018). Turning to NGOs, then, is as much a tactic to avoid hurtful negative experiences and dehumanisation within the state welfare system as much as it is to meet needs state support does not (Hodgetts et al. 2014:2048). However, it is important to emphasise that non-government welfare services are not used as an alternative system to state welfare support. Rather, NGO support is used supplement meagre main benefits and minimise reliance on WINZ. Services like food parcels are used to stretch budgets.

Largely, beneficiaries learn about NGO services they can weave into their support network through word-of-mouth. Crack, Turner and Heenan identify this as the "friends and family factor", noting that this type of word-of-mouth knowledge was how 70 percent of their research participants built up their network of support organisations (2007:195). Many NGO workers I interviewed also noted that a significant proportion of their service users arrived based on the recommendation of people they knew (Fieldnote 27 June 2018; 26 July 2018). It was also quite common for beneficiaries to be referred to an NGO by another NGO, to supplement the services they were already being provided (Fieldnote 26 July 2018; 13 August 2018). However, it was less common for people to search out an organisation on their own or to be referred by WINZ (Fieldnote 26 June 2018; 13 August 2018). One notable exception was a health-focused NGO which caters to under-25s, where the majority of their users were "walkins" seeking to enrol in services based on searching online (Fieldnote 1 August 2018). This indicates the importance of networking as a tactic for beneficiaries as they seek out help to make ends meet (Wynd 2005:9).

The services NGOs provide cater to need among beneficiaries - as well as other low-income and in-need groups - in a piecemeal way, helping to weave together gaps where the state has 
retreated under neoliberalism but unable to fully close them. As Crack, Turner and Heenan note in their study of Dunedin NGOs, "[i]n some cases, organisations were able to do no more than meet a client's immediate welfare needs, on a 'hand out' basis" (2007:196), though all their participant-organisations aimed to do more, helping service users develop "the tools necessary to improve their personal life situations as well as to secure for them all the income support benefits to which they had a legal entitlement" (2007:196). In this way, services attempted to address the specific complexities facing a service user to provide sustainable change rather than just short-term support (Crack, Turner and Heenan 2007:189). However, the impact of this approach is limited, given the majority of NGO service users are beneficiaries, with the majority facing caring responsibilities, illness or disability that reduce their ability to work and become "independent" from welfare (Crack, Turner and Heenan 2007:189). System inadequacies mean beneficiaries will always face shortfalls, with NGOs stepping in to meet them, according to Crack, Turner and Hennan's key informants (2007:197). For example, meagre benefits mean replacing clothing can be out-of-reach for beneficiaries. It can be far easier for a beneficiary to visit an NGO to request free second-hand clothing than to approach WINZ for a clothes grant for new items, as the grant requires an appointment to provide evidence of eligibility and need, then obtaining quotes from stores before having another appointment to have one quote approved, then waiting for payment to be loaded onto a Payment Card before going back to the store to purchase items (Fieldnote 18 October 2018). This reliance on non-state actors to provide access to basic goods such as clothing because state support treats it as a discretionary item illustrate Wacquant's point about how neoliberalism has unravelled social protections and lead to "the replacement of the collective right to recourse against unemployment and destitution by the individual obligation to take up gainful activity" (2009:5).

In this section, I have outlined the significance of NGOs to beneficiaries attempting to make ends meet. In the remainder of the chapter, I will discuss how NGOs "provide a sanctuary of inclusion and moral support, yet they also rely upon very limited resources, notably funding, in seeking to improve the material wellbeing of such clients", following Crack, Turner and Heenan (2007:189). I will then explore the importance of the digital sphere as a space to seek support, 
exchange knowledge, and push back against the perception of beneficiaries as "undeserving" under neoliberalism outlined earlier in this thesis.

\section{Above and Beyond: NGOs and Care}

NGOs do not just help beneficiaries to meet need: they also provide care and support. This is essential for beneficiaries who struggle to find care when they seek help from WINZ. As outlined at the beginning of Chapter Three, even small acts of care like keeping tissues on hand can make a significant difference to people seeking help. By providing care - ranging from short-term "impact day" advocacy support sessions at WINZ offices to long-term social work support - NGOs push back against the framing of beneficiaries as lacking capability and agency (Conradson 2008:2130). NGOs are, largely, acutely aware of the structural elements of poverty that create gaps individual behaviour cannot fill, such as the impossibility of "good" choices and budgeting skills to make up for expensive housing and welfare retrenchment, as identified by Graham, Hodgetts, Stolte and Chamberlain (2018:385). This influences how NGOs carry out their services, and why NGOs choose to centre the provision of care.

Choice was one key tactic used by NGOs to restore the dignity and positive experience of those who sought their help. For example, one NGO I volunteered with operated on a first-come, first-serve basis that recognised its mixed clientele, ranging from travellers and students to beneficiaries and homeless people. As food was set out, smaller items such as iced cupcakes were set out for anyone queuing early. Volunteers who helped run each day's food service were offered the next pick, and it was quite common for service users to take up a volunteering role for this reason, though volunteers also often took less food than service users. Food was then set aside for community groups and food parcels for those who could not attend by request. This food tended to be items that travelled well and did not need heating or refrigeration, such as bread, muffins and scones, compared to the broader range available onsite. Service users could then come through, choosing up to a set number of items out of the food on offer. 
Choice, for this organisation, was significant in two ways. First, it helped volunteers build positive relationships with users. For example, setting aside a food item because it was the favourite of a service user or volunteer attending that day was common when I volunteered. Second, letting people choose helped to improve users' wellbeing by ensuring people had access to nutritious, filling meals that they would eat and that their dignity and agency was respected. This latter aspect was the reason the NGO's organisers insisted on it being open to all: they wanted to ensure that if people needed food, they could have it without feeling stigmatised or dehumanised. Restoring a sense of dignity through the provision of services without shame was key for many of my NGO participants, as it helped to build relationships with service users and legitimised their experiences. In turn, this helped service users to rebuild confidence in their capacity to manage hardship (Graham et al. 2018:385; Crack, Turner and Heenan 2007:194). In this way, NGOs helped not only provide necessities, but also in restoring a sense of normality to service users (Graham et al. 2018:386).

Turning to NGOs, then, is not just significant as a tactic to meet pressing needs, but also as a tactic to restore humanity and experience care that is lacking in interactions with the state welfare system. NGOs provided more than services, such as food parcels or advocacy, but also a place to seek advice and talk out issues. Some organisations aimed to cultivate this sense of a "place to visit", where service users could engage socially and spend time without necessarily obtaining a specific service, in order to combat the social isolation being in poverty can bring (Crack, Turner and Heenan 2007:195). This was also important for a number of my survey respondents, with one writing "I have always done volunteer work in the community, so always been accepted". Being recognised as skilled - and actively seeking to become more skilled - in managing complex situations of hardship is also a positive contribution of the relationships NGOs and beneficiaries develop, both in terms of supporting wellbeing and in terms of actively demonstrating responsibility under the neoliberal paradigm, pushing back against the dominant narrative of beneficiaries as irresponsible in everyday life (Hodgetts et al. 2014:2042-2043). Here, then, NGOs work with beneficiaries to fight the criminalisation of poverty identified by Wacquant, incorporating the influence of neoliberalism while recognising the structural 
elements of poverty and maintaining a focus on meeting need in a positive way (Wacquant 2009:11; Woolford and Curran 2012:52-53).

\section{Hitting a Wall: Limits to NGO Provision}

However, there are also limits to NGOs' capacity to provide. Three key limitations are funding, demand, and the impact of neoliberalisation upon the structure and services of NGOs. As Conradson argues, the advent of neoliberalism in the 1990s placed new pressures on NGOs, through "increased interagency competition for funds, the compliance costs of contracts or simply the greater numbers of people seeking assistance" (2008:2127). These pressures have continued into the twenty-first century, as the state made welfare provision more conditional and punitive. The lack of funding in particular is a burden on NGOs, with some organisations needing to charge fees or request donations from service users (Cordery 2012:474; fieldnote 13 August 2018). Others rely on fundraising or donations from sponsors to ensure the organisation could continue, including one NGO interviewee who was part of efforts to procure the $\$ 5,000,000$ needed each year to keep their organisation operational (Fieldnote 28 November 2018). Even those who receive government funding find themselves unable to meet demand, with one NGO worker I spoke to noting that their health service had had to close its books and limit casual drop-in appointments in order to provide consistent and timely services to everyone enrolled (Fieldnote 1 August 2018).

NGO workers do their best to manage the shortages and demands their organisations face, however. For example, choice can be limited by what is donated or able to be purchased. In my other volunteering role, items available to service users were "diverted" from goods donated to the op-shop it used to fund its services. This means a balance must be struck between meeting the service's funding needs and the needs of its users, especially since a significant amount of donated clothing is too poor-quality to be sold or given out. Often, more practical items are kept and fancier items are sold. The time involved in preparing goods must also be considered, as some poorer-quality items can have stains washed out or minor repairs made or be taken to be made into other items by volunteer crafters. Demand for particular items can also vary, and 
this needs to be taken into consideration. All this is negotiated between the program coordinator, op-shop manager, craft team coordinator, their volunteers, and the overarching management. It can be tricky to accommodate each team's needs, and while everyone was united in wanting to help service users, understandings about what is needed where can clash. This negotiation within the service to balance the allocation of scarce resources mirrors other negotiations between NGOs, between NGOs and WINZ, and within beneficiary households to meet need as best as possible.

Demand, then, is a major factor determining the limits of NGO provision. Balancing provision and need becomes more difficult as demand increases, and there have been significant increases in demand in recent years as continuing neoliberal reform under the Key-English government and economic recession affected New Zealand (Woolford and Curran 2012:54; Fieldnotes 26 July 2018, 1 August 2018). This has also resulted in increased need for long-term support to address complex situations of hardship paired with compromised ability to work (Wynd 2005:18). While providers continue "to 'struggle on' as well as possible, always trying to meet client needs" (Crack, Turner and Heenan 2007:195), the sector is facing a crisis of continually increasing demand. This is further aggravated by the need for services to conform to neoliberal values and practices, such as encouraging clients to become "independent", reinforcing the penalisation of poverty as organisations have to bring in eligibility criteria or ration services to balance demand against the availability of services and ability to purchase goods (Wacquant 2009:12-13; Conradson 2008:2134). The state can also have high expectations on NGO providers. One interviewee working for a budgeting organisation recounted a meeting where the then-minister asked how they were stopping people from smoking, since it was expensive (Fieldnote 26 June 2018). They noted the ability to enforce behavioural change is far beyond their capability, they said, and they can only recommend change. Yet the expectation was that the organisation would "[effect] the authoritarian rectification of the behaviours of populations recalcitrant to the emerging economic and symbolic order", acting in "partnership" with the state to "encourage" responsibilisation through behavioural change (Wacquant 2009:14). As Woolford and Nelund argue, NGOs find 
themselves operating between demands of accountability and production under neoliberal regimes and the need for services that provide assistance and care (2013:300).

\section{Helping One Another}

Beneficiaries do not just look for support through NGOs and state-provided welfare. Increasingly, beneficiaries turn to the digital sphere: to Twitter hashtags collating their experiences, to blogs providing advice from advocates, to Facebook groups where people can share tips for interacting with WINZ and cheap recipes, discuss welfare reform and MSD statistics, vent, find nearby services, and help one another. In the digital sphere, beneficiaries have access to a community in a way they may not have otherwise. Of my survey respondents, the majority felt isolated with a limited ability to participate in their community, not only because of their limited income, but also because of the negative attitudes towards beneficiaries they encountered. However, one advantage of using social media is that feeds are customisable so communities can close themselves off from this negativity. As described in Chapter Two, Facebook group administrators I spoke with when seeking entry to groups or to advertise my survey took seriously their responsibility to keep their groups free of harm. Social media also widens the reach of volunteer advocates, who can assist people online who might not have access to their physical offices. As a result, the digital sphere is also increasingly able to meet beneficiaries' need for additional assistance and help coping with WINZ, particularly around building the skills needed to negotiate the welfare system (Woolford and Nelund 2013:312). Online networks offer care in a similar fashion to NGOs, becoming sources of advice, affirmation, confidence-building and hope. Here, beneficiaries can learn tactics to employ in their everyday lives (Graham et al. 2018:384; Baker and Davis 2017:542).

The digital sphere also functions as a site of political engagement, fostering discussion and encouraging participation in events like Welfare Expert Advisory Group (WEAG) community consultations. Respondents to my survey could clearly articulate changes they would make at WINZ, with a mix of frustrated large-scale plans in the vein of "scrap it and start over", but also comparatively small changes that could have a significant impact. Examples I saw included staff 
being given cultural competence and service training to help change office culture and ensuring staff understand the kinds of budgets and complicated situations beneficiaries live within to help beneficiary-staff relationships or simplifying guidelines and making them available to new beneficiaries to ensure better understanding of benefit entitlements, rights, and processes. One popular suggestion, lifting abatement rates to better reflect the current minimum wage, has become government policy after WEAG released its findings. One WEAG community meeting participant said, when asked about changes they would make, "it is important to remember that beneficiaries would rather have well-paid secure jobs but there's other circumstances involved. There's far too much stigma generated by the current environment around welfare people need to be treated as human and provided help when they need it" (Fieldnote 18 October 2018). Another noted "we need to maintain the current groundswell of voices to create a change in values based on real experiences - closer to a true expression of democracy where everyone has an equal say" (Fieldnote 18 October 2018). This illustrates beneficiaries' active engagement with the welfare system as they navigate it and resisting the undercurrent of dehumanisation introduced by neoliberalism identified by Woolford and Nelund (2013:312). This is movement back against the lack of "control over their representation and whose very being is therefore moulded by the categorisation - in the literal sense of public accusation - of outsiders, chief among them professionals in authoritative discourse such as politicians, journalists and social scientists" (Wacquant 2016:1084) that affect beneficiaries under the current neoliberal paradigm and moves towards challenging the automatic perception of beneficiaries as "undeserving". Here is the move towards having "all New Zealanders under[stand] the reality of what many of our own citizens endure in the struggle to make ends meet and live dignified lives" that Groot et al. called for (2017:16), generated from those most affected.

\section{Gaps Between Policy, Practice and Need}

In this chapter, I have discussed how beneficiaries turn away from the state to seek support in managing hardship. I have explored the fractured landscape of NGO service provision, its importance, and its limitations. I have also discussed emerging communities of support 
beneficiaries have formed among themselves in the digital sphere, where they can share tactics. However, even with broadened networks of support, beneficiaries still struggle to make ends meet, with NGOs only able to temporarily alleviate crisis. Yet public discussion and policy still prioritise individual blame, to be cured by individual action, in line with Wacquant's theory of the increasingly punitive carceral state under neoliberalism. As Graham et al. argue, there needs to be greater recognition in New Zealand that any one aspect of poverty "is intertwined with a wider range of insecurities and pressures" (2018:398). It is only when there is recognition of the "snowball effect" of hardship on beneficiaries - who are, again, largely individuals and families facing illness, disability, or caring responsibilities - and "that a food parcel or two will suffice "until their situation improves" is no longer viable" (Wynd 2005:18) for addressing poverty until individuals obtain employment will the gap between policy and practice and existing need begin to close. Ultimately, while NGOs and "informal" support networks of beneficiaries push back against the expectations of a carceral state through the support they provide to beneficiaries, it does not create lasting change. Beneficiaries and NGO workers are trapped in a decaying welfare system, subject to significant systematic inputs to poverty and barriers from escaping poverty that the neoliberal paradigm does not account for. Yet the system is not broken. As Wacquant argues, isolating and punishing welfare recipients as if their poverty is their individual fault and responsibility is the intended outcome of the carceral state under neoliberalism. In New Zealand, this effect is achieved through the deployment of strategies centred around the concept of deservingness. As a result, beneficiaries must mobilise every tactic available to them to weave together enough support to scrape by from a tattered web of welfare, designed to dehumanise and - as Wacquant argues - make compliant, fearful low-wage workers (2009:15). 


\section{Chapter Six: Constructing and Reforming New Zealand's Welfare Safety Net}

In this thesis, I have explored how the structure of the current welfare system makes it difficult, if not impossible, for beneficiaries to adequately meet their needs. Instead, beneficiaries and NGO workers must draw together fraying threads of welfare support to temporarily alleviate crisis through creating safety nets - a complex, time-consuming process that leaves people balancing precariously. I have also argued that an embedded neoliberal concept of deservingness has influenced the transformation of welfare provision over the last thirty years. Using Wacquant's concept of the carceral state, I have demonstrated how the penalisation and responsibilisation of poverty has not managed precarity but instead driven increased hardship. Yet I also found beneficiaries and NGO workers are employing tactics to "work around" the demands of state strategies and resist neoliberal value judgements to manage hardship, reaffirm worth, and share tactics to help others. This thesis has explored how the concept of deservingness has emerged; how the gaps in understanding poverty and support for people in poverty were produced; and how NGO workers and beneficiaries manage hardship. Neoliberalism has profoundly changed who is seen as deserving of support in New Zealand, what they need, and who is responsible for meeting that need to what degree. If New Zealand is to achieve the first UN Sustainable Development Goal of eradicating poverty by 2030, it appears a new approach is needed to recognise the complexity of poverty in New Zealand.

The thesis sets out the parameters of the current study of poverty and welfare anthropologically in the first chapter, before exploring the scope of hardship and study of poverty in New Zealand. In the second chapter, I outline my methodology of kinky multi-sited ethnography. I also discuss the challenges encountered in fieldwork and their influence on my methodology, noting the way that the punitive welfare system created significant limits, which structured my own methodology and the kinds of knowledge produced in this work. Finally, I outline the qualitative data collection and thematic data analysis methods used to explore 
beneficiaries' and NGO workers' experiences navigating the fragmented welfare service landscape and the support networks they weave together.

In the third chapter, I explored how New Zealand's welfare system has developed over time, particularly how a concept of deservingness has become embedded in welfare service provision over time, encompassing different groups along racialised, gendered and classed lines in different eras. I then discussed the transformation of the welfare system as neoliberalism replaced Keynesianism as the dominant political-economic paradigm in the 1980s and 1990s, with strongly punitive measures and individualised responsibilisation being introduced, then consolidated into the twenty-first century. I argued this entrenched idea of deservingness impacts on beneficiaries and NGO workers today, as beneficiaries are assumed to be "undeserving" of support as the default, must prove their deservingness, and often must turn to NGOs to meet their needs when state assistance is refused.

Next, I elaborate on how deservingness is experienced by beneficiaries today, in terms of both state support and complex need. In the first half of the chapter, I outlined the bureaucratic, punitive and thin safety net provided by WINZ, describing the complexities of the application process, welfare obligations, and harsh sanctions. I linked this to a wider gap between WINZ expectations of beneficiaries and beneficiaries' realities, discussing how WINZ advocates employment as a cure-all for poverty while the majority of beneficiaries experience disability or possess caring responsibilities that limit their employment opportunities. In the second half of the chapter, I discussed the complexities of poverty and the tactics used to manage them. In this way, I explored how state welfare makes it difficult for beneficiaries to adequately meet their needs, creating gaps in support that beneficiaries turn to NGOs to address.

Finally, the fifth chapter discussed how NGO workers and beneficiaries navigate a complex landscape of service provision to manage situations of hardship. I also examine at the limitations NGOs face as they attempt to address poverty and the way online networks are used by beneficiaries to share knowledge, support one another, and survive a dehumanising system. While Wacquant argues welfare is solely a site for the enactment of neoliberal ideals through the use of punitive measures and the dichotomy of deservingness, this research has 
demonstrated beneficiaries and NGOs also push back, adapting ideals such as entrepreneurship without accepting others, such as strict individualism. Together, NGO workers and beneficiaries manage the impacts of the gaps between the real ability to address need and the expectations of the current welfare system.

While this thesis is limited in scope, its limitations were productive, reflecting insights into the fears beneficiaries have of a punitive system. In this way, its limitations also reflect New Zealand's social welfare system in some provocative ways. Beyond demonstrating how people get by in contemporary New Zealand, it outlines the potential for further research into the experience of poverty with the hope of better addressing community need. Despite initial difficulties in data collection, this thesis provides a localised example of the impact of neoliberal reforms on hardship to the literature on the penalisation and responsibilisation of poverty under neoliberalism. This work adds to political anthropological discussions around poverty and welfare, demonstrating the links between policy and everyday life. It also contributes to a move within anthropology to conceptualise welfare outside of the neoliberal paradigm, humanising welfare recipients and showing the tactics beneficiaries and NGO workers employ to "work around" the current system and manage complex situations of hardship.

In 2017, Metiria Turei admitted she had lied to WINZ by omission. She did not inform WINZ about the flatmate who shared her and her baby daughter's home. That flatmate was her mother: she was a young single parent, studying full-time. She needed help and her full benefit. But the welfare safety net was gaping open beneath her. Like so many other New Zealanders, she had to weave together her own net to survive, balancing across threads. And survive she did: graduating, then becoming a list MP for the Greens, then party co-leader. She admitted what she did to drive change, to give others the chance to achieve what she had, and to work towards ending poverty in New Zealand. Imagine if the country did make change. Imagine if all the people who currently spend all their energy on juggling bills, sourcing food, caring for children and partners and relatives, just surviving had a little more space to breathe. Imagine if they had the space to work hard for their dreams, not just getting through the day. Imagine all the creativity and community demonstrated among social media and NGO networks could be shared further, without fear. Imagine what kind of country that could be. 


\section{Bibliography}

Andrews, Robyn.

2000. "'Having to Rebuild Everything': Women, Separation and Social Mobility in New Zealand". MA thesis, Massey University.

Atkinson, Neill.

2005. "The Rise and Fall of Happy Homes, 1918-1935". In Frontier of Dreams: The Story of New Zealand edited by Bronwyn Dalley. Auckland: Hachette Livre NZ Ltd.

Auckland City Mission.

2017. "Auckland City Mission History". Accessed 22 May 2019.

https://www.aucklandcitymission.org.nz/about-us/history/

2014. "Speaking for Ourselves: The Truth About What Keeps People in Poverty from

Those Who Live It. Family 100 Research Project". Accessed 23 June 2018.

https://www.aucklandcitymission.org.nz/wp-content/uploads/2016/05/Auckland-City-

Mission-Family100-Speaking-for-Ourselves.pdf

Aull Davies, Charlotte.

2008. Reflexive Ethnography: A guide to researching selves and others. London:

Routledge Taylor and Francis Group.

Baker, Maureen and Rosemary Du Plessis.

2011. "Family Welfare". Accessed 3 June 2019. https://teara.govt.nz/en/familywelfare/print

Batty, Elaine and John Flint.

2013. "Talking 'bout poor folks (thinking 'bout my folks): perspectives on comparative poverty in working class households". International Journal of Housing Policy 13(1):1-19. 
Baker, Tom and Courtney Davis.

2018. "Everyday Resistance to Workfare: Welfare Beneficiary Advocacy in Auckland, New Zealand". Social Policy \& Society 17(4):535-546.

Block, David.

2018. Economy and Sociolinguistics: Neoliberalism, Inequality and Social Class. London: Bloomsbury Publishing PLC.

Bockman, Johanna.

2012. "The political projects of neoliberalism". Social Anthropology 20(3):310-3017.

Bourgois, Philippe.

2004. "US Inner-city Apartheid: The Contours of Structural and Interpersonal Violence". In Violence in War and Peace: An Anthology edited by Nancy Scheper-Hughes and Philippe Bourgois. Oxford: Blackwell Publishing.

Briggs, Charles L.

2007. "Anthropology, Interviewing and Communicability in Contemporary Society". Current Anthropology 48(4):551-580.

Brooking, Tom.

2004. The History of New Zealand. Westport: Greenwood Press.

Bryers-Brown, Tarapuhi.

2015. "“He reached across the river and healed generations of hara": Structural violence, historical trauma and healing among contemporary Whanganui Māori”. MA thesis, Victoria University of Wellington.

Buchanan, Ian.

2000. Michel de Certeau: Cultural Theorist. London: SAGE Publications. 
Child Poverty Action Group and Action Station.

2018. "Welfare for Wellbeing". Accessed 15 December 2018.

https://www.cpag.org.nz/assets/Welfare\%20for\%20Wellbeing\%20PDF.pdf

Clifford, James.

1996. "Anthropology and/as Travel”. Etnofoor 9(2):5-15.

1983. “On Ethnographic Authority”. Representations 2(Spring):118-146.

Conradson, David.

2008. "Expressions of Charity and Action Towards Justice: Faith Based Welfare Provision in Urban New Zealand". Urban Studies 45(10):2117-2141.

2006. "Values, Practices and Strategic Divestment: Christian Social Service Organisations in New Zealand". In Landscapes of Voluntarism: New Spaces of Health, Welfare and Governance edited by Christine Milligan and David Conradson. Bristol: Bristol University Press, Policy Press.

Cordery, Carolyn J.

2012. “Funding Social Services: An historical analysis of responsibility for citizens' welfare in New Zealand". Accounting History 17(3-4):463-480.

Crack, Simon, Sarah Turner and Brian Heenan.

2007. "The changing face of voluntary welfare provision in New Zealand". Health \& Place 13:188-204.

Deacon, Alan.

2000. "Learning from the US? The Influence of American Ideas Upon 'New Labour' Thinking on Welfare Reform". Policy and Politics 21(1):5-18.

De Certeau, Michel.

1988. The Practice of Everyday Life. Berkeley: University of California Press. 
De Munck, Victor.

2009. Research Design and Methods for Studying Cultures. New York: Alta Mira Press.

Duck, Waverly 0.

2012. "An Ethnographic Portrait of a Precarious Life: Getting by on Even Less". American Academy of Political and Social Science Annals 642(July):124-138.

Duncanson, M., G. Oben, A. Wicken, G. Richardson, J. Adams and M. Pierson.

2018. Child Poverty Monitor 2018 Technical Report. Dunedin: New Zealand Child and Youth Epidemiology Service University of Otago.

Dwyer, Peter.

2000. Welfare Rights and Responsibilities: Contesting Social Citizenship. Bristol: Policy Press at the University of Bristol.

1998. "Conditional Citizens? Welfare Rights and Responsibilities in the Late 1990s". Critical Social Policy 18(4):493-517.

Edgar, lain and Andrew Russell.

1998. The Anthropology of Welfare. London: Routledge.

Edmunds, Susan.

2018. "More protection needed for prepay power customers: Consumer NZ". Stuff, June 7 2018. Stuff. https://www.stuff.co.nz/business/104524807/more-protection-neededfor-prepay-power-customers-consumer-nz

2015. "Prepaid power budgeting means families turn off heaters". Stuff, September 9 2015. https://www.stuff.co.nz/business/money/71856315/

Ehrenreich, Barbara.

2001. Nickel and Dimed: On (Not) Getting by in America. New York: Henry Hold and Company, LLC. 
Ely, Margot, Margaret Anzul, Teri Friedman, Diane Garner and Ann McCormack Steinmetz. 1993. Doing Qualitative Research: Circles Within Circles. London: The Falmer Press. Farmer, Paul.

2004. “An Anthropology of Structural Violence". Current Anthropology, 45(3):305-325.

Ferguson, James and Tania Murray Li.

2018. "Beyond the "Proper Job": Political-economic Analysis after the Century of Labouring Man". Working Paper 51. Cape Town: PLAAS, UWC.

Ferguson, James.

2015. Give a Man a Fish: Reflections on the New Politics of Distribution. Durham: Duke University Press.

2009. "The Uses of Neoliberalism". Antipode 41(S1):166-184.

Franklin, Harvey.

1991. "Economy". Special issue, "New Zealand in the 1980s: Market Forces in the Welfare State", Pacific Viewpoint 32(2).

Frerer, Kristine, and Catherine M. Vu.

2007. "An Anthropological View of Poverty". Journal of Human Behaviour in the Social Environment 16(1):73-86.

Garthwaite, Kayleigh.

2016. "Stigma, shame and 'people like us': an ethnographic study of foodbank use in the UK". Journal of Poverty and Social Justice 24(3):277-289.

Gibbs, Graham R.

2012. Analysing Qualitative Data. London: SAGE Publications, Ltd. 
Graham, Rebekah, Darrin Hodgetts, Ottilie Stolte and Kerry Chamberlain.

2018. "Hiding in plain sight: experiences of food insecurity and rationing in New Zealand". Food, Culture \& Society: An International Journal of Multidisciplinary Research 21(3):384-401.

Gray, Claire and Yvonne Crichton-Hill.

2019. ""You look a little bit dark for my liking": Māori and Pasifika women's experiences of welfare receipt in Aotearoa New Zealand". Aotearoa New Zealand Social Work 31(1):5-16.

Groot, Shiloh, Clifford Van Ommen, Bridgette Masters-Awatere and Natasha Tassell-Matamua. 2017. Precarity: Uncertain, Insecure and Unequal Lives in Aotearoa New Zealand. Auckland: Massey University Press.

Hancock, Ange-Marie.

2004. The Politics of Disgust: The Public Identity of the Welfare Queen. New York: New York University Press.

Harvey, David.

2005. A Brief History of Neoliberalism. Oxford: Oxford University Press.

Hodgetts, Darrin, Kerry Chamberlain, Yardena Tankel and Shiloh Groot.

2014. "Urban Poverty, Structural Violence and Welfare Provision for 100 Families in Auckland". Urban Studies 51(10):2036-2051.

2013. "Researching Poverty to Make a Difference: The need for reciprocity and advocacy in community research". The Australian Community Psychologist 25(1):46-59.

Hudson, Maui L. and Khyla Russell.

2009. "The Treaty of Waitangi and Research Ethics in Aotearoa". Bioethical Inquiry 6(0):61-68. 
James, Colin.

2017. Unquiet Time: Aotearoa/New Zealand in a fast changing world. Masterton: Fraser Books.

Jensen, Tracey and Imogen Tyler.

2015. "'Benefits broods': The cultural and political crafting of an anti-welfare commonsense". Critical Social Policy 35(4):470-491.

King, Michael.

2012. The Penguin History of New Zealand. Auckland: Penguin Group (NZ).

1997. 1000 Years of Māori History Nga Iwi O Te Motu. Auckland: Reed Books.

Koven, Michele.

2014. "Interviewing: Practice, Ideology, Genre, and Intertexuality". Annual Review of Anthropology 43(0):499-520.

Labrum, Bronwyn.

2009. "The changing meanings and practices of welfare, 1840s-1990s". In The New Oxford History of New Zealand edited by Giselle Byrnes. Melbourne: Oxford University Press.

Langer, Susanne and Højlund, Susanne.

2011. "An Anthropology of Welfare: Journeying towards the Good Life". Anthropology in Action 18(3):1-9.

Larner, Wendy, and Maria Butler.

2005. "Governmentalities of Local Partnerships: The Rise of a "Partnering State" in New Zealand". Studies in Political Economy 75(1):79-101. 
Larner, Wendy and David Craig.

2005. "After Neoliberalism? Community Activism and Local Partnerships in Aotearoa New Zealand". Antipode 37(3):402-424.

Larner, Wendy.

1997. "“A Means to an End": Neoliberalism and State Processes in New Zealand”. Studies in Political Economy 52(1):7-38.

Levinson, Martin P.

2010. “Accountability to research participants: unresolved dilemmas and unravelling ethics". Ethnography and Education 5(2):193-207.

Levy, Danya.

2011. "'Dob in a beneficiary' campaign feared”. The Dominion Post, 2 July 2011. http://www.stuff.co.nz/national/politics/5222122/Dob-in-a-beneficiary-campaignfeared

Lister, Ruth.

2007. "Inclusive Citizenship: Realising the Potential". Citizenship Studies 11(1):49-61.

2001. "Doing Good by Stealth: The Politics of Poverty and Inequality Under New Labour". IPPR Progressive Review 8(2):65-70.

Littlewood, David.

2017. "Chapter One: The Provision of Opportunities: Politics and the State". In New Zealand Between the Wars, edited by Rachael Bell. Auckland: Massey University Press.

Lynch, Jenny.

2002. New Zealand Women's Weekly 70 Years: From Pavlovas to Prime Ministers. Auckland: Random House New Zealand. 
Lyon-Callo, Vincent and Susan Brinn Hyatt.

2003. "The Neoliberal State and the Depoliticisation of Poverty: Activist Anthropology and "Ethnography from Below"“. Urban Anthropology 32(2):175-203.

Madden, Raymond.

2013. Being Ethnographic: A Guide to the Theory and Practice of Ethnography. London: SAGE Publications Ltd.

Magee, Ann.

1991. "Women". Special issue, "New Zealand in the 1980s: Market Forces in the Welfare State", Pacific Viewpoint 32(2).

Marcus, George E.

1995. "Ethnography in/of the World System: The Emergence of Multi-Sited Ethnography". Annual Review of Anthropology 24(1):95-117.

Marshall, T. H.

1964. Class, Citizenship and Social Development: Essays by T. H. Marshall. Chicago: University of Chicago Press.

McClure, Margaret.

1998. A Civilised Community: A History of Social Security in New Zealand 1989-1998. Auckland: Auckland University Press.

McGibbon, Ian and Bronwyn Dalley.

2005. “Hope and Heroes, 1935-1949". In Frontier of Dreams: The Story of New Zealand edited by Bronwyn Dalley. Auckland: Hachette Livre NZ Ltd.

McKinnon, Malcolm.

2016. The Broken Decade: Prosperity, depression and recovery in New Zealand, 1928-29. Dunedin: Otago University Press. 
McLauchlan, Gordon.

2014. A Short History of New Zealand. Auckland: David Bateman Ltd.

McLean, Gavin and Bronwyn Dalley.

2005. "Breaking Free, 1984-2005". In Frontier of Dreams: The Story of New Zealand edited by Bronwyn Dalley. Auckland: Hachette Livre NZ Ltd.

Ministry of Social Development.

2019a. Benefit Fact Sheets: Snapshot - June 2019 Quarter. Wellington: Ministry of Social Development.

2019b. “Benefit Receipt Overview - June 2019". Accessed 20 September 2019.

https://www.msd.govt.nz/documents/about-msd-and-our-work/publicationsresources/statistics/benefit/2019/quarterly-benefits-jun-19-a3-final.pdf

2018a. Tauākī Whakamaunga Atu Statement of Intent 2018-2022. Wellington: Ministry of Social Development.

2018b. Reporting on low-income and material hardship trends for children in the 2018 Household Incomes Report. Wellington: Ministry of Social Development.

2018c. "Jobseeker Support obligations for partners". Accessed 30 August 2019.

https://www.workandincome.govt.nz/on-a-benefit/obligations/jobseeker-support-

obligations-for-partners.htm|\#null.

2018d. "Benefit Sanctions - December 2018 quarter". Accessed 3 March 2019.

https://www.msd.govt.nz/about-msd-and-our-work/publications-

resources/statistics/benefit/lastest-quarterly-results/benefit-sanctions.html

Moon, Paul.

2011. New Zealand in the Twentieth Century: The Nation, The People. Auckland: HarperCollinsPublishers. 
Morgen, Sandra and Jeff Maskovsky.

2003. "The Anthropology of Welfare "Reform": New Perspectives on US Urban Poverty in the Post-Welfare Era". Annual Review of Anthropology 32:315-338.

Nader, Laura.

1972. "Up the anthropologist: perspectives gained from studying up". In Reinventing Anthropology edited by Dell Hymes. New York: Pantheon Books.

Narayan, Deepa and Patti Petesch.

2007. Moving Out of Poverty: Cross-Disciplinary Perspectives on Mobility. New York: Palgrave Macmillan and the World Bank.

National Ethics Advisory Committee - Kahui Matatika o te Motu.

2012. Ahuatanga u kit e tika me te pono mot e Rangahau Māori: Māori Research Ethics: An overview. Wellington: Ministry of Health.

New Zealand Parliament House of Representatives.

6 July 1976. "Mr Warren Cooper, MP for Otago Central, on the Domestic Purposes Benefit". Parliamentary Debates, vol. 403.

Nolan, Melanie.

2009. "Constantly on the move but going nowhere? Work, community and social mobility". In The New Oxford History of New Zealand edited by Giselle Byrnes. Melbourne: Oxford University Press.

Office of the Children's Commissioner.

2017. “Child Poverty Monitor 2017: Sustainable improvements needed". Accessed 6 May 2019. http://www.occ.org.nz/publications/news/child-poverty-monitor-2017$\underline{\text { media-release/ }}$ 
One News.

2019a. "Exclusive: Major Concerns as WINZ uses 'one size fits all' data for food grants". One News, 4 September 2019. https://www.tvnz.co.nz/one-news/new-

zealand/exclusive-major-concerns-winz-uses-one-size-fits-all-data-food-

grants?utm source=The+Bulletin\&utm campaign=00dba54c2e-

EMAIL CAMPAIGN 20180301 COPY 01\&utm medium=email\&utm term=0 552336 $\underline{\mathrm{e} 15 \mathrm{a}-00 \mathrm{dba} 54 \mathrm{c} 2 \mathrm{e}-533808865}$

2019b. "Beneficiaries failing drugs tests still hit with sanctions". One News, 19 August 2019. https://www.tvnz.co.nz/one-news/new-zealand/beneficiaries-failing-drugs-testsstill-hit-sanctions

Orchard, Sam.

2017. “\#We Are Beneficiaries”. Accessed 31 March 2018.

http://www.thesamorchard.com/wp-content/uploads/2018/03/WAB-Report.pdf

Peck, Jamie.

2010. "Zombie neoliberalism and the ambidextrous state". Theoretical Criminology 14(1):104-110.

Pemberton, Simon, Eldin Fahmy, Eileen Sutton and Karen Bell.

2016. "Navigating the stigmatised identities of poverty in austere times: Resisting and responding to narratives of personal failure". Critical Social Policy 36(1):21-37.

Phillips, Jock.

2005. “Generations, 1965-1984". In Frontier of Dreams: The Story of New Zealand edited by Bronwyn Dalley. Auckland: Hachette Livre NZ Ltd.

Rector, Robert, Kirk Johnson and Sarah Youssef.

1999. "Response to Edward O’Boyle's Article". Review of Social Economy 57(3):302-305. 
Rose, Nikolas.

2000. "Government and Control". The British Journal of Criminology 40(2):321-339.

Rose, Nikolas and Peter Miller.

2010. "Political Power Beyond the State: Problematics of Government". The British Journal of Sociology 61(1):271-303.

Rutherford, Danilyn.

2012. "Kinky Empiricism". Cultural Anthropology 27(3):465-479.

Sanders, Cynthia K.

2006. "Absolute-Income-Based Measures of Poverty". In Encyclopedia of World Poverty, edited by M. Odekon. Thousand Oaks: Sage Publications Inc.

http://dx.doi.org/10.4135/9781412939607.n1 p1-3.

Satherley, Dan.

2018. "Sanctions motivate beneficiaries to get jobs - Simon Bridges". Newshub, 23 July

2018. https://www.newshub.co.nz/home/politics/2018/07/sanctions-motivatebeneficiaries-to-get-jobs-simon-bridges.html

Sharman, Russell Leigh.

2007. "Style Matters: Ethnography as Method and Genre". Anthropology and Humanism 32(1):117-129.

Smith, Claire, Winsome Ruth Parnell, Rachel Clare Brown and Andrew R. Gray.

2013. "Balancing the diet and the budget: Food purchasing practices of food-insecure families in New Zealand". Nutrition and Dietetics 70:278-285.

Social Investment Agency.

2017. “About the Social Investment Agency". Accessed 3 March 2019.

https://sia.govt.nz/about-us/about-the-social-investment-agency/ 
Spencer-Wood, Suzanne M.

2011. "Impoverishment, Criminalisation, and the Culture of Poverty". Historical Archaeology 45(3):1-10.

Statistics New Zealand.

2019. "Measuring child poverty: concepts and definitions". Accessed 3 March 2019.

https://www.stats.govt.nz/methods/measuring-child-poverty-concepts-and-definitions

1933. The New Zealand Official Year-Book 1933. Wellington: Census and Statistics

Office. Accessed from Statistics New Zealand Digital Yearbook Collection, 20 July 2017. https://www3.stats.govt.nz/New Zealand Official Yearbooks/1933/NZOYB 1933.html \#idchapter 1214143

Stephens, Māmari.

2013. "Seeking the Common Good or Just Making Us Be Good? Recent amendment to New Zealand's social security law". Victoria University of Wellington Law Review 44(2):383-401.

Stephens, Robert, Charles Waldegrave and Paul Frater. 1995. "Measuring Poverty in New Zealand". Social Policy Journal of New Zealand, 5(0):123.

Tennant, Margaret.

2013. "Fun and fundraising: the selling of charity in New Zealand's past". Social History $38(1): 46-65$.

2008. "Two to Tango: The Partnership Between Charity and the Welfare State in New Zealand 1940-1970". New Zealand Journal of History 42(1):1-21.

2007. The Fabric of Welfare: Voluntary Organisations, Government and Welfare in New Zealand, 1840-2005. Wellington: Bridget Williams Books. 
2005. "Welfare Interactions: Māori, Government and the Voluntary Sector in New Zealand". History Australia 2(3):80.1-80.15.

The Treasury.

2015. "How Social Investment Works". Accessed 3 March 2019.

https://treasury.govt.nz/information-and-services/state-sector-leadership/crossagency-initiatives/social-investment/how-social-investment-works

Thirlway, Francis.

2016. "Everyday Tactics in Local Moral Worlds: E-Cigarette Practices in a Working-Class Area of the UK". Social Science and Medicine 170(December):106-113.

Trnka, Susanna and Catherine Trundle.

2017. Competing Responsibilities: The Ethics and Politics of Contemporary Life. Durham: Duke University Press.

2014. “Competing Responsibilities: Moving Beyond Neoliberal Responsibilisation". Anthropological Forum 24(2):136-153.

Trundle, Catherine.

2014. Americans in Tuscany: Charity, Compassion and Belonging. New York: Berghahn Books.

United States Census Bureau.

2018. "How the Census Bureau measures poverty". Accessed 30 April 2019. https://www.census.gov/topics/income-poverty/poverty/guidance/povertymeasures.html

Van der Krogt, Christopher J.

2017. "Chapter Eleven: Conscience of the Nation? The Churches as Political Actors". In New Zealand Between the Wars, edited by Rachael Bell. Auckland: Massey University Press. 
Van Maanen, John.

2011. Tales of the Field: On Writing Ethnography. Chicago: The University of Chicago Press.

Wacquant, Loïc.

2016. "Revisiting territories of relegation: Class, ethnicity and state in the making of advanced marginality". Urban Studies 53(6):1077-1088.

2010. "Crafting the Neoliberal State: Workfare, Prisonfare, and Social Insecurity". Sociological Forum 25(2):197-220.

2009. Punishing the Poor: The Neoliberal Government of Social Insecurity. Durham: Duke University Press.

2004. "Comment on an Anthropology of Structural Violence". Current Anthropology, 45(3):322.

2001. "The Penalisation of Poverty and the Rise of Neo-liberalism". European Journal on Criminal Policy and Research 9:401-412.

Wanhalla, Angela.

2009. "Family, Community and Gender." In The New Oxford History of New Zealand edited by Giselle Byrnes. Melbourne: Oxford University Press.

Welfare Expert Advisory Group.

2019a. "Whakamana Tāngata Restoring Dignity to Social Security in New Zealand Executive Summary”. Accessed 6 May 2019.

http://www.weag.govt.nz/assets/documents/WEAG-Report/3a22acc869/WEAGExecutive-Summary-with-QR-code-160419.pdf

2019b. "Whakamana Tāngata Restoring Dignity to Social Security in New Zealand Key Facts". Accessed 5 May 2019. https://weag.cwp.govt.nz/assets/documents/WEAGreport/efc60ff2a8/Whakamana-Tangata-Key-Facts-v2.pdf 
2019c. "Example Families and Budgets: Investigating the Adequacy of Income". Accessed 5 May 2019. http://www.weag.govt.nz/assets/documents/WEAGreport/background-documents/5269349623/Example-families-010419.pdf

Wolf, Eric Robert.

1990. Europe and the People Without History. Berkeley: University of California Press.

Woolford, Andrew and Amelia Curran.

2012. "Community Positions, Neoliberal Dispositions: Managing Nonprofit Social Services Within the Bureaucratic Field". Critical Sociology 39(1):45-63.

Woolford, Andrew and Amanda Nelund.

2013. "The Responsibilities of the Poor: Performing Neoliberal Citizenship within the Bureaucratic Field". Social Service Review 87(2):292-318.

Wynd, Donna.

2005. Hard to Swallow: Foodbank use in New Zealand. Auckland: Child Poverty Action Group. 


\section{Appendices}

Appendix 1: Material Hardship List ${ }^{15}$

\section{7}

\section{Material hardship - list of 17 items in household survey}

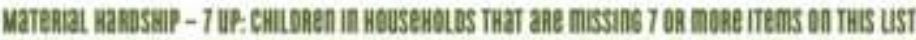

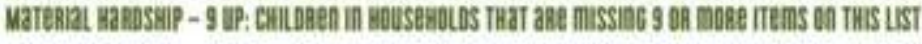

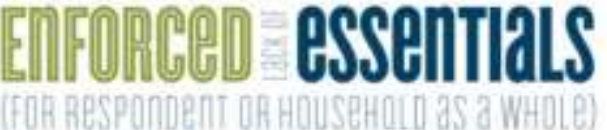

1. meal with meat, fish or chicken (or vegetarian equivalent) at least each 2nd day

2. two pairs of shoes in good repair and suitable for everyday use

3. suitable clothes for important or special occasions

4. presents for family and friends on special occasions

5. home contents insurance

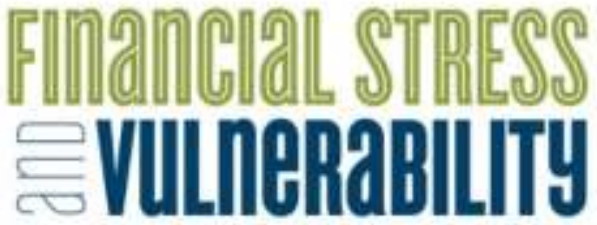

6. borrowed money from family or friends more than once in the last 12 months to cover everyday living costs

7. feel 'very limited' by the money available when thinking about purchase of clothes or shoes for self (options were: not at all, a little, quite limited, and very limited)

8. could not pay an unexpected and unavoidable bill of $\$ 500$ within a month without borrowing

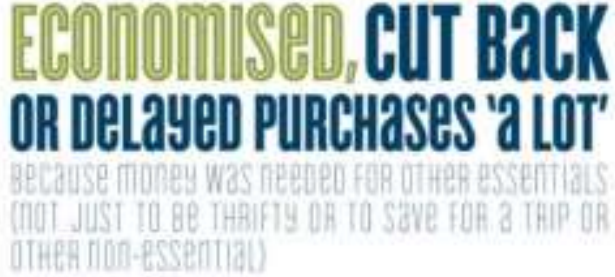

9. went without or cut back on fresh fruit and vegetables

10. bought cheaper cuts of meat or bought less than wanted

11. put up with feeling cold to save on heating costs

12. postponed visits to the doctor

13. postponed visits to the dentist

14. did without or cut back on trips to the shops or other local places

15. delayed repairing or replacing broken or damaged appliances

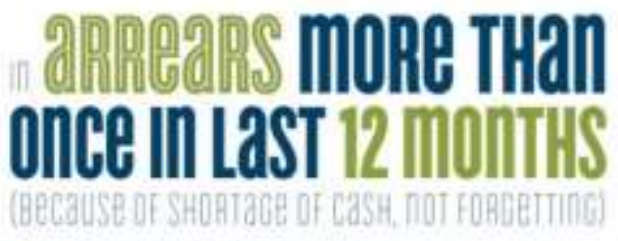

16. rates, electricity, water

17. vehicle registration, insurance or warrant of fitness 
Making and Resisting the Narrative of 'Good' and 'Bad' Beneficiaries in New Zealand's Welfare System

Q1 Hi!

I am interested in understanding how a social narrative has been constructed in New Zealand that beneficiaries are "bad", which welfare support agencies then "put into action" through obligations and sanctions for my Master's thesis. In this survey, I would like to ask you about your experiences accessing welfare support in New Zealand through government agencies and charities, and your opinion about attitudes towards beneficiaries in New Zealand. Your responses will be kept completely confidential.

The study should take you around 15 minutes to complete. Your participation in this research is voluntary. You have the right to withdraw at any point during the study, for any reason. You can skip any question in the survey. If you would like more information about this research, please email Evelyn Walford-Bourke

By clicking the button below, you acknowledge that your participation in the study is voluntary, you are 18 years of age, and that you are aware that you can choose to end your participation in the study at any time and for any reason.

Please note that this survey will be best displayed on a laptop or desktop computer. Some features may be less compatible for use on a mobile device.

Thank you!

I consent, begin the study

I do not consent; I do not wish to participate 
Q3 Are you receiving a main benefit from WINZ?

Yes - Jobseeker Support

Yes - Jobseeker Support with medical exemption

Yes - Sole Parent Support

Yes - Supported Living Payment

Yes - Youth Payment/Young Parent Payment

Yes - other

No

Q4 Are you receiving a supplementary payment from WINZ? Please choose all that apply

Yes - Accommodation Supplement

Yes - Disability Allowance

Yes - Temporary Additional Support / Special Benefit

Yes - other

No 
Q5 Do you receive Working for Families payments, such as Best Start or Family Tax Credits?

Yes - WFF through WINZ

Yes - WFF through IRD

No

Q6 Have you received help from other welfare support organisations? Please choose all that apply

Yes - food bank or community pantry

Yes - health organisation

Yes - church / church organisation

Yes - budgeting organisation

Yes - counsellors

Yes - advocacy organisation

Yes - legal support

Yes - drop in centre

Yes - online support groups

Yes - in-person support groups

Yes - other

No 
Q8 Has it been easy for you to access welfare support? Why or why not?

Q9 What processes do you need to go through to access welfare support, from WINZ or from other organisations?

Q10 How would you describe your financial situation?

Q12 What strategies do you use to make ends meet?

Q13 Do you think there is a negative attitude towards beneficiaries in New Zealand? Where does this attitude show up?

Q14 How do you think being on a benefit impacts how you can participate in your community? 
Q15 Have the welfare reforms introduced since 2013 affected your ability to make ends meet? How?

Q16 If you could change one thing about New Zealand's welfare system, what would it be?

Q17 What kinds of things has welfare support helped you to do? What kind of positive experiences have you had of accessing welfare support?

Q19 Do you have any other comments you want to share about your experiences of New Zealand's welfare system? 


\section{Multi-Choice Question Results}

Q3 Are you receiving a main benefit from WINZ?

Field

Choice Count

Yes - Jobseeker Support

Yes - Jobseeker Support with medical exemption

Yes - Sole Parent Support

No

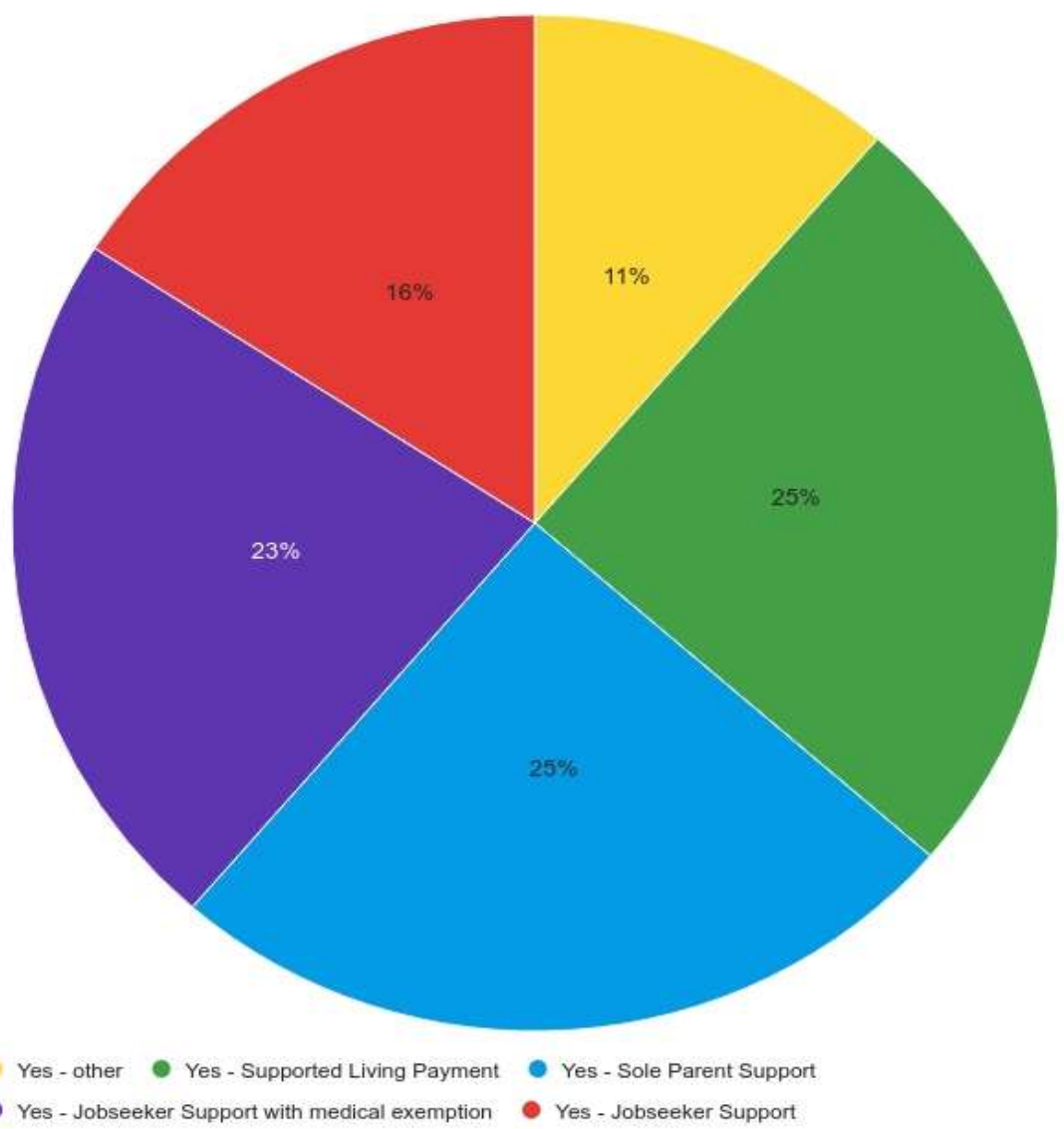


Q4 Are you receiving a supplementary payment from WINZ? ${ }^{16}$

Field

Choice Count

Yes - Accommodation Supplement 33

Yes - Disability Allowance

Yes - Temporary Additional Support / Special Benefit

18

Yes - other

No

9

Total

85

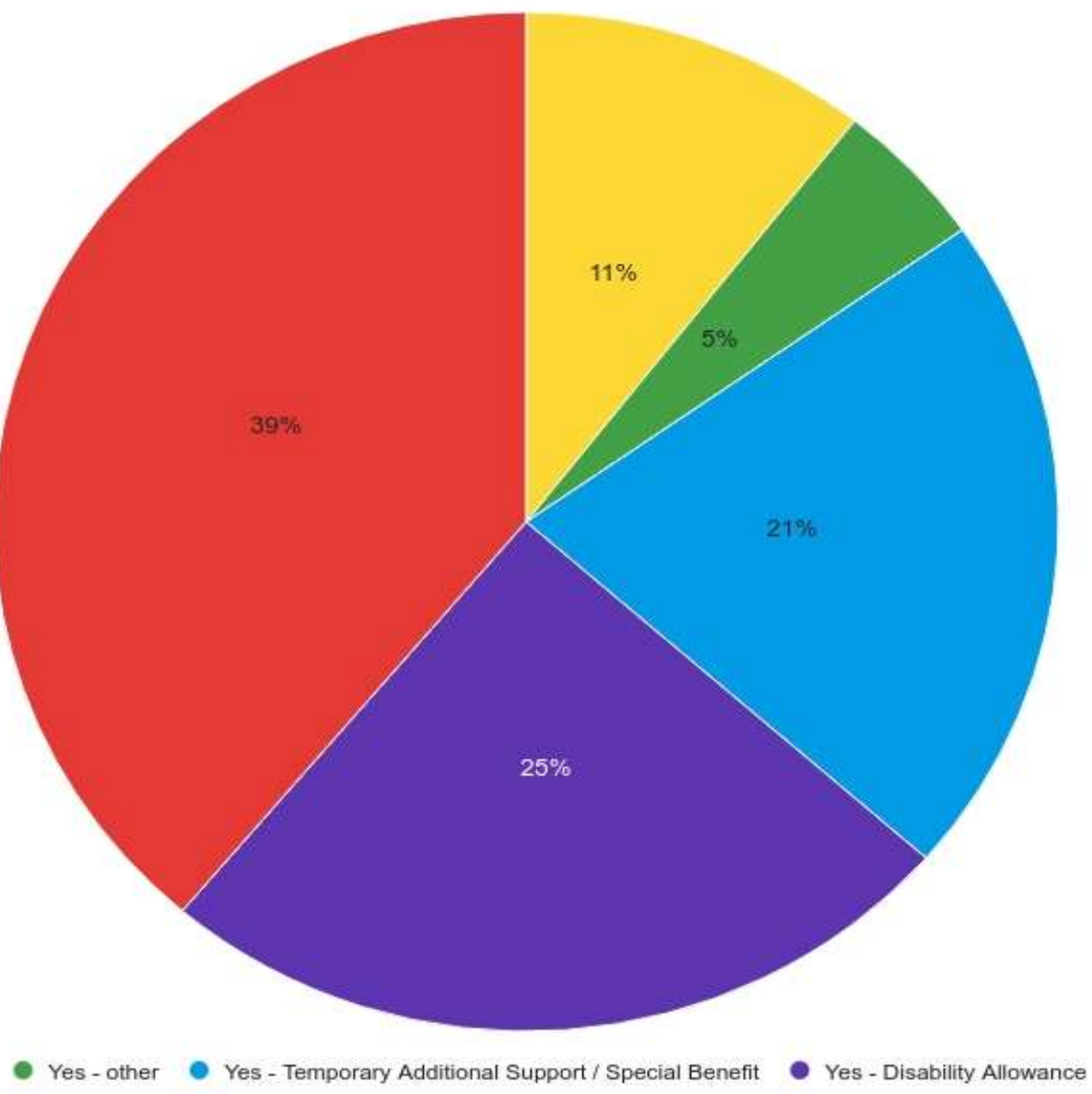

No

- Yes - Temporary Additional Support/ Special Benefit

Yes - Disability Allowance

- Yes-Accommodation Supplement

16 'Other' included Unsupported Child Benefit (2), Child Disability Allowance (1) and Winter Energy Payment (1) 
Q5 Do you receive Working for Families payments, such as Best Start or Family Tax Credits?

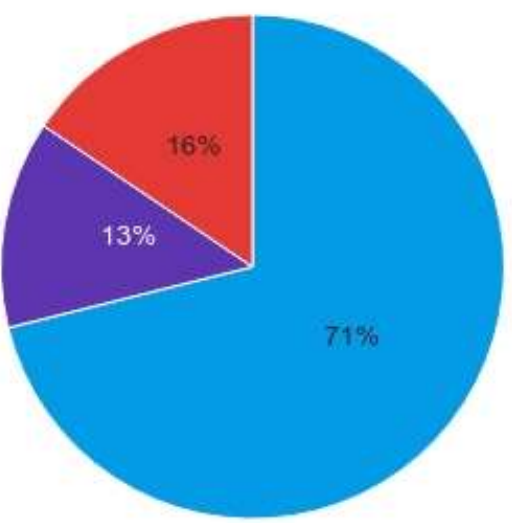

- No

Yes - WFF through IRD

Yes - WFF through WINZ

Q6 Have you received help from other welfare support organisations? 
Appendix 3: Survey Results Summary

Of the 44 respondents to the survey, 17 were on Jobseeker Support including 10 with a medical exemption, 10 on Sole Parent Support and 11 on Supported Living Payment. One respondent did not receive a main benefit. Five respondents selected 'other', with three receiving superannuation, one on a veteran's pension and one receiving the Support Living Payment as a caregiver. No respondents were receiving the youth payment or young parents' payment.

In addition, 39 of the respondents received supplementary payments. Many received multiple supplementary payments, with a total of 83 selections made by 44 respondents, including the 5 'no' choices. Thirty-two people received an Accommodation Supplement; 21 received Disability Allowance; 18 received Temporary Additional Support or a Special Benefit. Special benefits were abolished as part of the 2000s reforms, but people already receiving one were allowed to keep the payment for as long as they qualified for it or chose to move onto Temporary Additional Support. Of the three people chose 'other', two received the Unsupported Child Benefit and a third noted the Winter Energy Payment. The WEP is a secondary payment introduced after the 2018 election, which all WINZ beneficiaries and superannuants receive annually over the winter months to cover an expected increase in energy bills.

Most of the respondents (32) did not receive Working for Families payments or tax credits. Seven respondents received the payment through WINZ and five through IRD.

The majority of the respondents had sought help from other welfare support organisations. Again, many chose multiple sources, with 72 choices (excluding 14 'no' selections) from 44 respondents. Fifteen selected food bank or community pantry; seven chose health organisation; four chose church organisation; 11 chose budgeting organisation; 11 chose counsellors; seven chose advocacy organisation; six chose legal support; one chose drop in centre; seven chose online support groups and three chose in person support groups. This demonstrates the range of organisations involved in individual welfare support networks.

Of the responses, there were 27 completed surveys (i.e. all questions were responded to). All 44 respondents completed at least the first 6 multiple choice questions, exiting once the long- 
answer questions were reached. Of the 'other' respondents, two of those on superannuation and the person on the veteran's pension did not fully complete the survey. The third person on superannuation noted in their response they had transitioned from a benefit to superannuation in the last year, so I feel confident including their data as part of the 27 complete responses. Responses to Q8 (Has it been easy for you to access welfare support?) could be classified into four categories - yes, mostly yes, no, mostly no - recognising the tone of the overall experience. Answers categorised as "Yes" included answers like "yes, easy process" and "Yes, because I have been in the system so long and make a point of knowing the SSA and my entitlements. I also have an advocate I can call upon for difficult issues". "Mostly yes" answers included replies like "Reasonably. I've learnt how to use the system through help through friends" and "Basic benefit yes although everything is always worked out incorrectly and I've usually had to send them their own legislation before I get listened to". I categorised as "No" responses such as "No because they treat you like a criminal when you go into WINZ", "It's been difficult to access support because of my fear of WINZ. I try to minimise my interactions with them, as any contact with WINZ causes me severe anxiety. This anxiety prevents me accessing additional support when I need it" and "No. A lot of errors made by WINZ. One time it took over 3 weeks just to contact someone at my branch". Finally, answers categorised as "mostly no" included "Not really, it's hard to know what you're entitled to", "The process and paper work needed can take a while to get together many appointments to be sent to get more information a two week wait for next appointment to bring information back", and "It varies wildly. But generally not. There seems to be a culture of intentional delaying tactics, it's very difficult to get an initial appointment. I have had to phone every day and nag... being told every time that there are no available appointments for weeks. Eventually the nagging pays off."

Processes listed in response to Q9 (What processes do you need to go through to access welfare support, from WINZ or from other organisations?) could be categorised as primary or secondary. I defined primary activities as activities that were directly necessary to obtain or continue to hold a benefit, while I defined secondary activities as those that include a supportive element, obtaining a secondary service or fulfil a requirement for additional proof of need. 
Primary activities included:

- Phone calls

- Completing online applications

- Accessing WINZ MAP website

- Fill in, submit, and resubmit forms

- Submit evidence to verify costs, such as bills or receipts

- Attend appointments

- Renew medical certificates

- Create RealMe and MyMSD accounts

- Wait in an office

- Submit evidence letters, such as from a GP or specialists

- Speak to case manager

- Bring proof of identity

- Reapply or be reassessed for eligibility

- Notify WINZ of any changes to situation

- Attend WINZ seminars or recommended activities

Secondary activities could include:

- Following up

- Consult an advocate or support worker

- Doctor appointments

- Psychotherapist or psychologist visits

- Internet access

- Obtaining petrol or travel

- Ask friends

- Knowledge of rights and entitlements

- "Armour" 
Two key quotations from the responses to this question summarise the general feeling well: "The application process and revealing in some cases very personal information can be very intrusive" and "Far too much - and not a lot of support".

Q10 (How would you describe your financial situation?) produced two major stories: first, that working or transitioning to work made living situations harder; and second, that people feel they are living hand-to-mouth, unable to afford essentials. Key words used here repeatedly across responses included struggle, poverty, poor, and surviving. Emotive descriptors like dire and horrible were also repeatedly used by some respondents. Others preferred 'weighting'type terms like below average and very low income.

Strategies listed in Q12 included:

- Budget / prioritise essentials (13)

- Network with friends, family (6)

- Break the rules - examples included taking cash jobs and busking (5)

- Don't visit doctor or purchase prescriptions (3)

- Sell things (2)

- Take on debt - examples included taking on loans, credit cards and overdrafts (5)

- Not eat, eat little or eat less (4)

- Find free food, take leftovers or use a food bank (2)

- Use WINZ hardship applications or check full entitlement (2)

- Don't use heater (2)

- Don't use or reduce use of hot water (1)

- Use automatic payments for services - doctor, veterinarian (1)

- Vegetable garden (1)

- Don't buy new things or buy second hand (3)

- Go to bed early (1)

- Pay everything in cash (1)

- Live in sub-par housing (1)

- Go without clothes or shoes (2) 
- Don't have a car or walk places (2)

- Don't buy meat or be vegan (2)

- Buy in bulk, on special, or shop around for cheapest option (4)

The majority of responses to Q13 agreed there was a negative attitude towards beneficiaries in New Zealand. Places that negativity appeared were listed as:

- Online comments or social media (5)

- Workplaces (4)

- News media (7)

- Housing agencies or landlords (1)

- Daily conversation (3)

- Family (2)

- Government and politicians (4)

- By government staff - examples included MSD and the MoJ (6)

- Talkback radio (1)

- Other services - examples included by doctors (1)

- Everywhere (4)

Two people responded that they did not encounter negativity: "Within my friend group there is no negative attitude towards it. We all mostly need it and encourage each other to take the help we can get when we need it" and "I have not struck any negativity". Another response indicated that the negativity was "deserved" and linked this to stereotypes of beneficiaries: "Yes, in some cases it is deserved. There are a lot that seem to choose it as a lifestyle. How on earth do people on a benefit (unemployed or sole parent) afford to smoke, drink, gamble, buy takeaways, have Sky etc? There is no way I can afford any of that. There are people on it that are genuine, but so many don't seem to have any thoughts of helping themselves \& turning their life around". Yet other respondents push back against these stereotypes, writing "Yes, people think beneficiaries are lazy. There are some good people who just need help getting back on their feet. This attitude comes from the media always portraying beneficiaries as lazy criminals" and "Absolutely. We are scapegoated as drug taking drunken losers. In fact, I spend 
30 hours a week volunteering at a charity store. I have a degree in textiles and my knowledge is useful here." Further, some respondents describe this attitude as "bene bashing", outlining key aspects as being told beneficiaries "bludge off government" and should "get a job" which means "Everyone is tarred with the same brush". Several note that they "don't tell anyone" (particularly potential employers) about receiving a benefit as a result. One writes "People who own homes or have never had to endure a WINZ meeting don't really [know] how stigmatising the culture and staff are". Another outlines the clash between their experience of negativity and beneficiary stigma and the reality of their situation: "Yes of course. Before I even applied for the medical exemption jobseeker benefit, my cousin told me not to "become one of those people who stays on the benefit forever." I had had to leave university because my mental illness was so damaging. I could barely get myself up and dressed every day, and all some of my family were concerned about was that I didn't get too comfortable on the benefit. It's not that easy to get comfortable on the benefit. I was getting $\$ 170$ a week for board, food, petrol, medications, and everything else."

The majority of respondents to Q14 (How do you think being on a benefit impacts how you can participate in your community) indicate that being on a benefit does impact their ability to participate (22), while four indicate it impacts their ability to participate only to some extent and three say it does not affect their ability to participate in their community. Respondents repeatedly mention that being on a benefit is an isolating experience; that it impacts on their self-esteem and self-confidence as they are subject to stigma or treated differently and cannot afford travel, petrol or other costs to socialise and participate in their communities. Again, emotive language is used by some respondents: "frowned upon", "treated like scum", "my neighbours hate me", with feelings of shame and fear both around losing a benefit and around being found to be on a benefit or to not have enough money to participate.

In contrast, several respondents (9) say the 2011 welfare reforms have not impacted them. Five more say that rises in cost of living have impacted them much more than any reforms. Four respondents were unaware of the changes. Six said the changes had impacted them, with a further three stating they had been impacted to a degree. Some noted that there were new obligations, the application process became more difficult, and it was harder to find out 
information. Several said benefit levels are not enough to cope with high living costs. Finally, one person who said the 2011 cuts had not impacted them said this was a matter of luck, but that they had been affected by the 1991 reforms, which "were more savage and have never been redressed".

A key statement repeated in the responses was that it was not worth working or getting a parttime job as you would lose too much income or gain very little income:

- "A poverty mentality is encouraged and the gap between beneficiary and employed single financial is too small to make it more of an option"

- "Yes, they are punitive. When you want to earn a little extra you are penalised by having money deducted by WINZ. No incentive to try to help yourself and no encouragement to do so."

- "Less money I lost 30 week from this they felt I was getting too much and with part time work I was taxed to hell"

- "Financially it's not worth getting a part time job as you lose too much money - why work 15 hours a week only to end up with \$10 more in your pocket??? It just doesn't make sense."

Respondents also had a range of answers for Q19, "If you could change one thing about New Zealand's welfare system, what would it be?":

- Change attitudes / for there to be more empathy or sympathy (9)

- More money (6)

- More fairness or transparency (2)

- Less punitive / lower abatement rates so working is less punished (4)

- To scrap the system and start over (2)

- For hardship grants to be automatically paid as soon as your count 'refreshes' (1)

- For individual need to be considered more (1)

- For the system to be more accessible (particularly around the online application system and eligibility appointments) (5) 
- Clearer definition of relationship status (1)

However, one respondent noted that "one thing could not fix nothing so would be a useless exercise". In addition, another respondent linked their response to stereotypes of beneficiaries: "I think people on medical exemption should get more money than those on the normal jobseeker. I understand that those on a normal jobseeker shouldn't feel comfortable, or they will never want to get a job. People with medical exemption who are not required to be looking for a job because of their medical conditions should not have to struggle to make ends meet. They shouldn't have to worry so much about money while they are working on recovering."

A common theme of responses to Q17 (What kind of things has welfare support helped you to do? What kind of positive experiences have you had of accessing welfare support?) is that positive experiences rely entirely on the individual staff member involved or the presence of an advocate. Responses included:

- $\quad$ Pay for essential goods (8)

- Pay for essential services (4)

- Nothing (7)

- To transition to work (1)

- Travel assistance (1)

- To pay bills or debt (4)

- Money (5)

- To recover (2)

- To become an advocate (1)

In the final question, respondents were asked if they had any other comments to make - and many did: four respondents wished to be clear that being on a benefit was not "easy option"; eight wanted to note that WINZ workers needed a better attitude or that WINZ needed a culture change; three called for a general overhaul of the welfare system; and four said that most beneficiaries do not do anything to find themselves in need of help, they are not stereotypes, and they should not be treated like they are to blame for their situations. 
Other responses included:

- "Pleased to see the staff attitude is changing toward how they treat clients. Used to be made to feel and was treated as if a second-class citizen but now a different attitude seems to be happening."

- "There is one group that always misses out - single, under 65 with no kids \& serious medical condition"

- "I'm not a criminal or a drug addict. The welfare system is there for a reason."

- "I would need about six pages ..."

- 'The case managers make you feel like a loser you're nothing without them you don't do what I say no money"

- "Fundamental issues are inadequacy of benefit levels which are set below liveability on purpose. Abatement rate of $\$ 80$ before tax if you work part time means it is financially pointless to work"

- "Far too much bureaucracy and fortress mentality at offices and centralising services people lose touch with their local community"

- "I have been dealing with WINZ for over twenty years, and I'm still stunned at the degree of incompetence and hostility that I experience in every interaction with them." 
Appendix 4: Benefit Rates

Main Benefit Rates as at 1 April $2019^{17}$

\begin{tabular}{ll}
\hline Age and relationship status & $\begin{array}{l}\text { Weekly net (after tax) } \\
\text { rate }\end{array}$ \\
\hline JS: Single, 18-19, away from parent/s & $\$ 182.47$ \\
\hline JS: Married, civil union or de facto couple without children & $\$ 364.94$ \\
& $\$ 182.47$ each \\
\hline SS: Single, 20-24 years & $\$ 182.47$ \\
\hline JS: Single, 25+ years & $\$ 218.98$ \\
\hline JS: Married, civil union or de facto couple with children & $\$ 391.00$ \\
& $\$ 195.50$ each \\
\hline JS: Married, civil union or de facto couple with children and one & $\$ 208.53$ \\
partner not on a benefit & \\
\hline SPS or JS: Sole parent & $\$ 339.69$ \\
\hline SLP: Single, 18+ years & $\$ 273.70$ \\
\hline SLP: Married, civil union or de facto couple without children & $\$ 456.14$ \\
& $\$ 228.07$ each \\
\hline SLP: Sole parent & $\$ 385.60$ \\
\hline SLP: Married, civil union or de facto couple with children & $\$ 482.20$ \\
& $\$ 241.10$ each \\
\hline SLP: Married, civil union or de facto couple with children and & $\$ 254.12$ \\
one partner not on a benefit & \\
\hline
\end{tabular}

Income Limits for One-Off Payments ${ }^{18}$

\begin{tabular}{lll}
\hline Age and relationship status & $\begin{array}{l}\text { Weekly gross income } \\
\text { limit }\end{array}$ & $\begin{array}{l}\text { Annual gross income } \\
\text { limit }\end{array}$ \\
\hline Single, $18+$ & $\$ 574.91$ & $\$ 29,895.32$ \\
\hline $\begin{array}{l}\text { Married, civil union or de facto } \\
\text { couple }\end{array}$ & $\$ 835.04$ & $\$ 43,422.08$ \\
\hline Sole parent with one child & $\$ 697.63$ & $\$ 36,276.76$ \\
\hline Sole parent with multiple children & $\$ 734.99$ & $\$ 38,219.48$ \\
\hline
\end{tabular}

\footnotetext{
${ }^{17} \mathrm{~A}$ full list of payment rates and thresholds, including Superannuation and Student Allowance, is available: https://www.workandincome.govt.nz/products/benefit-rates/benefit-rates-at-1-april-2019.html\#null ${ }^{18} \mathrm{~A}$ full list of asset and income limits is available: https://www.workandincome.govt.nz/products/payment-forone-off-costs/index.html
} 
Asset Limits for One-Off Payments

\begin{tabular}{ll}
\hline Relationship status & Asset limit \\
\hline Single & $\$ 1095.16$ \\
\hline Married, civil union or de facto couple and sole parents & $\$ 1824.83$ \\
\hline
\end{tabular}

Asset limits exclude "day-to-day" assets such as homes and cars, but include assets like savings.

Supplementary Payment Rates: Accommodation Supplement as at 1 April $2019^{19}$

Accommodation supplement payments are based on area, benefit type, and household composition with weekly rent- or mortgage-payment based entry thresholds. The payments can be broken down into three bands.

\section{Band One}

\begin{tabular}{ll}
\hline Benefit type and relationship status & Entry Threshold \\
SLP: Single, $18+$ & Rent: $\$ 68$ \\
& Mortgage: $\$ 82$ \\
JS: Single, $18+$ & Rent: \$55 \\
& Mortgage: \$66
\end{tabular}

Maximum weekly payment rates for band one are $\$ 165$ for recipients living in area one; $\$ 105$ for those in area two; $\$ 80$ for area three; and $\$ 70$ for area four.

\section{Band Two}

\section{Benefit type and relationship status Entry Threshold}

SLP: Married, civil union or de facto couple Rent: \$114

without children

Mortgage: \$137

SLP: Sole parent with one child $\quad$ Rent: $\$ 125$

Mortgage: \$150

SPS or JS: Sole parent with one child Rent: $\$ 113$

Mortgage: \$136

JS: Married, civil union or de facto Rent: $\$ 91$

couple without children Mortgage: $\$ 109$

Maximum weekly payment rates for band two are $\$ 235$ for recipients living in area one; $\$ 155$ for those in area two; $\$ 105$ for area three; and $\$ 80$ for area four.

\footnotetext{
${ }^{19} \mathrm{~A}$ map of the accommodation supplement areas is available: https://www.msd.govt.nz/about-msd-and-ourwork/newsroom/2017/budget-2017/new-regions.html
} 


\section{Band Three}

Benefit type and relationship status

SLP: Married, civil union or de facto couple with children

SLP: Sole parent with multiple children

SPS or JS: Sole parent with multiple children

JS: Married, civil union or de facto couple with children

\section{Entry Threshold}

Rent: $\$ 149$

Mortgage: $\$ 179$

Rent: $\$ 125$

Mortgage: $\$ 150$

Rent: $\$ 113$

Mortgage: \$136

Rent: $\$ 126$

Mortgage: $\$ 151$

$\$ 220$ for those in area two; $\$ 160$ for area three; and $\$ 120$ for area four.

Supplementary Payment Rates: Disability Allowance as at 1 April 2019

\begin{tabular}{ll}
\hline Age and relationship status & Gross income limit \\
\hline Single, $18+$ & $\$ 661.30$ \\
\hline $\begin{array}{l}\text { Married, civil union or de } \\
\text { facto couple }\end{array}$ & $\$ 983.12$ \\
\hline Sole parent with one child & $\$ 753.94$ \\
\hline $\begin{array}{l}\text { Sole parent with multiple } \\
\text { children }\end{array}$ & $\$ 794.34$ \\
\hline
\end{tabular}

The maximum standard rate of Disability Allowance is $\$ 64.29$ per week, while the special rate is $\$ 40.10$ per week and the child rate is $\$ 48.45$ per week. 